\title{
Prediction of Spontaneous Preterm Birth \\ Clinical and Immunological Aspects
}

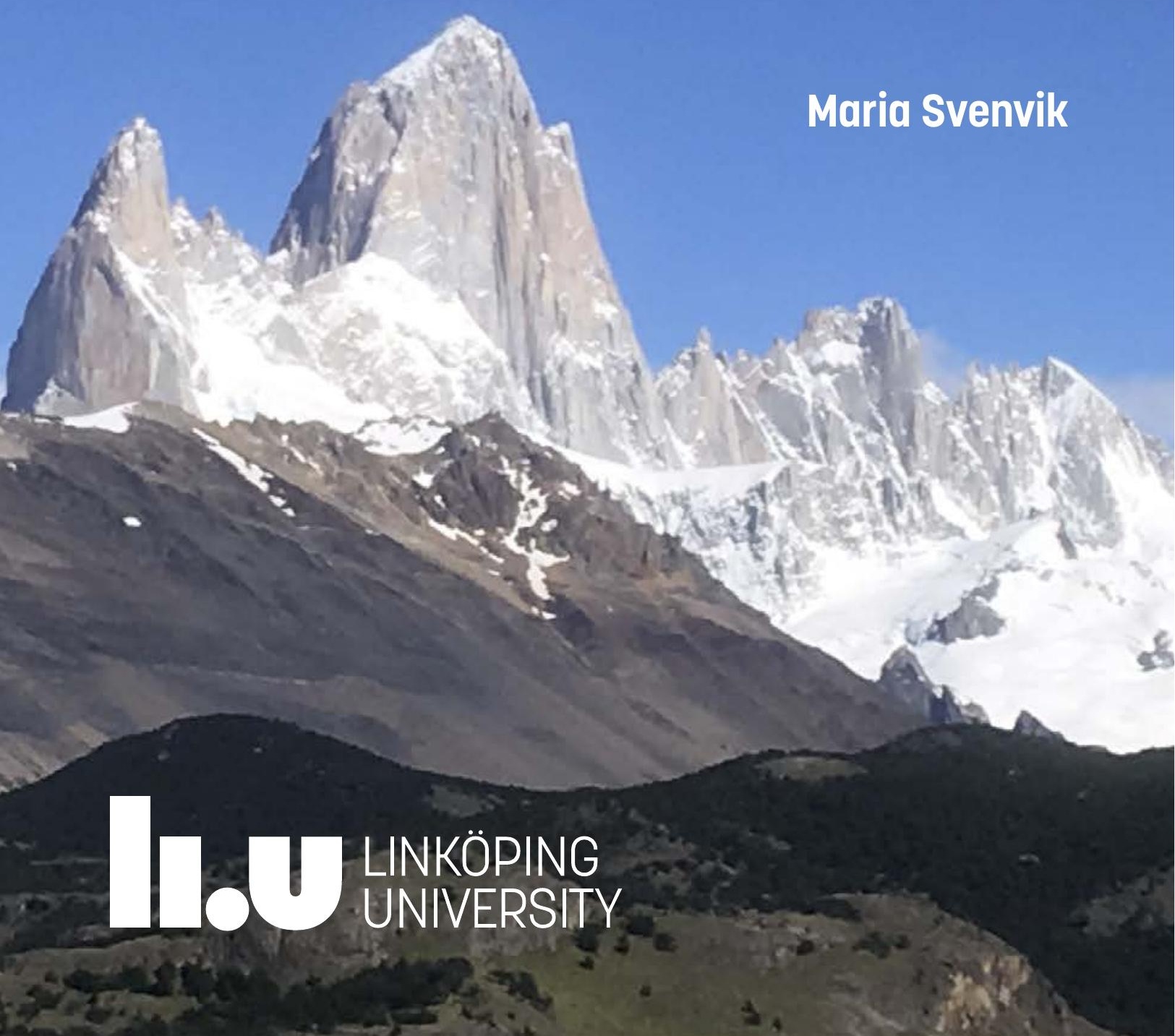





\section{Prediction of \\ Spontaneous Preterm Birth}

Clinical and Immunological Aspects

Maria Svenvik

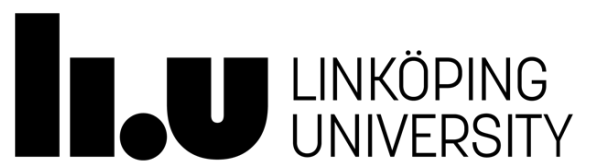

Department of Biomedical and Clinical Sciences,

Linköping University, Linköping, Sweden

Department of Obstetrics and Gynaecology,

Region Kalmar County, Kalmar, Sweden

Linköping 2021 
(cc) EY-NC This work is licensed under a Creative Commons AttributionNonCommercial 4.0 International License.

https://creativecommons.org/licenses/by-nc/4.0/

Copyright @ ( Maria Svenvik, 2021

Cover: Monte Fitz Roy and Cerro Torre, Argentina, by Maria Svenvik.

Published figures and papers have been reprinted with permission from the copyright holders.

Printed by LiU-tryck, Linköping, Sweden, 2021

ISBN: 978-91-7929-659-9

ISSN: 0345-0082 


\section{Main supervisor}

Professor Jan Ernerudh, Linköping University, Sweden

\section{Co-supervisors}

Professor Marie Blomberg, Linköping University, Sweden

Professor Maria Jenmalm, Linköping University, Sweden

\section{Faculty opponent}

Teresa Cobo, Maternal and foetal medicine specialist, Hospital Clinic Barcelona, Clinical researcher, Institut d'Investigacions Biomèdiques Agustí Pi i Sunyer (IDIBAPS), University of Barcelona, Spain

\section{Funding}

This work was supported by the Medical Research Council of Southeast Sweden (FORSS), Region Kalmar County, Medical Inflammation and Infection Centre (MIIC), Linköping University, and ALF grants, Region Östergötland. 

In loving memory of

my wise grandmother,

\title{
Elna Karlsson
}

1916-2006

\begin{abstract}
who was allowed only a few years
of education due to the mere fact
\end{abstract}

that she was a girl.

I am very grateful that circumstances have changed. 



\section{Abstract}

Background: Preterm birth (PTB), defined as birth before 37 weeks of gestation, accounts for most neonatal death and morbidity. Accurate prediction is a pre-requisite for the prevention and proper management of PTB. However, methods for prediction are unsatisfactory, although sonographic cervical length has a moderate predictive value. For clinical utility, adding a biomarker could increase the predictive accuracy. The immune system has an important regulatory role during pregnancy. Thus, presumptive predictive biomarkers may be searched for among immune-related molecules, such as cytokines, chemokines and other inflammation-associated mediators.

The aims of this thesis were to identify clinical risk factors and immunological prediction markers for PTB, both in women at increased risk of PTB because of preterm labour (PTL) or preterm prelabour rupture of the membranes (PPROM), and in asymptomatic women in early pregnancy. An additional aim was to explore immune reaction patterns in PTL and PPROM compared to normal pregnancy.

Material and methods: In a retrospective registry study, including 20,643 women who delivered during a five-year period, risk factors for Apgar score $<7$ at five minutes and risk factors for PTB $<32$ weeks were investigated using univariate and multivariate logistic regression. Furthermore, in a multi-centre mixed case-control and prospective cohort study of women with PTL <34 weeks of gestation ( $n=80)$, PPROM ( $n=40)$, as well as antenatal controls $(n=44)$ and controls in labour at term $(n=40)$, plasma levels of cytokines and chemokines representing different types of immune responses were analysed with a multiplex bead assay. In addition, an extended protein analysis exploring 92 inflammation-associated plasma proteins using proximity extension assay (PEA) was performed, as well as analysis of 67 different oxylipins by liquid chromatography coupled to tandem mass spectrometry. Finally, the PEA technique was used also to explore plasma proteins in a case-control study including 46 women with PTB and 46 women with normal pregnancies and delivery at term.

Results and conclusions: A number of partly preventable clinical risk factors for PTB $<32$ weeks were identified, for example smoking (odds ratio (OR) 1.61 (95\% confidence interval (CI) 1.07-2.41)); preeclampsia (OR 5.48 (95\% CI 3.39-8.86)); and multiple gestation (OR 15 (95\% CI 10-24)). The most evident risk factor for low Apgar scores was PTB; the more preterm the higher the risk. This provides important information for health care professionals, and offers motivations for preventive strategies regarding smoking cessation. 
Both PTL and PPROM were associated with a more pro-inflammatory profile compared to antenatal controls, with an increase in CXCL1. In addition, PTL showed higher CCL17 levels, and PPROM showed higher IL-6 levels compared with normal pregnancy. The inflammatory profile was even higher in labour at term, reflected by higher levels of CXCL1, CXCL8, and IL-6 compared with PTL, probably due to the more advanced stage of the parturition process in these women.

To identify women with PTL and subsequent PTB $<34$ weeks of gestation, we found that a combination of the proteins IL-6, IL-17C, IL-10RB, and FGF-23 strongly correlated with PTB <34 weeks with an area under the curve (AUC) of 0.90 ; inferring a sensitivity of $90 \%$, and specificity of $74 \%$. For the prediction of delivery within 48 hours in women with PTL, the combination of IL-6 and IL-17C displayed an AUC of 0.88, with a sensitivity of $100 \%$, and a specificity of $71 \%$. Additionally, plasma levels of oxylipins were associated with time of birth. Lower levels of 9,10-DiHODE were associated with PTB <34 weeks (adjusted (a) OR 0.12 (0.024-0.62)) and with delivery within 48 hours (aOR 0.13 (0.019-0.93)), while higher levels of 11,12-DiHETre were associated with delivery <34 weeks (aOR 6.19 (1.17-32.7)) and higher levels of 8-HETE were associated with delivery within 48 hours (aOR 5.01 (1.13-22.14)).

In asymptomatic women, plasma levels of combinations of inflammation-associated proteins in the first and the second trimester also revealed predictive information regarding subsequent risk for PTB $<34$ weeks. Combining MMP10 ${ }^{\text {triml } 1}, \mathrm{sCD} 40^{\text {trim2 }}, \mathrm{M}-$ $\mathrm{CSF}^{\text {trim2 }}$, Flt3L ${ }^{\text {trim2 }}$, and FGF-21 ${ }^{\text {diff }}$ (diff= difference in protein levels comparing the first and second trimesters) provided a prediction model with an AUC of 0.90. Proteins from the first trimester exclusively (sCD40 and MMP10) rendered an AUC of 0.76.

This work provides valuable knowledge in the field of PTB and PTL with useful information on risk factors for PTB. Important associations between levels of inflammation-associated proteins and oxylipins with PTB following PTL were found. Before these findings can have clinical implications, they need to be validated in other cohorts. Additionally, in order to be clinically useful as a prediction tool for PTB, a bedside test is needed. Since the PEA technique is PCR-based, this might be achievable. For prediction of PTB in early pregnancy, we have interesting findings with acceptable accuracy based on samples from both the first and the second trimesters. However, as preventive interventions for PTB are preferably initiated early in pregnancy, a prediction tool has better value if it is based on plasma samples from the first trimester. Therefore, we plan to extend this study and evaluate other potential protein biomarkers. 


\section{Table of Contents}

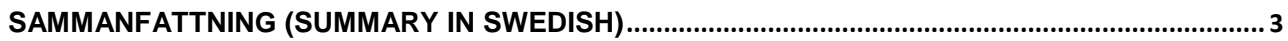

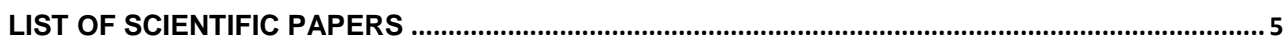

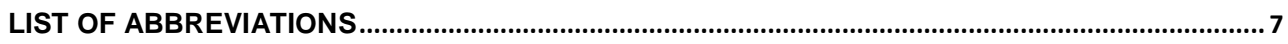

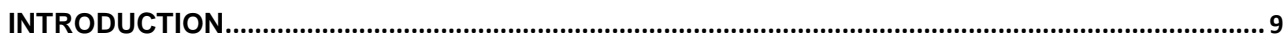

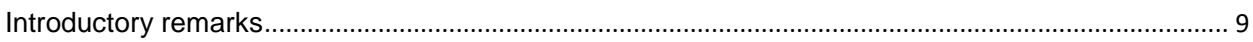

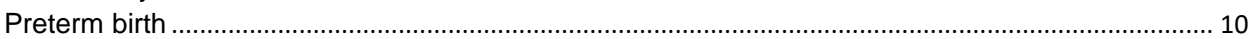

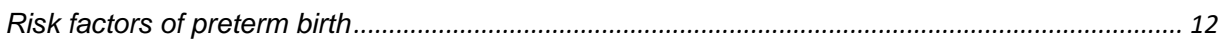

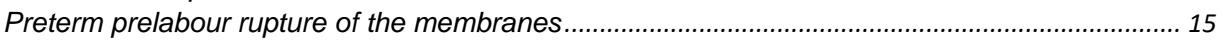

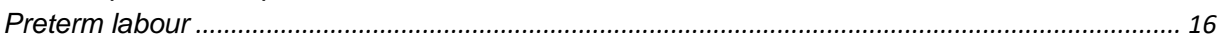

Cervical length in preterm labour .............................................................................................................. 16

Biomarkers for preterm birth in preterm labour ................................................................................................... 17

Prediction of preterm birth in early pregnancy......................................................................... 20

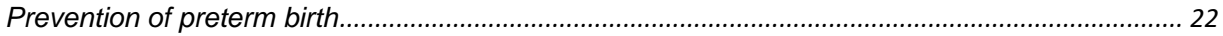

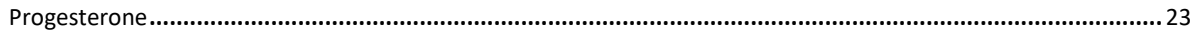

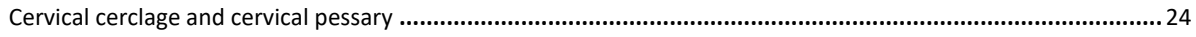

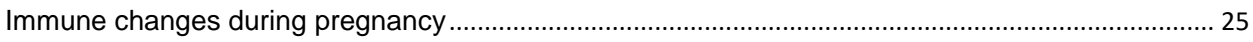

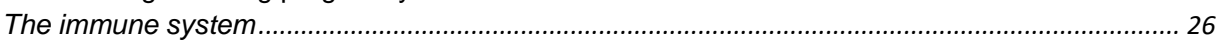

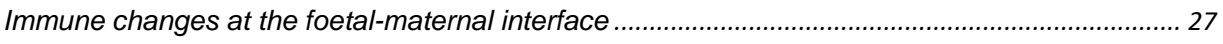

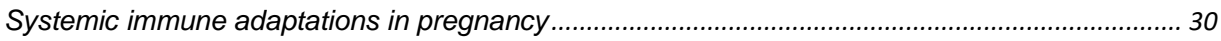

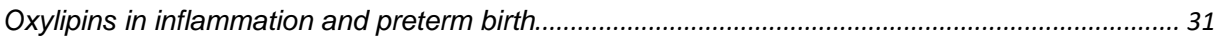

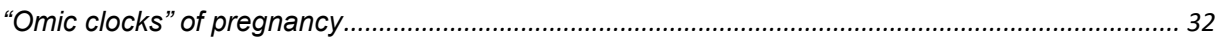

The process of parturition and the preterm labour syndrome .............................................................. 33

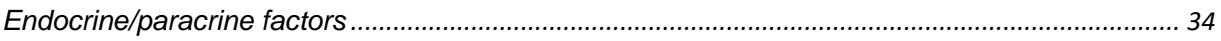

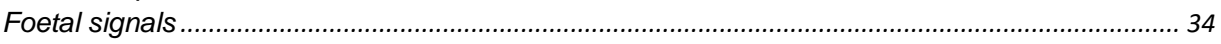

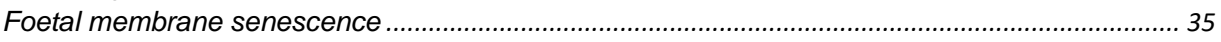

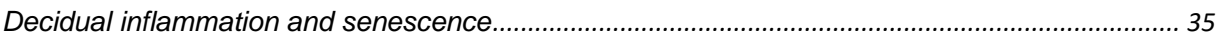

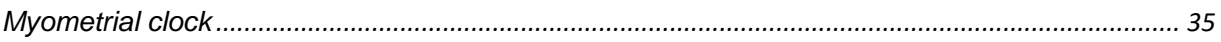

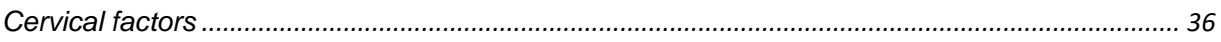

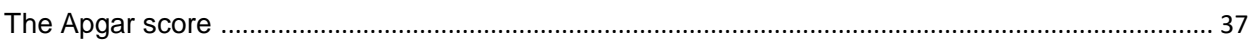

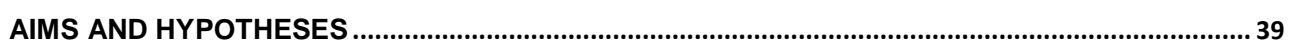

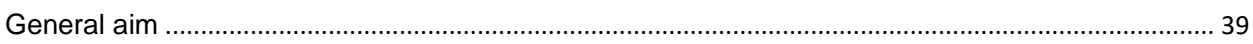

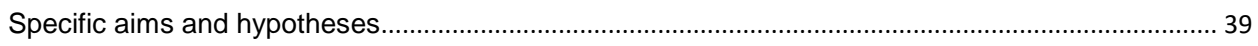

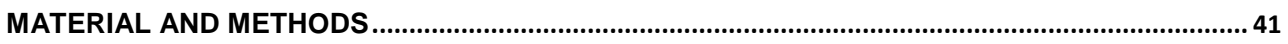

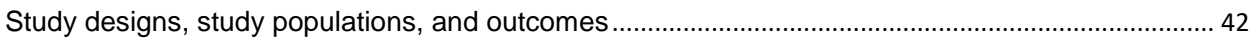

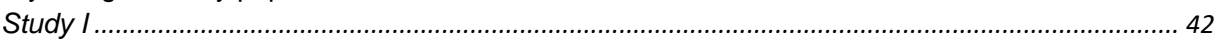

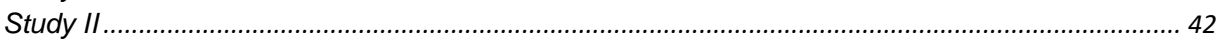

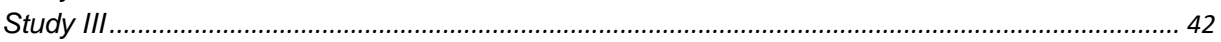

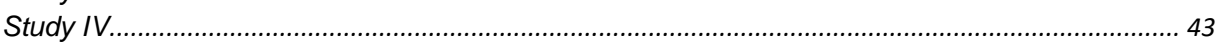

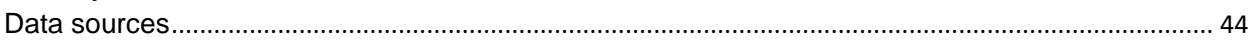

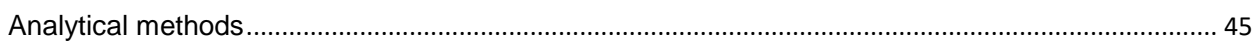

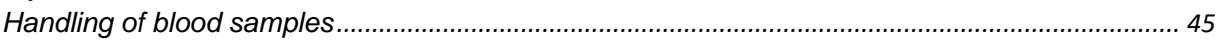

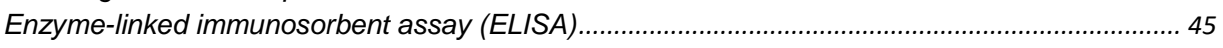

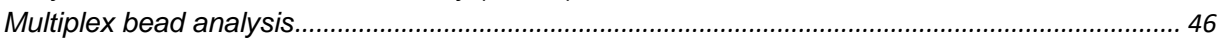

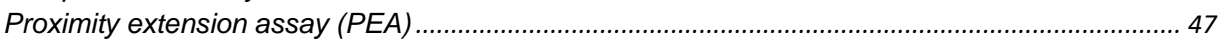

High performance liquid chromatography coupled to tandem mass spectrometry........................... 48

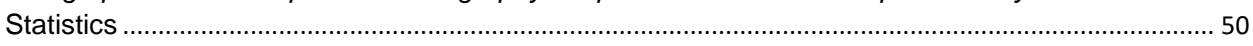

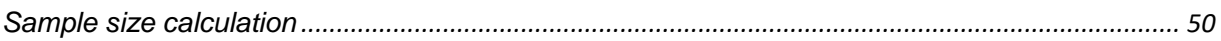


Descriptive statistics.

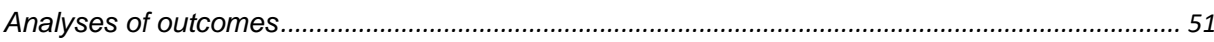

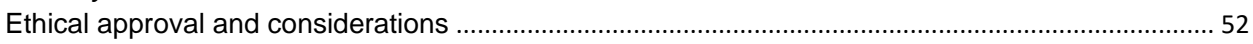

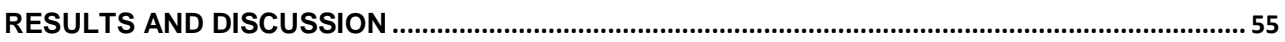

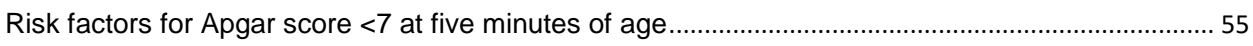

Risk factors for preterm birth $<32$ weeks of gestation ............................................................................ 57

Complex immune profiles in preterm labour, PPROM, labour at term, and antenatal controls ......... 59

Prediction of preterm birth $<34$ weeks of gestation and within 48 hours of presenting with preterm

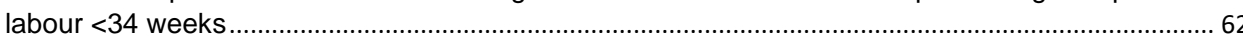

Combinatory prediction model for preterm birth with IL-6, IL-17C, IL-10RB, FGF-23, and cervical

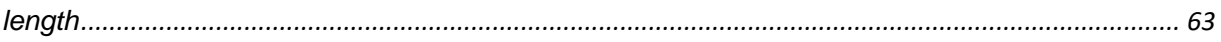

Associations between the oxylipins 9,10-DiHODE, 11,12-DiHETrE, 8-HETE, and preterm birth 67 Early prediction of preterm birth $<34$ weeks of gestation based on first and second trimester plasma

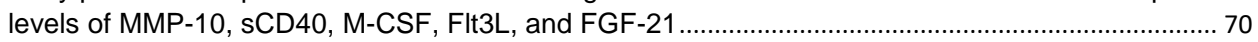

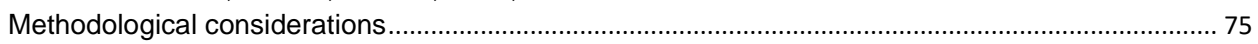

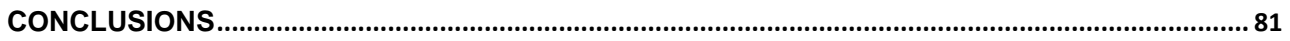

CONCLUDING REMARKS AND FUTURE PERSPECTIVES ..........................................................83

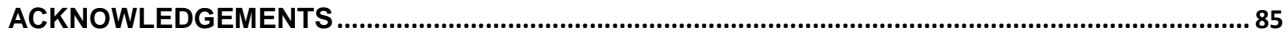

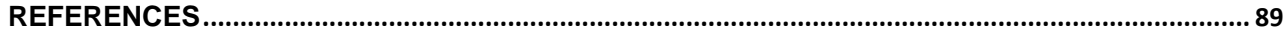

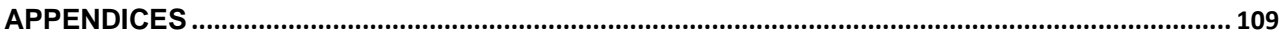

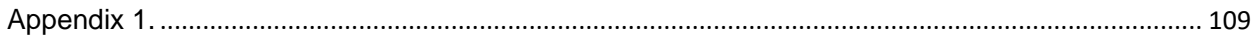

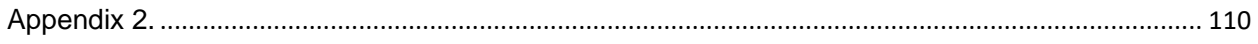

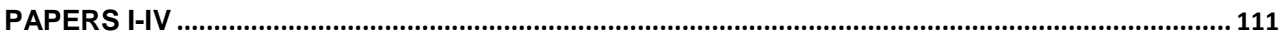




\section{Sammanfattning (Summary in Swedish)}

\section{Prediktion av spontan förtidsbörd: Kliniska och immunologiska aspekter}

Förtidsbörd betyder födsel före 37:e graviditetsveckan. Komplikationer efter förtidsbörd är den vanligaste orsaken till död och sjuklighet hos nyfödda barn. För att kunna förebygga förtidsbörd behövs det tillförlitliga metoder för att förutspå (predicera) förtidsbörd. Ultraljudsmätning av livmoderhalsen ger viss information om senare risk för förtidsbörd. Det behövs dock andra metoder för att öka träffsäkerheten. Man vet att immunsystemet har en viktig roll under graviditet. Därför är det tänkbart att olika ämnen inom immunsystemet skulle kunna predicera förtidsbörd.

Syftet med den här avhandlingen var att hitta kliniska och immunologiska markörer för att predicera förtidsbörd, både hos kvinnor med hotande förtidsbörd (för tidig start av värkarbete och påverkan på livmoderhalsen samt för tidig vattenavgång) och hos kvinnor i tidig graviditet utan symtom.

I en registerstudie omfattande drygt 20000 kvinnor fann vi att några av riskfaktorerna för förtidsbörd före 32:a graviditetsveckan var tvillinggraviditet, havandeskapsförgiftning, rökning samt att vara förstföderska. Vidare såg vi att den tydligaste riskfaktorn för låg Apgar-poäng (ett sätt att bedöma välbefinnandet hos ett nyfött barn, där låg poäng innebär att barnet inte mår bra) var förtidsbörd och att ju tidigare under graviditeten ett barn föddes desto större var risken för låg Apgar-poäng.

Hos en grupp kvinnor med hotande förtidsbörd jämfört med kvinnor med normal graviditet jämförde vi mönstren av olika immunologiska signalämnen i blodet. Vi fann detta mönster mer komplicerat än vad man tidigare trott. När vi följde hur det gick för kvinnor med för tidigt värkarbete utan vattenavgång fann vi att endast en fjärdedel av dessa kvinnor födde före 34:e graviditetsveckan. Vi fann att olika ämnen inom immunsystemet var förknippade med födsel före 34 veckor. Detta gällde både proteiner och oxylipiner, som är ämnen som bildas vid nedbrytning av fettsyror. En kombination av flera olika av dessa proteiner tillsammans med längden på livmoderhalsen kunde med relativt god träffsäkerhet förutspå vilka kvinnor som skulle föda före 34 veckor samt inom två dygn.

Vi undersökte också nivåer av immunologiskt viktiga proteiner i blodprover från tidig graviditet hos kvinnor som senare födde för tidigt. Även här fann vi att kombinationer av proteiner kunde förutspå förlossning före 34:e graviditetsveckan med relativt god träffsäkerhet.

För att komma till klinisk användning måste våra undersökningsfynd först säkerställas genom att undersöka andra grupper av kvinnor. 


\section{List of Scientific Papers}

I.

Preterm Birth: A Prominent Risk Factor for Low Apgar Scores.

Maria Svenvik, Lars Brudin, and Marie Blomberg.

Biomed Res Int. 2015;2015:978079. doi: 10.1155/2015/978079.

II. High-sensitivity detection of inflammation-associated plasma proteins predicts preterm birth in preterm labour.

Maria Svenvik, Maria C. Jenmalm, Lars Brudin, Johanna Raffetseder, Sandra Hellberg, Daniel Axelsson, Gunnel Lindell, Marie Blomberg, and Jan Ernerudh.

Manuscript.

III. Plasma oxylipin levels associated with preterm birth in preterm labour.

Maria Svenvik, Johanna Raffetseder, Lars Brudin, Richard Lindberg, Marie Blomberg, Daniel Axelsson, Maria C. Jenmalm, Jan Ernerudh, and Malin L. Nording.

Prostaglandins Leukot Essent Fatty Acids. 2021 Mar;166:102251. doi: 10.1016/j.plefa.2021.102251.

IV. Early prediction of spontaneous preterm birth before 34 weeks of gestation by a combination of inflammation-associated plasma proteins measured by proximity extension assay.

Maria Svenvik, Johanna Raffetseder, Lars Brudin, Göran Berg, Sandra Hellberg, Marie Blomberg, Maria Jenmalm, and Jan Ernerudh.

Manuscript.

The published papers are reprinted by permission of the publishers. 


\section{List of Abbreviations}

17-OHPC 17-hydroxyprogesterone caproate

AA Arachidonic acid

ALA $\quad \alpha$-linolenic acid

aOR Adjusted odds ratio

AS5min $<7$ Apgar score $<7$ at five minutes of age

AUC Area under the curve

BMI Body mass index

CCL C-C motif ligand

CD40L Cluster of differentiation 40 ligand

cf Cell-free

CI Confidence interval

CL Cervical length

COX Cyclooxygenase

CRH Corticotrophin-releasing hormone

CRP C-reactive protein

CTG Cardiotocography

CTL Cytotoxic T lymphocyte

CXCL C-X-C motif ligand

CXCR Chemokine receptor

CYP Cytochrome P450

DAMP Damage-associated molecular pattern

DGLA Dihomo- $\gamma$-linolenic acid

DHA Docosahexaenoic acid

ELISA Enzyme-Linked Immunosorbent Assay

EPA Eicosapentaenoic acid

FFN Foetal fibronectin

FGF Fibroblast growth factor

Flt3L FMS-like tyrosine kinase 3 ligand

GM-CSF Granulocyte Macrophage-Colony Stimulating Factor

hCG human chorionic gonadotrophin

HPA Hypothalamic-pituitary-adrenal

HPLC High performance liquid chromatography

HRP Horse radish peroxidase

ICD-11 International Statistical Classification of Diseases and Related Health

Problems 11th Revision

IFN Interferon

IL Interleukin

IL-10RB IL-10 receptor subunit beta 


$\begin{array}{ll}\text { IQR } & \text { Interquartile range } \\ \text { IUGR } & \text { Intrauterine growth restriction } \\ \text { LA } & \text { Linoleic acid } \\ \text { LOX } & \text { Lipoxygenase } \\ \text { M-CSF } & \text { Macrophage colony-stimulating factor } \\ \text { MMP } & \text { Matrix metalloproteinases } \\ \text { MS } & \text { Multiple sclerosis } \\ \text { MS-MS } & \text { Tandem mass spectrometry } \\ \text { NK } & \text { Natural killer } \\ \text { NPV } & \text { Negative predictive value } \\ \text { NPX } & \text { Normalized Protein eXpression } \\ \text { OR } & \text { Odds ratio } \\ \text { P4 } & \text { Natural progesterone } \\ \text { PAMG-1 } & \text { Placental alpha macroglobulin-1 } \\ \text { PCR } & \text { Polymerase chain reaction } \\ \text { PEA } & \text { Proximity extension assay } \\ \text { PG } & \text { Prostaglandin } \\ \text { phIGFBP-1 } & \text { Phosphorylated insulin-like growth factor binding protein-1 } \\ \text { PPROM } & \text { Preterm prelabour rupture of the membranes } \\ \text { PPV } & \text { Positive predictive value } \\ \text { PRR } & \text { Pattern recognition receptor } \\ \text { PTB } & \text { Preterm birth } \\ \text { PTL } & \text { Preterm labour } \\ \text { PUFA } & \text { Polyunsaturated fatty acids } \\ \text { ROC } & \text { Receiver operating characteristic } \\ \text { RR } & \text { Relative risk } \\ \text { sCD40 } & \text { Soluble cluster of differentiation } 40 \\ \text { SD } & \text { Standard deviation } \\ \text { sPTB } & \text { Spontaneous PTB } \\ \text { Th } & \text { T helper } \\ \text { TNF } & \text { Tumour necrosis factor } \\ \text { Treg } & \text { Regulatory T cell } \\ & \\ & \end{array}$




\section{Introduction}

\section{Introductory remarks}

Preterm birth (PTB) is defined by the World Health Organization as birth before 37 weeks of gestation ${ }^{1}$. Globally, about 15 million infants are born preterm every year ${ }^{2-4}$. In many cases the underlying cause is unknown. As living conditions for children have improved along with the possibilities to treat diseases, such as pneumonia and infections causing diarrhoea, the complications of PTB are now the leading cause of mortality for children under the age of five, resulting in the deaths of one million infants annually $y^{3,5}$. Despite efforts to decrease the number of PTBs, results so far have been disappointing. Currently, there are limited options for both predicting and preventing PTB.

It is known that women with threatened preterm labour (PTL), i.e. women with preterm regular contractions and a shortened cervix, more often deliver at term than preterm ${ }^{6}$. The clinical and biomedical tools to assess these women and discriminate those that will go on and deliver preterm from those who will continue their pregnancy until term are inadequate. This means that many women with threatened PTL are hospitalised and receive potentially harmful treatments unnecessarily.

In the context of PTB, the changes of the immune system are highly relevant since the maternal immune system must adapt and develop tolerance towards foetal antigens during pregnancy. If this immune tolerance is not developed properly, it is plausible that it might contribute to the initiation of preterm delivery. Possibly, immunological regulation in relation to delivery is reflected in the levels of different immune related plasma proteins and other compounds. 


\section{Preterm birth}

Almost 15 million infants are born preterm every year ${ }^{3,7,8}$. Globally, the PTB rate is $11 \%$, but varies considerably between different countries, from 5\% in some European countries to $18 \%$ in a few African countries ${ }^{2,3,7,8}$ (Figure 1). In Sweden the rate of PTB was $5.6 \%$ in $2019^{9}$.

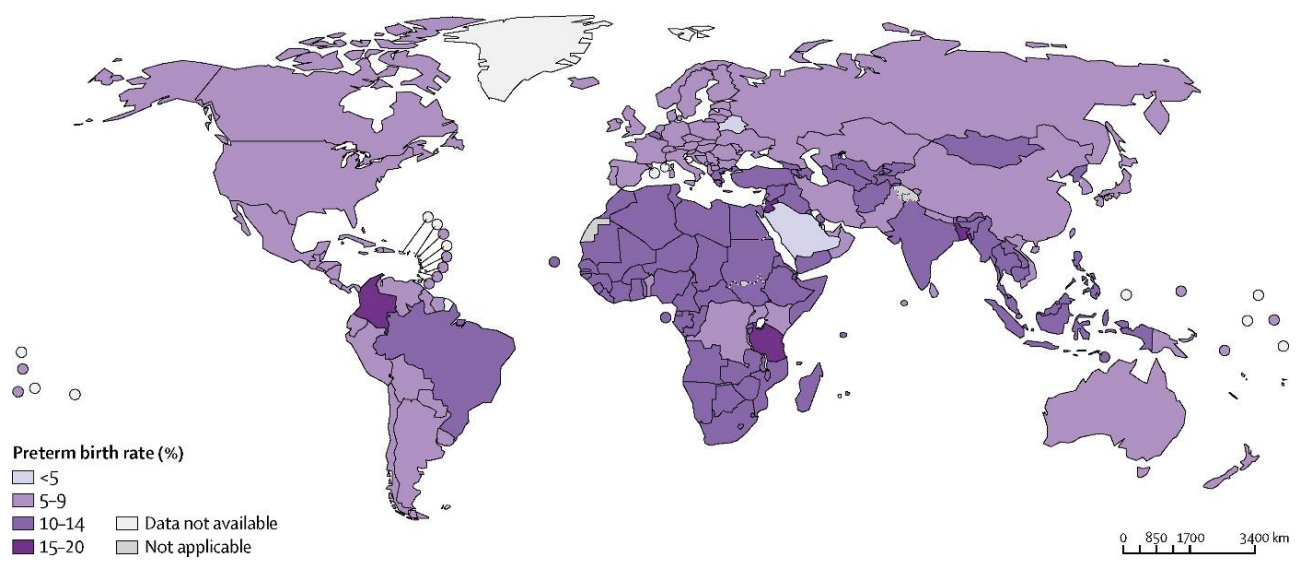

Figure 1. Estimated preterm birth rates in 2014.

Figure by S. Chawanpaiboon et al (2019); Global, regional, and national estimates of levels of preterm birth in 2014: a systematic review and modelling analysis, The Lancet Global Health ${ }^{8}$ (publisher Elsevier).

Reprinted under the Creative Commons CC-BY-NC-ND license.

PTB is subdivided into the categories of extremely preterm ( $<28$ weeks; about $5 \%$ ), very preterm $28-31+6$ weeks; $15 \%)$, moderate (32-33+6 weeks; $12-20 \%)$ and late preterm (34-36+6 weeks; $60-70 \%)^{4,6}$. The gestational age at birth has important consequences for mortality and morbidity, which decrease with increasing gestational age $e^{4,10-12}$, exemplified by findings in the French EPIPAGE-1 and EPIPAGE-2 studies and the Swedish EXPRESS study. Children born at 25 weeks had $40 \%$ risk of death before discharge from hospital, whereas children born at 32-34 weeks had a 99\% survival rate $^{13}$. The rate of discharge home without severe morbidity was $30 \%$ in children born at 25 weeks of gestation, but $97 \%$ in children born at 32 weeks ${ }^{13}$. Correspondingly, the prevalence of cerebral palsy was $20 \%$ among the children who were born at 24-26 weeks of gestation, and considerably lower (4\%) among children born at 32 weeks ${ }^{14}$. Studies on children born before 27 weeks of gestation and who were subjected to active perinatal care follow the same pattern; in children born at 23 weeks, the one-year survival without major neonatal morbidity was $9 \%$ compared to $54 \%$ in the children born at 26 weeks ${ }^{15}$. At a follow-up at 2.5 years of age, moderate or severe overall disability decreased with 
gestational age at birth (22 weeks, $60 \%$; 23 weeks, $51 \%$; 24 weeks, $34 \%$; 25 weeks, $27 \%$; and 26 weeks, $17 \%)^{16}$.

The most serious complications in the neonatal period are intraventricular haemorrhage, periventricular leukomalacia, bronchopulmonary dysplasia, sepsis, and necrotising enterocolitis ${ }^{4,15}$. Children who survive may suffer from complications in various organ systems, for example visual ${ }^{17,18}$ and hearing ${ }^{18}$ impairment, respiratory diseases ${ }^{19}$, and neurodevelopmental disorders ${ }^{16,20,21}$. They are also at risk for poorer physical, mental, and social health in adult life, with increased rates of cerebral palsy and other neurosensory disabilities, increased rates of intellectual disabilities and lower levels of graduation from high school, as well as lower post-secondary educational attainment, although this is strongly correlated to the parental social class. There is no increased risk of unemployment, but there is a risk of lower wealth and lower paid employment. Psychiatric disorders are more common and individuals born preterm may suffer from premature ageing, with shortened life expectancy, hypertension and cardio-metabolic disorders. There is also evidence for lower reproductive rates and fewer are married or co-habiting. However, the self-perceived quality of life is similar in adulthood among those who were born preterm and those who were born at term ${ }^{11,22-24}$. 


\section{Risk factors of preterm birth}

About one third (30-35\%) of PTBs are medically indicated, due to for example preeclampsia, intrauterine growth restriction (IUGR), or placental complications, such as abruption or placenta praevia. About two thirds of PBTs are spontaneous ${ }^{4,6,7}$, preceded by PTL; 40-45\%) or preterm prelabour rupture of membranes (PPROM; 25$30 \%{ }^{6}$, even up to $40-50 \%^{25,26}$ ).

There are a number of risk factors associated with spontaneous PTB (sPTB), ranging from anthropometric, hereditary, social and environmental factors in maternal characteristics to important factors in reproductive history and current pregnancy characteristics $^{27}$. Some of the most important risk factors are listed in Table 1, with relative risk (RR) numbers adapted from the references following in this section, representing a low (RR 1.1-1.5), moderate (RR 1.6-2.5), or high $(R R>2.5)$ risk increase.

One of the most important risk factors is previous PTB, with about four to six times increased risk in the following pregnancy ${ }^{28}$. The increased risk of SPTB applies to both previous spontaneous and previous medically indicated $\mathrm{PTB}^{4,29,30}$. Other important risk factors in reproductive history are previous stillbirth ${ }^{31}$, a short interpregnancy interval (less than six months) ${ }^{32,33}$, and nulli-parity ${ }^{34}$.

In the current pregnancy multiple gestation poses a significant risk for SPTB with an odds ratio $(\mathrm{OR})$ of more than $10^{35}$. Furthermore, a cervical length $(\mathrm{CL}) \leq 25 \mathrm{~mm}$ is also a strong risk factor, which will be discussed later ${ }^{6,30}$. Other matters of importance are if conception was achieved by assisted reproductive technique; genitourinary or extragenital infections afflicting the pregnant woman; active periodontal disease during pregnancy ${ }^{6,30}$; and polyhydramnios ${ }^{36}$. Interestingly, non-obstetric surgical interventions during pregnancy, both intraabdominal and others, also seem to pose a risk for SPTB later in pregnancy, with a rate varying between different studies $(15-41 \%)^{37-39}$.

Among the maternal characteristics that entail a significantly increased risk are hereditary factors. This hereditary aspect is reflected in the higher incidence of sPTB in certain ethnic groups, exemplified by African-American women having at least a twofold increased risk compared to Caucasian women ${ }^{4,40}$. Furthermore, if the pregnant woman herself was born preterm ${ }^{41}$ or has a sister who has experienced sPTB $^{6}$ this also entails a slightly increased risk. Aberrations of the uterus, like an intrauterine septum ${ }^{42}$ or previous conisation ${ }^{30,43}$ pose a moderate risk. Smoking is an important risk factor, as it is preventable and composes a significant risk for SPTB with a RR of approximately 1.6-1.8 $8^{44,45}$. Moreover, both very young $(<18)^{46}$ and older age $\left(>40^{47}\right.$; in other studies $>35^{28}$ ) are associated with $\mathrm{SPTB}$, where the strongest association concerns young age with a moderate risk increase. Underweight (body mass index (BMI) $<19)^{30,48}$ is moderately associated with SPTB and obesity seems to increase the risk for extreme 
PTB $^{49}$. However, for early and moderate sPTB, obesity might be protective ${ }^{6}$. Finally, intercurrent maternal disease like thyroid disease, asthma, diabetes, hypertension, and depression $^{6}$, as well as low socio-economic status ${ }^{40,45,50}$ are risk factors for sPTB.

Despite all these risk factors, in up to two thirds of cases of PTB there is no risk factor present $^{28}$, hence they are considered idiopathic, although subclinical infections are regarded as a plausible cause in many of those cases ${ }^{7}$.

Infection-induced inflammations include acute chorioamnionitis, funisitis, and chorionic vasculitis. A pro-inflammatory response to infection can cause weakening of foetal membranes and may initiate preterm myometrial contractions. The infectious agents gain access to the amniotic cavity mainly by ascending from the lower genital tract, and more rarely by haematogenous spread. An intra-amniotic infection may also be iatrogenic, for example after amniocentesis. The frequency of diagnosed chorioamnionitis is inversely correlated to gestational age at delivery; $94 \%$ at $21-24$ weeks; $40 \%$ at $25-28$ weeks, and $4 \%$ at term (37-41 weeks of gestation). However, chorioamnionitis may also be caused by sterile inflammation. Verified intra-amniotic microbial invasion is more frequent in PPROM than in PTL; $17-58 \%$ and 9-34\%, respectively. Some of the most common pathogens associated with PTL are Fusobacterium nucleatum, Ureaplasma spp, Gardnerella vaginalis, Mycoplasma hominis, and Streptococcus agalactiae ${ }^{51}$.

As mentioned above, multiple gestations are at higher risk for PTB. In the United States as many as $60 \%$ of twins are born before 37 weeks of gestation and $20 \%$ before 34 weeks ${ }^{52}$. However, the focus of this thesis will be singleton pregnancies; therefore the following remarks are in relation to singleton SPTB. 


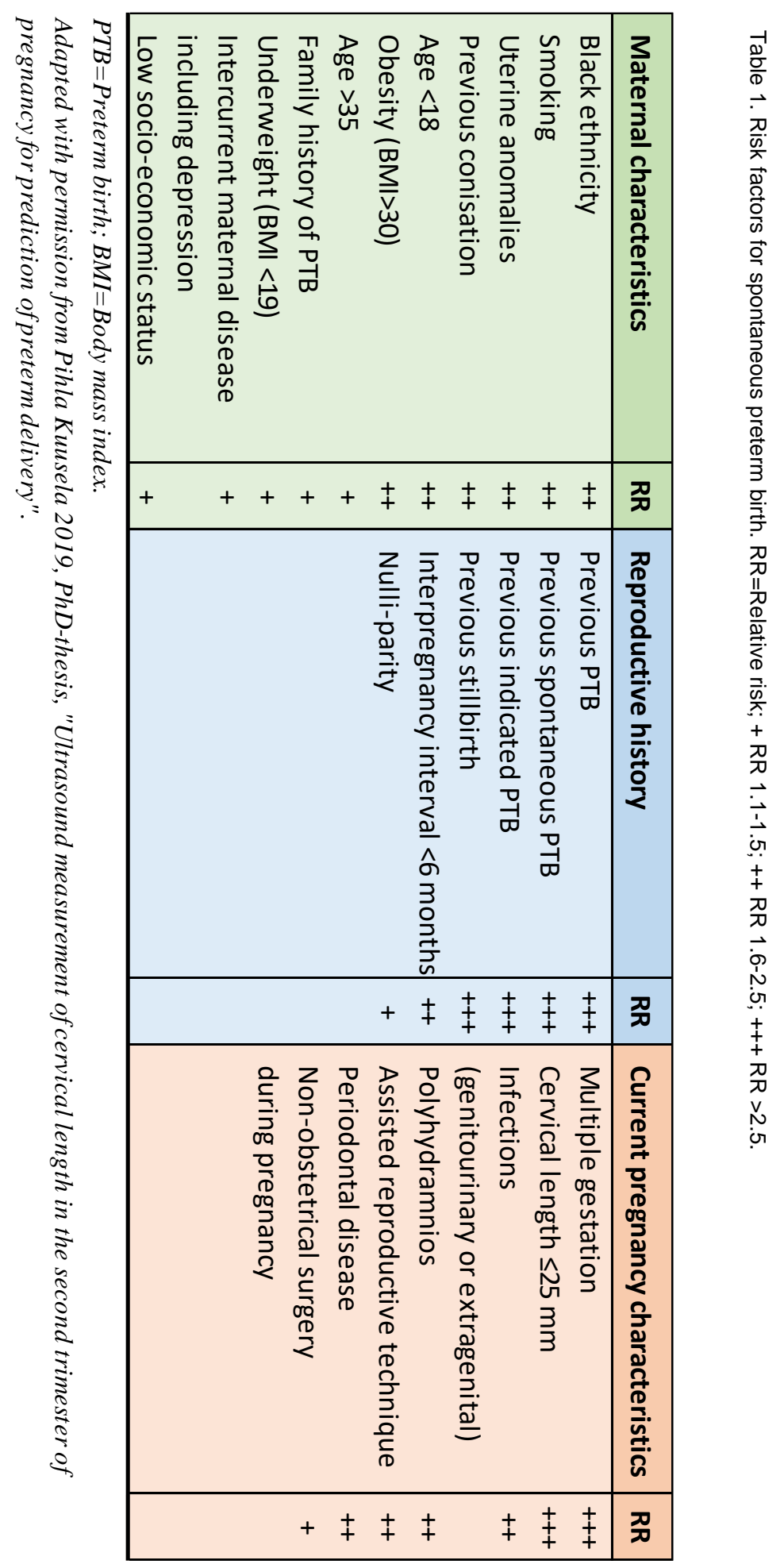




\section{Preterm prelabour rupture of the membranes}

The foetal membranes include two cellular layers; the internal amnion, which is a single layer of cuboidal epithelium, and the external thicker chorion, consisting of trophoblasts ${ }^{53}$. PPROM means rupture of the foetal membranes before 37 weeks of gestation occurring at least one hour before the onset of contractions ${ }^{6}$. PPROM affects $3-4 \%$ of pregnancies ${ }^{25}$ and is generally regarded as a disease of the foetal membranes. An inflammatory process is believed to be involved in the membrane weakening, caused by different processes such as infections and oxidative stress resulting for example from smoking $^{6,25}$. Sterile inflammation is also associated with the concept of senescence of the foetal membranes, resulting in preterm ageing of the membranes. Reduced capability of remodelling in micro-fractures that occur during the course of pregnancy might also contribute to the weakening process ${ }^{25}$.

A majority of women with PPROM deliver within days; however several weeks can elapse before contractions start, rendering these women and foetuses more vulnerable to ascending infections ${ }^{7}$. Due to the increased risk of infections, the management of PPROM varies between expectant management and planned early birth. According to a Cochrane review by Bond et al, there was no difference between the two approaches of management in the primary outcomes, which were incidence of neonatal sepsis (RR 0.93, 95\% confidence interval (CI) 0.66-1.3), and ascertained neonatal infection with positive blood culture (RR 1.24, 95\% CI 0.7-2.21). However, planned early birth was associated with an increased incidence of respiratory distress syndrome (RR 1.26, 95\% CI 1.05-1.53) and an increased rate of caesarean section (RR 1.26, 95\% CI 1.11-1.44). Regarding some of the secondary maternal outcomes in the review, early birth was associated with a decreased incidence of chorioamnionitis (RR 0.50, 95\% CI 0.26-0.95) but an increased rate of endometritis (RR $1.6195 \%$ CI 1.00-2.59). A secondary neonatal outcome was neonatal death, which was more frequent after early birth (RR 2.55, 95\% CI 1.17-5.56). Furthermore, prophylactic use of antibiotics was shown to reduce maternal infections in expectant management ${ }^{54}$.

In a large randomised trial in 2001, the prophylactic use of the antibiotic erythromycin, after diagnosis of PPROM without overt sign of infection, was associated with better neonatal outcomes, defined by a composite outcome of neonatal death, chronic lung disease, or major cerebral abnormality on ultrasonography. However, the use of another antibiotic (co-amoxiclav) was associated with necrotising enterocolitis ${ }^{55}$. A latter Cochrane review consolidates some beneficial effects from certain prophylactic antibiotics in PPROM in terms of prolongation of pregnancy, and in several short-term neonatal morbidity markers such as decreased neonatal infection rates, decreased use of surfactants, and less need for oxygen therapy. However, there was no significant reduction in perinatal mortality ${ }^{56}$. 


\section{Preterm labour}

PTL presents with preterm regular contractions, cervical change, but intact membranes, and is one of the most common reasons for antenatal obstetric hospitalisation during pregnancy ${ }^{57,58}$, yet a majority of women with PTL will eventually deliver at term ${ }^{6}$. The lack of reliable methods to assess women with PTL, implies that women might be subjected to unnecessary hospitalisation, avoidable transports to tertiary centres, and unwarranted treatments with potential side effects.

Corticosteroids are usually administrated before 34 weeks of gestation, which is distinctly beneficial for foetal organ maturation and for decreasing neonatal respiratory distress $^{59}$, obviously also in PPROM. However, some controversies exist regarding the use of corticosteroids ${ }^{60}$, partly based on adverse effects in animal models ${ }^{61}$. In addition, there is data proposing that the administration of betamethasone might interact with immune factors and pancreatic $\beta$-cells, possibly increasing the risk of type 1 diabetes mellitus ${ }^{62}$. This hypothesis is strengthened by the findings in a randomized trial that betamethasone treatment was associated with an increased risk of insulin resistance in early adulthood in the off-spring ${ }^{63}$.

Tocolytics are often administrated in order to prolong gestation and to enable transport to tertiary centres. The most commonly used agents are oxytocin-receptor antagonists (atosiban), $\beta 2$-agonists (terbutaline), calcium channel blockers (nifedipine), and prostaglandin (PG) synthetase inhibitors. However, these agents have side-effects, for example; terbutaline causes unpleasant side effects of tachycardia, palpitations, and tremor, and there are also concerns about maternal safety; PG synthetase inhibitors may cause adverse foetal effects ${ }^{64}$. Therefore, it is essential to identify the women in true need of treatment.

In contrast to PPROM, routine use of prophylactic antibiotics in PTL does not indicate improved neonatal outcomes, but rather a possible association with short- and longerterm harm for children (cerebral palsy in subgroup analysis). However, maternal infections may be reduced ${ }^{65}$.

\section{Cervical length in preterm labour}

Transvaginal ultrasound measurement of CL in PTL has a modest predictive value of PTB, varying between studies, due to for example different cut-offs of CL and different study populations. According to a meta-analysis ${ }^{66}$ the risk in PTL for PTB before 37 weeks of gestation is decreased just by measuring CL compared to when it is not measured. However, this conclusion has been questioned ${ }^{67}$. Some studies, including a meta-analysis, propose $15 \mathrm{~mm}$ as a cut-off for subsequent PTB and for PTB within a 
week $^{68-71}$, but it should be pointed out that there is heterogeneity among studies. Furthermore, it has been proposed that withholding tocolytics is safe with a CL $>15 \mathrm{~mm}$, although it is not clarified whether this also holds true for the withholding of corticosteroids $\mathrm{s}^{72}$. A cut-off of $20 \mathrm{~mm}$ has also been associated with an increase in subsequent $\mathrm{PTB}^{73,74}$, as has a cut-off of $25 \mathrm{~mm}^{75}$. Another interesting finding is that the gestational week at presentation is important for the cut-off value $e^{74,75}$. A CL of $\geq 25 \mathrm{~mm}$ has been considered a cut-off at which discharge from hospital is safe ${ }^{76}$. In summary, the various findings of CL in relation to various outcomes (gestational age at PTB or duration of pregnancy after an episode of PTL) makes the use of CL as a sole predictor of PTB subsequent to PTL less valuable. Another shortcoming is the lack of personalised assessment, taking into account for example maternal BMI, parity, and ethnicity.

\section{Biomarkers for preterm birth in preterm labour}

There are three commercially available bedside biomarkers intended for vaginal/cervical testing of risk for PTB in women with PTL. These include foetal fibronectin (FFN), phosphorylated insulin-like growth factor binding protein-1 (phIGFBP-1, Actim Partus ${ }^{\circledR}$ ), and placental alpha macroglobulin-1 (PAMG-1, Partosure $($ ).

FFN, an extracellular matrix glycoprotein generated in the decidua and chorion, is present in secretions of the cervix and vagina before 20 weeks of gestation. However, its presence after 22 weeks of gestation has been associated with PTB both in symptomatic and asymptomatic women. Yet, in a meta-analysis FFN testing in singleton gestations with threatened PTL was not associated with a reduction in PTB or improvement in perinatal outcome ${ }^{77}$.

The protein phIGFBP-1 is produced in the decidua. Uterine contractions can cause tissue disruption at the choriodecidual interface, resulting in leakage of phIGFBP-1 into cervicovaginal secretions. Its presence has been associated with PTB in several studies. However, when systematically reviewed in a meta-analysis, the conclusions were that after one episode of PTL the test had low predictive performance for PTB at $<34$ and $<37$ weeks of gestation with positive and negative likelihood ratios of 2.7 and 3.5, and 0.4 and 0.5 , respectively ${ }^{78}$.

PAMG-1, a protein normally present in amniotic fluid, seems to have some value as a predictor of PTB within seven and 14 days after presenting with PTL ${ }^{79}$. However, a review explored the prognostic accuracy of the three commercially available bedside cervicovaginal biomarker tests in combination with CL measurement (combined test) compared to $\mathrm{CL}$ measurement alone and/or a biomarker test alone. The primary outcome 
was delivery within seven days after presenting with PTL at 22-34 weeks of gestation. Neither combined tests nor any of the biomarkers alone were shown to be superior in prognostic accuracy of delivery within seven days. However, data was limited, and further studies were recommended ${ }^{80}$.

In a number of previous studies different immune-related potential biomarkers have been investigated in various compartments: cervicovaginal fluid, blood/plasma/serum, and amniotic fluid. CL is sometimes included in a combination with biomarkers. Different outcomes are reported: delivery within 48 hours, seven days, 14 days, PTB at $<32,<34,<36$, or $<37$ weeks of gestation. Furthermore, the intention in some studies is not only to predict PTB but also to evaluate the level of intra-amniotic inflammation or presence of infection. Moreover, for data description different statistical approaches have been used. Altogether, this causes difficulties when comparing results from different studies. Below (Table 2) is a presentation of selected previous studies ${ }^{81-89}$. 


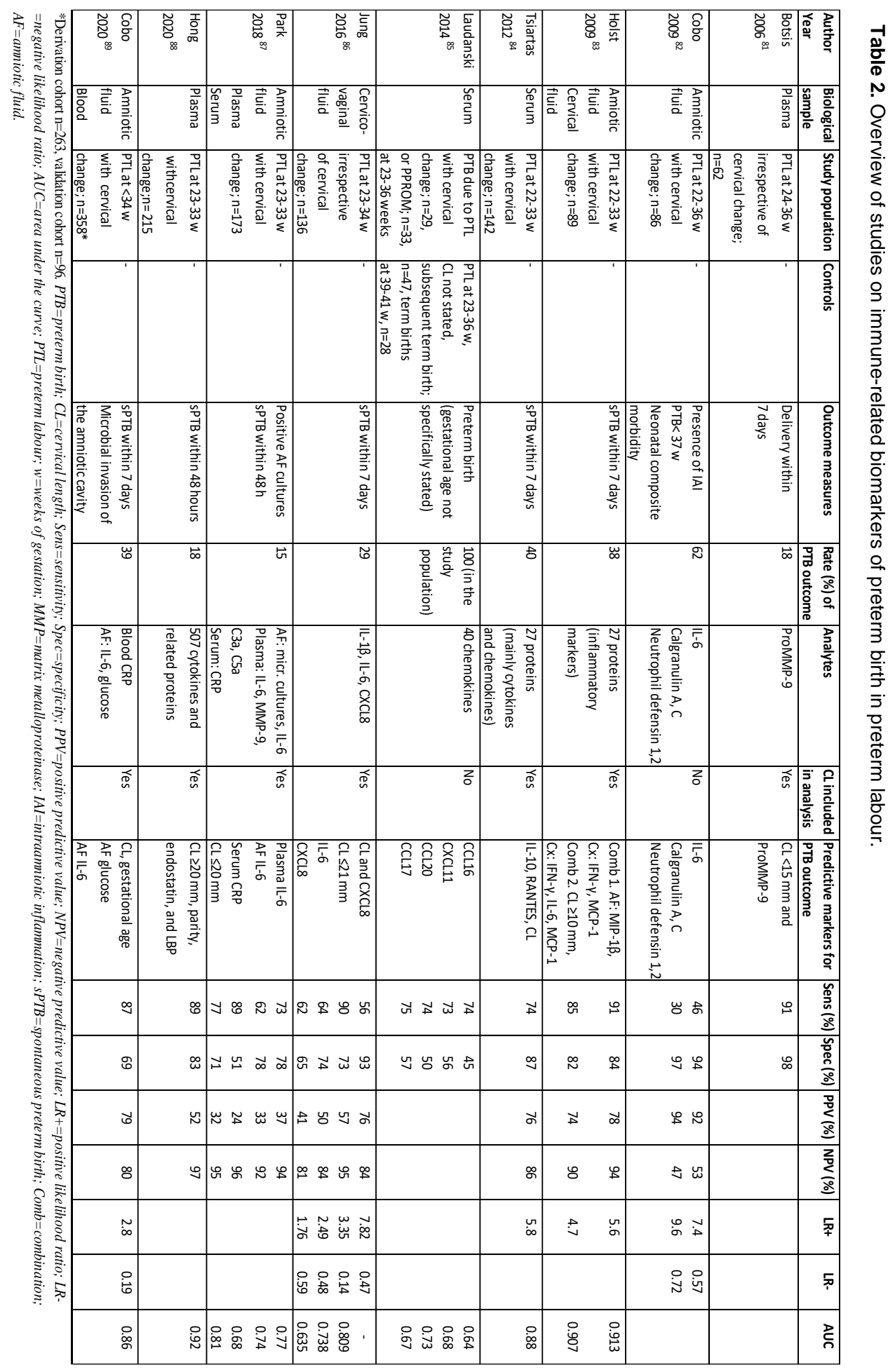




\section{Prediction of preterm birth in early pregnancy}

The purposes of identifying predictive markers for PTB in early pregnancy are as follows: to distinguish the women at risk in order to offer potential preventive treatments or other interventions; to define a population at risk for the purpose of studying an intervention; and to increase knowledge regarding the underlying mechanisms of $\mathrm{PTB}^{90}$.

Studies of the predictive value of transvaginal sonographic CL in asymptomatic women during the second trimester have shown an inverse correlation between CL and the risk of PTB. The specificity of CL measurement in relation to subsequent PTB depends on which cut-off is used, exemplified by findings of $\mathrm{CL} \leq 20 \mathrm{~mm}$, implying a specificity of 99.9\% (95\% CI 99.8-100\%) for PTB <34 weeks of gestation, while lower specificities are found for $\mathrm{CL} \leq 30 \mathrm{~mm}$ and $\mathrm{CL} \leq 35 \mathrm{~mm} ; 90.1 \%$ (95\% CI 89.0-91.2\%) and $65.5 \%$ (95\% CI 63.8-67.3\%), respectively. Furthermore, in a study performed at 22-24 weeks of gestation $1.7 \%$ of women had a CL $<15 \mathrm{~mm}$ but accounted for $86 \%$ of PTB $<28$ weeks of gestation. It has been advocated that singleton pregnant women with a prior PTB should undergo routine CL screening. However, routine CL screening in a low-risk population must follow strict guidelines ${ }^{91}$. In Sweden, a study on asymptomatic women undergoing transvaginal CL ultrasound either at 18-20 weeks of gestation $(n=11,072)$ or at 21-23 weeks of gestation $(n=6,288)$ or on both occasions $(n=6,179)$ concluded that, although second trimester sonographic CL can identify women at high risk of SPTB, the diagnostic performance was moderate in this population with a low rate of SPTB $<33$ weeks of gestation ( $0.47 \%)$ and a low prevalence of CL $\leq 25 \mathrm{~mm}$ ( $4.0 \%$ at $18-20$ weeks and $4.4 \%$ at 21-23 weeks of gestation, respectively). The discriminative ability of CL $\leq 25 \mathrm{~mm}$ for sPTB $<33$ weeks at $18-20$ weeks showed an area under the curve (AUC) of 0.65 compared to 0.76 at 21-23 weeks. A CL of $\leq 25 \mathrm{~mm}$ at $21-23$ weeks predicted sPTB $<33$ weeks of gestation with a sensitivity of $38.5 \%$, a specificity of $95.8 \%$, and a positive predictive value (PPV) and a negative predictive value (NPV) at $3.6 \%$ and $99.7 \%$, respectively. The authors suggested that a health economic analysis including their results was warranted ${ }^{92}$. Given the reported moderate performance of screening of CL in a low-risk population of mainly Caucasian women, a general screening of CL to predict PTB in similar populations cannot be recommended at present.

Regarding biomarkers for prediction of SPTB, Menon et al published a review in 2011, presenting an overview of the SPTB biomarkers that had been studied during the past 40 years, both in PTL and in asymptomatic women in early pregnancy. The review covered 217 studies, in which a total of 116 biomarkers had been assayed. A large proportion of the investigated biomarkers were related to immune function and inflammation, the most frequently reported of all markers was interleukin (IL)-6. A majority of the studies included European or North American populations. Despite the extensive research, no reliable biomarker for PTB prediction was recognised ${ }^{93}$. 
In another review from 2011, Conde-Agudelo et al ${ }^{94}$ aimed to investigate the accuracy of novel biomarkers for the prediction of SPTB in singleton asymptomatic women. Some biomarkers, for which predictive values for SPTB were previously established and considered moderate to minimal, were excluded (cervicovaginal FFN, serum alphafetoprotein, serum human chorionic gonadotrophin (hCG), serum corticotrophinreleasing hormone (CRH), salivary or serum oestriol). The review included 72 studies, in which 30 novel biomarkers in 89,786 women were evaluated. The two single most frequently studied biomarkers were C-reactive protein (CRP) and IL-6 (in 14 and 13 studies, respectively). Proteomic profile (desmoplakin isoform-1, stratifin, and thrombospondin-1 precursor) ${ }^{95}$ and prolactin ${ }^{96}$ in cervicovaginal fluid and matrix metalloproteinase (MMP)-8 in amniotic fluid ${ }^{97}$ were the only biomarkers with a positive likelihood ratio $>10$, although these markers had been evaluated only in one small study each. IL-6 and angiogenin in amniotic fluid and hCG and phIGFBP-1 in cervicovaginal fluid had a moderate predictive accuracy. No other biomarkers were found to have predictive value. Accordingly, the authors concluded that none of the biomarkers was a clinically useful test ${ }^{94}$.

The cervicovaginal biomarker, phIGFBP-1, was more recently reviewed once more by Conde-Agudelo et al, and its predictive accuracy in asymptomatic women was again considered as minimal ${ }^{78}$. There are similar results for FFN; despite an RR of $8.2(95 \%$ CI 4.8-13.9), the sensitivity was only $23 \%$ for prediction of PTB $<35$ weeks of gestation $^{98}$.

Recently, promising results have emerged from a pilot study concerning circulating cellfree (cf)RNA-transcripts, in which measurement of nine placenta specific cfRNAtranscripts predicted gestational age as accurately as ultrasound, assessed in longitudinally sampled blood from 31 healthy pregnant Danish women (Caucasian ethnicity). Furthermore, in a cohort of 38 North American women (African-American ethnicity) regarded as having a high risk of PTB (PTL; $n=15$, prior $\mathrm{PPTB} ; \mathrm{n}=23$ ) seven cfRNA transcripts correctly classified women who delivered preterm $(n=13)$ with a PPV of $80 \%$ in blood tests taken up to two months before parturition ${ }^{99}$.

In conclusion, a diversity of proposed predictive markers (CL and biomarkers) have been investigated, so far without convincing clinical utility regarding prediction of SPTB in asymptomatic women, indicating the need for further research. 


\section{Prevention of preterm birth}

The important task of prevention of PTB must focus on primary, secondary, and tertiary preventive strategies. Primary preventive interventions aim at the general population of pregnant, or pre-pregnant, women, secondary prevention focuses on groups of women with increased risk of PTB, while tertiary prevention aims at decreasing mortality and morbidity among preterm born infants, and includes for example the administration of corticosteroids, tocolytics, antibiotics, and referral to tertiary centres in women with PTL or PPROM. Primary preventive strategies might include public educational interventions, public and professional policies, such as refraining from multiple gestations in connection with assisted reproductive techniques, nutritional supplements in some cases, behavioural changes (including diet, exercise, and decreasing the prevalence of smoking), improved access to prenatal care, and screening for and treatment of asymptomatic bacteriuria and lower genital tract infections. However, except for some lifestyle and behavioural changes, few of the interventions have been shown to be effective ${ }^{100,101}$.

Interestingly, in a randomised double-blind placebo-controlled study in low- and middle-income countries daily administration of $81 \mathrm{mg}$ aspirin (acetylsalicylic acid), initiated at 6-13 weeks of gestation in nulliparous women with singleton pregnancies, reduced the incidence of PTB at $<37$ weeks (RR 0.89 (95\% CI 0.81-0.98)), and PTB $<34$ weeks (RR 0.75 (95\% CI 0.61-0.93)), and also reduced perinatal mortality (RR 0.86 $(0.73-1.00))^{102}$.

According to a Cochrane review, there is evidence for a beneficial effect of supplementation with omega-3 polyunsaturated fatty acids (PUFA) for the prevention of PTB, mainly studied in women at risk for PTB (PTB <37 weeks of gestation RR 0.89 (95\% CI 0.81-0.97), PTB < 34 weeks RR 0.58 (95\% CI 0.44 to 0.77$))^{103}$.

Regarding secondary preventive strategies, treatment with progesterone, cervical cerclage, and cervical pessary are the most studied interventions, and will be briefly presented below. Historically, antepartum bed rest was often recommended to women at increased risk of PTB. However, data does not support this regimen as there is no evidence of decreased rates of PTB after bed rest ${ }^{104}$. Therefore, it should rather be advocated against, since bed rest is associated with a substantially increased risk of venous thromboembolism ${ }^{105}$. 


\section{Progesterone}

The scientific rationale behind the use of progesterone to prevent PTB is the knowledge that start of labour at term is preceded by a "functional withdrawal" of progesterone. Unlike several other mammals, in which parturition is preceded by a decrease in the levels of circulating progesterone, pregnant women have increased progesterone levels throughout pregnancy; levels do not drop until after parturition. However, changes in the levels and functions in the progesterone receptors in the myometrium result in a decreased response to progesterone stimulation; hence a "functional withdrawal", which favours a "functional" oestrogen activation, which augments myometrial contractility ${ }^{106}$. Progesterone may also maintain uterine quiescence; in vitro natural progesterone (P4) has been shown to inhibit contraction in human myometrial strips ${ }^{107}$.

P4 can be administered orally, vaginally, rectally or intramuscularly. Alternatively, an intramuscular injection of $17 \alpha$-hydroxyprogesterone caproate (17-OHPC) can be administered. However, there is a lack of evidence to support the use of 17-OHPC in prevention of $\mathrm{PTB}^{108}$. Outcomes with vaginally administered $\mathrm{P} 4$ differ between studies with different study populations; in 2003 a Brazilian double-blind randomised placebocontrolled trial in high-risk singletons showed a significant reduction in PTB $<34$ weeks $(2.7 \% \text { vs } 18.5 \% ; \mathrm{p}<0.05)^{109}$. In 2007, an international multi-centre double-blind randomised placebo-controlled trial, in which a short cervix was the entry criterion, showed a significant reduction in PTB $<34$ weeks compared to placebo $(19.2 \%$ vs $34.4 \%$; RR 0.56 (95\% CI 0.36-0.86)); however, the frequency of PTB in the study population was very $\mathrm{high}^{110}$. Another international multi-centre double-blind randomised placebo-controlled trial, published by Hassan et al in 2011, including asymptomatic women with singleton pregnancies and a short cervix, showed a significant reduction in the rate of PTB before 33 weeks of gestation (adjusted RR 0.52 (95\% CI 0.31-0.91) $)^{111}$. According to a meta-analysis by Romero et al in 2012 administration of vaginally progesterone resulted in a significant reduction in PTB $<33$ weeks (RR 0.58 (95\% CI 0.42-0.80) $)^{112}$. Previous results of beneficial effects were then contradicted by Norman et $a l^{113}$ when, according to the large $(\mathrm{n}=1,228)$ double-blind randomised placebo-controlled OPPTIMUM trial involving a northern European asymptomatic singleton high-risk population for $\mathrm{PTB}$, the use of vaginal progesterone did not demonstrate any reduced risk of PTB. However, there were no adverse neonatal outcomes or any long-term benefit or harm for the children at follow-up at two years of age. Romero et al then published updated meta-analyses including data from the OPPTIMUM study, still showing a decreased risk of PTB $\leq 34$ weeks of gestation, and of foetal death (RR 0.66 (95\% CI 0.52-0.83) $)^{114}$, as well as a significant reduction in PTB <33 weeks of gestation $0.62(95 \%$ CI $0.47-0.81))^{115}$. In conclusion, there is room for further studies, and possibly different sub-cohorts of women at risk for PTB should be investigated. 
There are two methods of supplying mechanical support and keeping the cervix closed; cervical cerclage and cervical pessary. The indications for these two preventive strategies are similar; history of previous PTB or recurrent late miscarriages, i.e. a history of cervical insufficiency, or mid-trimester short $\mathrm{CL}^{30,116}$.

The cerclage, or cervical stich, is a suture placed around the cervix under local, regional or general anaesthesia using a transvaginal technique, generally executed at 12-15 weeks of gestation. In some cases, the cerclage is placed via the transabdominal route. The disadvantages of cerclage are risk of infection, bleeding, and uterine contractions, which might lead to pregnancy loss or PTL ${ }^{116}$.

The cervical pessary is a flexible silicone ring placed around the cervix without a need for anaesthesia. It is easy to remove and the primary adverse effect is vaginal discharge $\mathrm{e}^{30,117}$.

According to a Cochrane Database review, cerclage in high-risk women (either with a history of prior PTB or sonographic short cervix or both) with singleton pregnancies reduces the risk of PTB <37 weeks of gestation (RR 0.80 (95\% CI 0.69-0.95)), <34 weeks of gestation (RR 0.77 (95\% CI 0.66-0.89)), and <28 weeks of gestation (RR 0.80 (95\% CI 0.64-1.00)), and probably also reduces the risk of perinatal deaths. It was not possible to draw any conclusions as to whether cerclage is more or less effective than other treatments, including vaginal progesterone ${ }^{116}$. In another systematic review, cerclage in women with a mid-trimester sonographic short cervix $<25 \mathrm{~mm}$, but without previous PTB, did not seem to prevent $\mathrm{PTB}<35,<34,<32,<28$, and $<24$ weeks of gestation, although in sub-groups with $\mathrm{CL}<10 \mathrm{~mm}$ cerclage seemed to be efficacious in preventing PTB <35 weeks of gestation (RR 0.68 (95\% CI 0.47-0.98)), possibly in combination with tocolytics and antibiotics. However, the authors commented that there was a low quality of evidence ${ }^{118}$.

Regarding the cervical pessary, in a meta-analysis including 12 randomised trials with asymptomatic women with a high risk of PTB due to a history of PTB, mid-trimester sonographic short CL, uterine anomalies, previous conisation, or multiple gestation, no evidence was found to support the use of a cervical pessary to prevent PTB in singleton pregnancies (or in multiple gestations) $)^{119}$.

To summarise, regarding these two interventions there is need for further studies, taking into account the effects of preventive strategies in different sub-groups of women considered at high risk for SPTB. 


\section{Immune changes during pregnancy}

Pregnancy poses a challenge to the whole human body in many respects, not least the immune system, which must harbour the semi-allogeneic foetus displaying paternal antigens, but still protect the mother from pathogens and other immunological threats. During the course of pregnancy, maternal immune cells are in close contact with the placental villous trophoblasts of foetal origin. In addition, there is an exchange of cells between mother and foetus, resulting in foetal (foetal cells transferred to the mother) and maternal microchimerism (maternal cells transferred to the foetus), which can continue to exist for decades in a multitude of tissues. Via the placenta, there is also an exchange of foetal cf RNA, cf DNA, exosomes and other microvesicles ${ }^{120}$.

Several adaptive changes in the maternal immune system occur during the course of a normal pregnancy. Clinically those alterations are visualised by the change in the course of disease during pregnancy in some immune mediated disorders, for example multiple sclerosis (MS) $)^{121}$ and rheumatoid arthritis ${ }^{122,123}$. Pregnant women affected by these diseases experience amelioration, which is most evident in the third trimester. However, postpartum there is often a relapse of symptoms ${ }^{121-123}$. The relapse rate in MS during pregnancy is actually decreased by as much as $70 \%{ }^{121}$, comparable to the effects of one of the presently most efficient available treatment for MS (natalizumab) ${ }^{124}$.

The basis for these improvements in the course of certain diseases is changes in the immune system. During pregnancy, the different stages of pregnancy require different immune properties. First, pro-inflammation is a pre-requisite for the process of implantation $^{120}$. Thereafter, the immune system is instead skewed towards tolerance to allow foetal growth and development, as well as development of the placenta ${ }^{120,123,125,126}$. Finally, at term there is again a pro-inflammatory state, which is essential for the break of tolerance in order for the initiation of labour to occur ${ }^{120,123,126,127}$. If those adaptations of the immune system do not occur in an orderly way and on a timely basis, pregnancy complications might arise such as PTB, preeclampsia, and IUGR.

Another aspect of the immune system adaptation during pregnancy is a possible effect on the defence mechanisms towards infections. Although pregnant women generally are not more prone to infectious diseases, there is evidence that some infectious agents, for example hepatitis E, cytomegalovirus, herpes simplex virus, malaria parasites and influenza, that depend on T helper (Th)1-mediated responses, may cause more severe disease symptoms or have an increased infectivity in pregnancy, especially in the third trimester, compared to the non-pregnant state ${ }^{128}$. As for the relatively novel coronavirus disease 2019, the risk of severe symptoms during pregnancy may be higher than in the general population $^{129}$, although more evidence is needed. 
The immune system is generally divided into the innate and adaptive immune systems, although they are integrated and collaborative systems. Innate immunity is based on properties already present before infections occur, and constitutes a variety of epithelial barriers (in skin and mucosal tissues), and several cell types including phagocytic cells (neutrophils and macrophages), mast cells, natural killer (NK) cells, and the soluble factors of the complement system. Innate immune cells recognise microbial agents with their pattern recognition receptors (PRR) and they can elicit a rapid response to pathogens and antimicrobial peptides. Adaptive immunity, on the other hand, is slower in its first response, but with repeated exposure to a certain pathogen it elicits strong and rapid responses. Adaptive immunity is mediated by lymphocytes: B cells with antibody production, cytotoxic T cells (CTL), Th cells, and regulatory T cells (Treg). Adaptive immune reactions are highly specific and also have memory properties, meaning that repeated exposure to an antigen results in a more forceful response. Cytokines and chemokines (chemotactic cytokines), which are proteins synthesised by all innate and adaptive cells, as well as by many other cell types, are the "messengers of communication" between the cells of the immune system, and thus mediate inflammatory reactions. Several subsets of lymphocytes produce signature cytokines and chemokines ${ }^{130}$. The differentiation of Th cell subsets is presented in Figure 2 and lymphocyte effector functions of the adaptive immune system are presented in Table 3.

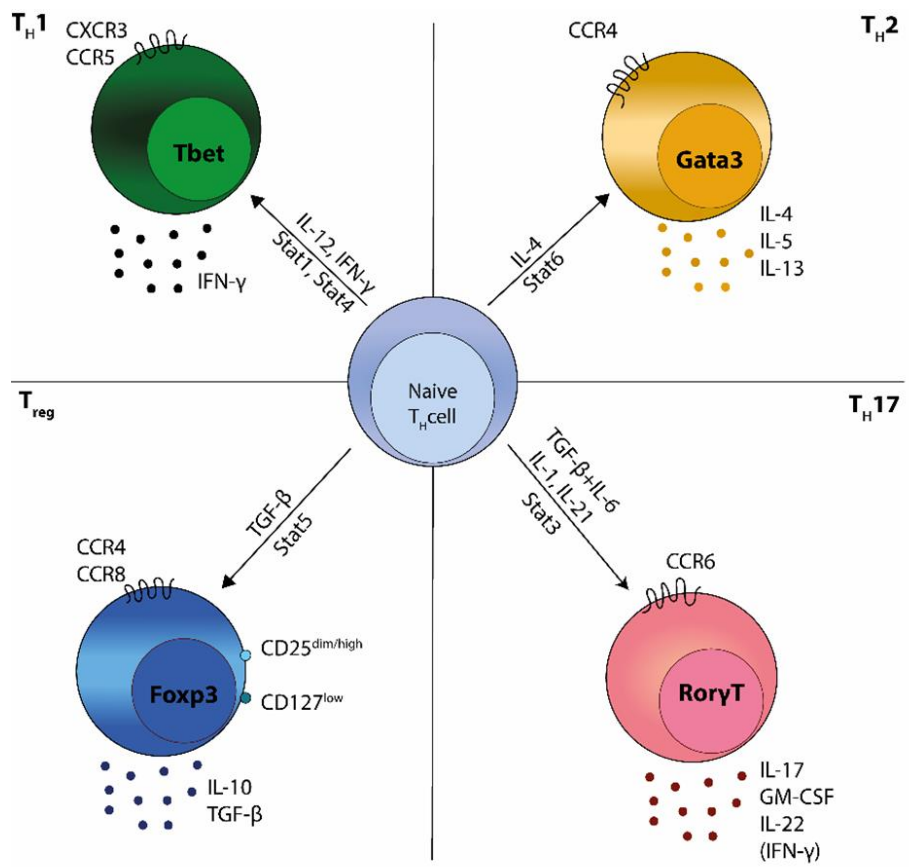

$\mathbf{T}_{\mathrm{H}} \mathbf{2}$ Figure 2. Schematic overview of Th cell differrentiation. Differentiation is induced in response to different cytokines in the surrounding environment, which activate the master transcription factors and the signalling transducer and activator of transcription (STAT) proteins that are required for Th cell fate determination and cytokine production. The different Th subsets secrete different characteristic cytokines and express different chemokine receptors that enable them to respond to different chemotactic signals produced at the site of inflammation. Image courtesy of Sandra Hellberg, Linköping University. 


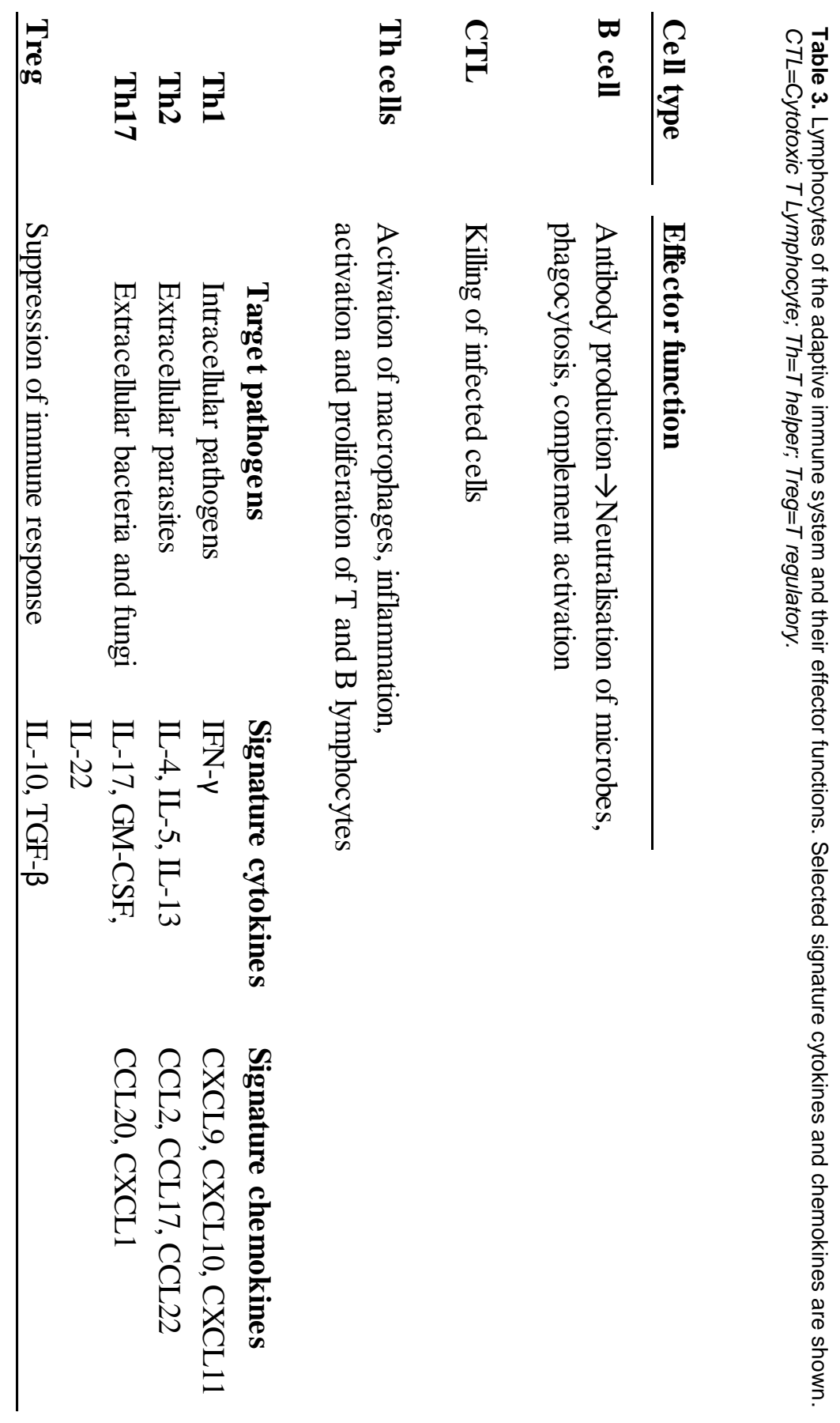


The pregnancy related immune changes are most evident at the foetal-maternal interface (Figure 3), where the decidua is invaded by a different set of immune cells than those that are present in the non-pregnant state. The majority of the invading cells $(70 \%)$ are NK cells and only a small proportion are T-cells, granulocytes and B cells ${ }^{125,131}$. However, the monocytes/macrophages make up the second largest immune cell population in the decidua, and they show immuno-tolerant properties ${ }^{132,133}$. The decidual macrophages are generally of an immune regulatory M2-like type ${ }^{120}$, which is promoted by for example macrophage colony-stimulating factor (M-CSF) ${ }^{131}$, and are important not only for inducing an immune-tolerant environment, but also for spiral artery remodelling ${ }^{125}$. The NK cells in the decidua are important for trophoblast invasion (via secretion of the chemokines C-X-C motif ligand (CXCL) 8 and CXCL10) and angiogenesis for spiral artery remodelling (via secretion of for example vascular endothelial growth factor, placental growth factor, and angiopoietins) ${ }^{125,131}$.

Regarding cells of the adaptive immune system at the foetal-maternal interface, $\mathrm{T}$ cells are present in a low frequency $\left(\sim 10-20 \%\right.$ of the leukocytes in first trimester $\left.{ }^{131}\right)$, have a different composition of cell subsets compared to blood, and frequently display the $\gamma \delta$ T cell receptor instead of the $\alpha \beta$ T cell receptor (which is predominant in the circulation), contributing to foetal immune tolerance and regulating trophoblast invasion and proliferation $^{125}$. Furthermore, in normal early pregnancy there is also evidence of expansion of Treg cells ${ }^{134}$ with immunosuppressive features ${ }^{131}$ and lower presence of Th17 cells ${ }^{134}$ in the decidua. Additionally, in normal early pregnancy there is a moderate Th1 activity controlled by Treg cells creating a mild inflammatory environment ${ }^{134}$. In fact, for implantation, inflammation is a necessary component. However, for the continuation of a successful pregnancy, the inflammation needs to be resolved and a tolerogenic milieu established ${ }^{120}$.

Hence, the composition of leukocytes at the foetal-maternal interface displays very different proportions and properties compared to the composition in the peripheral circulation, which is dominated by neutrophil granulocytes and $\mathrm{T}$ cells. 

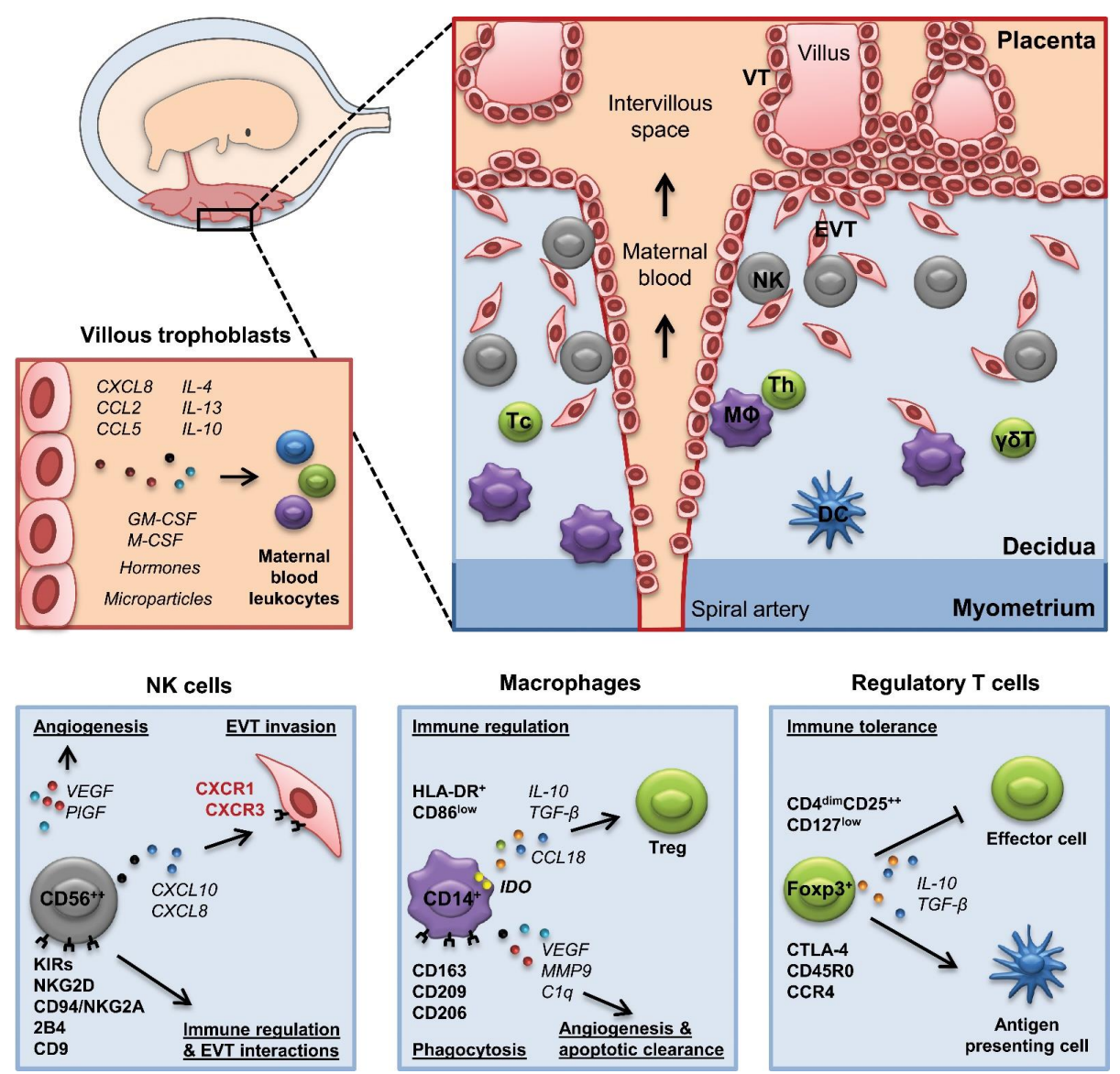

Figure 3. The foetal-maternal interface. Foetal-derived trophoblast cells are in contact with maternal immune cells at two sites: (1) villous trophoblasts (VTs) are surrounded by maternal immune cells in the intervillous space and (2) invading extravillous trophoblasts (EVTs) interact with decidual leukocytes. The VTs produce various cytokines and chemokines, and generate microparticles that may affect maternal blood leukocytes. The major decidual leukocyte populations are natural killer (NK) cells, macrophages (MФ), and T cells (cytotoxic [Tc], helper [Th], and $y \delta$ Tcells). A small population of dendritic cells (DCs) is also present. The main functions of NK cells, macrophages, and regulatory $T$ cells (Tregs) are summarised schematically. NK cells support spiral artery remodelling and EVT invasion via the production of angiogenic and chemotactic factors. The interaction between NK cell receptors and ligands on EVTs is important for adequate decidual NK cell function. The macrophages have immune regulatory properties that may support tissue homeostasis, for example by clearing infections and limiting $T$ cell activation. They also support spiral artery remodelling via angiogenic factors and the clearance of apoptotic debris. Tregs are important immune suppressors and might contribute to foetal tolerance by inhibiting $T$ cell activation and interacting with antigen presenting cells. CTLA-4= cytotoxic $T$ lymphocyte antigen 4; Foxp3= forkhead box p3; GM-CSF= granulocyte-macrophage colonystimulating factor; $I D O=$ indoleamine 2,3-dioxygenase; $K I R=$ killer immunoglobulin-like receptor; $M$ $C S F=$ macrophage colony-stimulating factor; $M M P 9=$ matrix metalloproteinase 9; $P I G F=$ placental growth factor; VEGF= vascular endothelial growth factor. Article Copyright (c) 2013 Authors, Source DOI: $10.1177 / 0192623313482205^{125}$. 


\section{Systemic immune adaptations in pregnancy}

At the systemic level, the innate immune system is amplified, reflected in an increase in the total count of peripherally circulating leukocytes ${ }^{135}$, due to an expansion of circulating neutrophil granulocytes and monocytes, which are also in a more activated state. The numbers of NK cells and dendritic cells are decreased and the NK cells show increased tolerogenic properties ${ }^{125}$.

Also the adaptive immune system displays a significant change. Traditionally, according to the Th1/Th2-concept, a successful pregnancy has been regarded as dependent on a shift towards a more Th2-like response ${ }^{125,136}$. Pregnancy hormones and other factors like progesterone, oestradiol, leukaemic inhibitory factor, and $\mathrm{PGD}_{2}$ supposedly affect the Th2-shift ${ }^{135}$. This shift partly explains why Th1-mediated diseases such as MS are ameliorated during pregnancy, while the risk of infection with intracellular pathogens such as malaria and influenza virus increases. However, more recently it has been understood that this is a simplified view of the adaptive immune system in pregnancy. Rather, the whole concept of Th1/Th2/Th17/Treg must be taken into account, and also the different stages of pregnancy require different immune properties for a normal outcome ${ }^{125}$. In early pregnancy, the Th1 cytokines interferon (IFN)- $\gamma$ and the proinflammatory cytokine tumour necrosis factor (TNF) are needed for the first stages of successful placentation ${ }^{125}$. Further supporting the importance of subsets of Th cells is the association between PTB and polymorphism and expression of the G-protein coupled chemokine receptor (CXCR) 3, expressed for example on Th1 cells ${ }^{137}$, as well as increased CXCR3 expression in choriodecidual leukocytes in PTL ${ }^{127}$.

While Treg cells are important for the promotion of immune tolerance, peripheral blood levels of Treg cells are unchanged in pregnancy ${ }^{125,138}$, or may even be lower ${ }^{139}$, implying that Treg cells exert their most important tolerogenic functions at the foetal-maternal interface, where they are enriched ${ }^{134}$. However, it has been shown that there is a different composition of Treg subsets in blood in term versus $\mathrm{PTL}^{140}$. Furthermore, in PTL there are indications that low circulating Treg levels are associated with subsequent PTB, and could be used to predict PTB, along with short $\mathrm{CL}^{141}$.

Less is known about the role of Th17 in pregnancy; both increased and unaltered numbers have been reported ${ }^{125}$.

Although IL-6 is associated with Th2 and Th17-cells, it is primarily a pro-inflammatory cytokine. Longitudinal profiling of pro- and inflammatory plasma cytokines (IL-1 $\beta$, IL6 , IL-10 and TNF) throughout pregnancy, without signs of infection, has revealed that IL-6 is associated with sPTB ${ }^{142}$. In infection-related PTL, IL-6 in amniotic fluid and cervico-vaginal sampling is a sensitive indicator of $\mathrm{PTB}^{135}$. 
Another pro-inflammatory protein, the chemokine CXCL8, secreted by many cell types, for example macrophages and epithelial cells, has been shown to attract leukocytes, particularly neutrophils, to the decidua and cervix at the onset of labour, and to be significantly increased in PTL $^{135}$.

Taken together, the immune system is tightly regulated during pregnancy and this regulation involves both innate and adaptive immunity; a disrupted regulation might lead to labour at term or preterm ${ }^{143}$.

\section{Oxylipins in inflammation and preterm birth}

Beyond the cytokines, chemokines, and other proteins attributed to $\mathrm{T}$ cell subsets and other immune cells, several other molecules are relevant for the concept of inflammation. Fatty acid metabolites, called oxylipins, are synthesised by several cell types and have important regulatory roles in various inflammatory and homeostatic processes in a broad variety of tissues ${ }^{144}$. The metabolites are derived from PUFAs such as arachidonic acid (AA), linoleic acid (LA), eicosapentaenoic acid (EPA), docosahexaenoic acid (DHA), dihomo- $\gamma$-linolenic acid (DGLA), and $\alpha$-linolenic acid (ALA). The most important enzymatic cascades involved in the formation of oxylipins are catalysed by cyclooxygenase (COX), lipoxygenase (LOX), and cytochrome P450 $(\mathrm{CYP})^{145}$.

In relation to labour and pregnancy the most well-known group of oxylipins are the prostanoids, including PGs. Prostanoids are involved in some important processes in pregnancy, such as endothelial cell activation ${ }^{146}$ and resolution of inflammation ${ }^{147,148}$, and there is evidence of elevation of prostanoids in amniotic fluid before the onset of labour, both preterm and at term ${ }^{149-151}$. Moreover, as mentioned previously, $\mathrm{PGD}_{2}$ has a role in promoting the Th1/Th2 dichotomy ${ }^{135}$. Clinically, the PGs dinoprostone and misoprostol are used for labour induction.

It has been suggested that a subset of oxylipins might serve as potential early biomarkers for $\mathrm{SPTB}^{152}$, and that low circulating levels of omega-3 PUFAs (EPA and DHA) are a risk factor for early $\mathrm{PTB}^{153}$. The authors hypothesised that several underlying mechanisms are plausible, such as the impact of dietary long chain fatty acids on the production of eicosanoids involved in the parturition process, on the myometrial activity, and on inflammatory pathways ${ }^{153}$. 
Recently, several interesting longitudinal studies have further explored the systemic changes during pregnancy with a systems biology approach, i.e. investigating, at a global level, a very large number of different compounds and cells. The maternal plasma proteome changes as a function of gestational age with several proteins displaying a five-fold change in abundance. Many of the changes are associated with immune system-related proteins ${ }^{154}$. Furthermore, as the changes in the plasma proteome seem to be precisely timed, it was possible to develop a prediction model for gestational age, based on 74 proteins, one of which is chorionic somatomammotropin hormone, involved for example in the regulation of $\mathrm{T}$ cell function during pregnancy. It was possible to reduce the number of proteins in the model to only eight without the model losing its predictive power ${ }^{155}$. In addition to this "proteomic clock of pregnancy", an "immune clock" was also reported based on profiling of peripheral immune cells regarding cell frequencies and subsets, as well as cell type-specific signalling capacity. This "immune clock" also revealed a precisely timed chronology of immune adaptations during pregnancy ${ }^{156}$. Additionally, extraction of RNA in cf plasma and quantification of RNA in a transcriptomic model showed a steady increase in expression of genes related to host immune response and also that the average expression of mRNA signatures of $\mathrm{T}$ cells and $\mathrm{B}$ cells follows unique patterns during gestation ${ }^{157}$, hence there is a "transcriptomic clock". Finally, in a multi-omics model a combination of a very large number of compounds from different longitudinally collected biological samples was investigated; cytokines in plasma and serum, single cell characterisation of the immune system in whole blood, plasma proteomics, plasma metabolomics, and cf transcriptomics in plasma, as well as microbiome profiling from vaginal swabs, saliva, stool, and tooth/gum samples. Following a machine learning approach, several biologically plausible correlations between the "omics" datasets were found, and a chronology was found even among these diverse biological events. Interestingly, the proteomic layer showed the strongest correlation with gestational age, emphasising the feasibility of using proteins as biomarkers that can be measured in the circulation ${ }^{158}$.

To conclude, these studies provide a valuable body of knowledge about fine-tuned chronological changes during normal pregnancy, several related to the immune system, which may function as the starting position in the on-going work towards understanding how deviations from these changes can cause pregnancy complications, including PTB. 


\section{The process of parturition and the preterm labour syndrome}

The process of parturition displays the same terminal pathways whether it occurs at term or preterm, resulting in cervical changes (softening, shortening, and dilation), myometrial contractions and weakening of the foetal membranes, eventually causing a rupture of the membranes. This is referred to as "the common pathway of parturition" (Figure 4$)^{7}$, which is regarded as a pro-inflammatory event. However, the mechanisms for the onset of labour are unclear, even enigmatic. The concept of "pregnancy clocks" has been suggested and reviewed by Menon et al, involving several mechanisms that operate in harmony in order to initiate labour at the optimal time ${ }^{53}$.

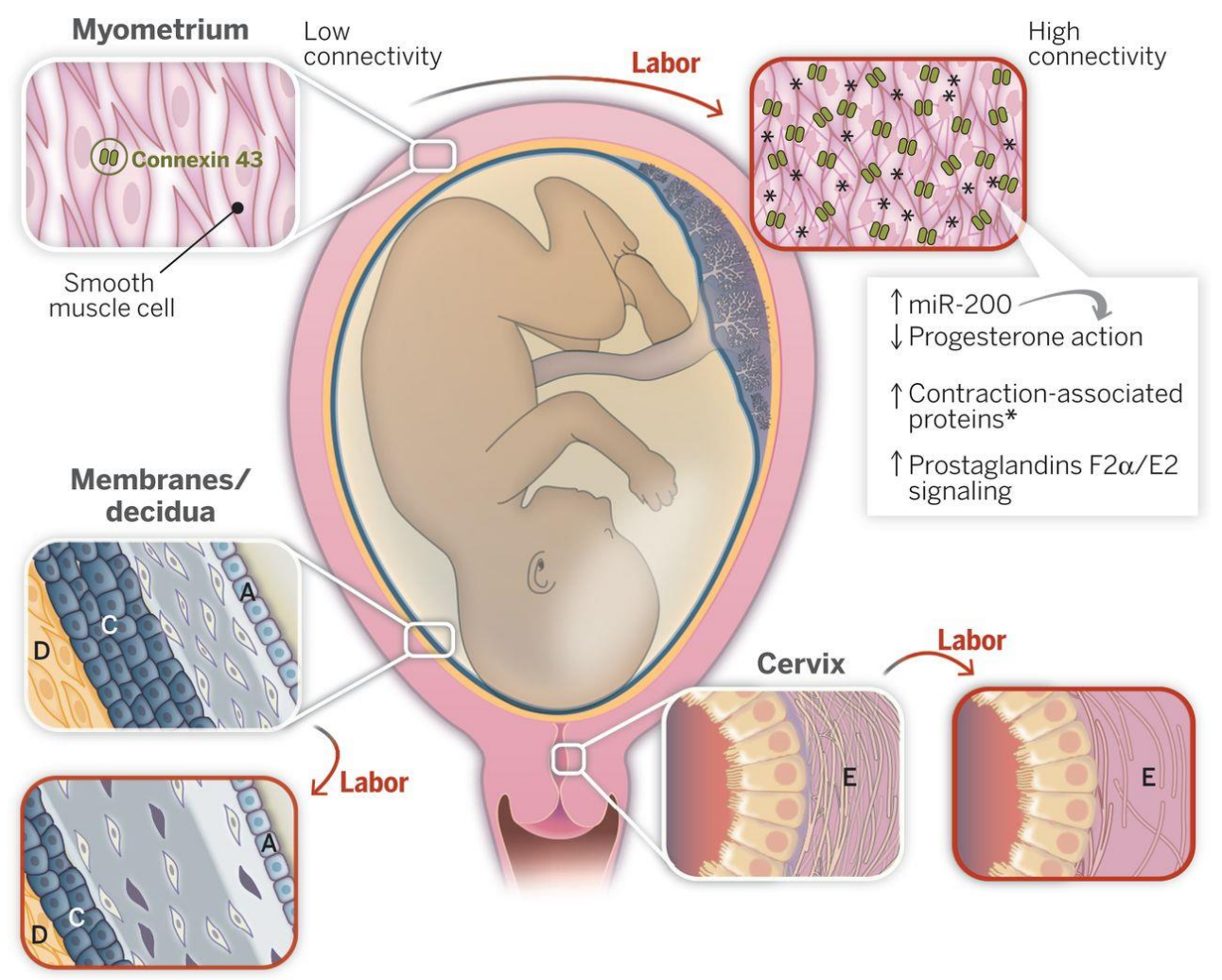

Figure 4. Labour (term and preterm) is characterised by increased myometrial contractility, cervical dilation, and rupture of the chorioamniotic membranes. From [R. Romero, S.K. Dey, and S.J. Fisher (2014). Preterm labor: One syndrome, many causes. Science, 345 (6198), 760-765] $]^{7}$ Reprinted with permission from AAAS.

In PTL, pathological processes supposedly activate one of the components in the common pathway. These pathological processes might involve pro-inflammatory 
pathways triggered by infection, decidual haemorrhage and vascular disease, senescence of the decidua or other pregnancy-related tissues, disruption of maternal-foetal tolerance, decline in progesterone action, uterine overdistension (as in multiple gestation or polyhydramnios), and maternal stress (Figure 5). The phenotype of PTL can be referred to as "the preterm labour syndrome" .

The "pregnancy clocks" are related to factors in endocrine/paracrine signalling, foetal membranes, the decidua, the myometrium, the cervix, and possibly the foetus ${ }^{53,159}$.

\section{Endocrine/paracrine factors}

The hypothalamic-pituitary-adrenal (HPA) axis plays a role in the parturition process. Birth timing in sheep seems to be strictly controlled by the foetal HPA axis, whereas in humans there are inconsistent findings as to the role of CRH levels ${ }^{53}$.

In several other mammals a surge of glucocorticosteroids in maternal and foetal plasma, as well as in amniotic fluid, precedes the start of labour. Cortisol promotes placental CRH production, creating a positive feed-back loop. However, in humans there is instead a progressive increase of corticosteroids in the circulation during pregnancy and no surge at the onset of labour, although it has been suggested that there is a boosted local paracrine action in the foetal membranes and the myometrium. In addition, as gestational age advances, cortisol is locally generated from cortisone by the decidua and the foetal amnion cells, resulting in high local concentrations of cortisol in the foetal membranes, which stimulates local production of PGs. Besides having a maturation effect on several foetal organ systems, glucocorticoids also contribute to increased PG synthesis, through for example up-regulation of COX-2. PGs are potent mediators of myometrial contractility, and an increase in $\mathrm{PGE}_{2}$ and $\mathrm{PGF}_{2 \alpha}$ in amniotic fluid can be measured prior to onset of parturition. Furthermore, pro-inflammatory cytokines like IL$1 \beta$, IL-6, and TNF display circadian patterns and have all been associated with labour ${ }^{53}$.

The peptide oxytocin, produced by the posterior pituitary gland, as well as by trophoblasts in the placental membranes and decidua, and possibly by the foetus, displays faster pulses in labour than before the onset of labour. The myometrial receptors for oxytocin respond by mobilising intracellular calcium and thus stimulate myometrial contractions $^{53}$.

\section{Foetal signals}

Foetal organ maturation signals, for example increased lung surfactant, have been associated with the release of PGs and inflammatory cascades from the foetal membranes. The foetal signals might also induce progesterone withdrawal ${ }^{53}$. 
Interestingly, it has been shown that $\mathrm{T}$ cells collected from the umbilical cord blood of preterm infants promote myometrial contractility in vitro, mediated through IFN- $\gamma$ and TNF. T cells from term infants do not exert this effect ${ }^{160}$.

\section{Foetal membrane senescence}

There seems to be a physiological ageing process of foetal membranes, which contributes to the sterile inflammation that promotes labour. This sterile inflammation may initiate the inflammatory cascade leading to a contractile state in the myometrium and ripening of the cervix. Decreased telomere length has been suggested to be one of the signals of importance, possibly accelerated by oxidative stress. Also, damageassociated molecular pattern (DAMP) markers are released by senescent foetal membranes, which through activation of PRRs can further enhance the inflammatory response. Certain DAMPs may also cause a progesterone receptor switch, possibly favouring functional progesterone withdrawal in myometrial cells ${ }^{53}$.

\section{Decidual inflammation and senescence}

Decidual stromal cells seem to go through spontaneous senescence due to inhibition of certain cellular functions, exemplified by the fact that early-to-mid-decidua displays different gene expressions compared to late gestation decidua (at least in mice) ${ }^{53}$. Also the immune cell population of the decidua changes in composition and function during the course of pregnancy, as mentioned in a previous section ${ }^{120}$. It is believed that the decidua can activate parturition via inflammatory signals controlling the types and functions of the present immune cells ${ }^{53}$. As gestational age advances, this might be associated with withdrawal of active suppression or with an augmented capacity to generate inflammatory signals, coherent with the hypothesis that senescence in decidual cells can be provoked by increased production of pro-inflammatory mediators in response to stretching of the decidua caused by the growing foetus ${ }^{159}$. Because of their expression of pro-inflammatory mediators, decidual macrophages are considered an important cell type in the contribution to parturition, and there is evidence for accumulation of decidual macrophages in both term and preterm labour ${ }^{131}$. In addition, according to a "two-hit hypothesis", a hereditary (in the maternal lineage) exaggerated inflammatory response to an external stimulus, for example an ascending infection, predisposes to PTB $^{159}$.

\section{Myometrial clock}

During pregnancy the normal contractile state of the myometrium must be actively suppressed in order to allow the 500-fold expansion necessary for a term pregnancy; hence there is need for uterine quiescence. The myometrial contractions in term labour 
result from withdrawal of the mechanisms that support the quiescent state; mainly progesterone, but to a lesser extent also factors that promote contractions, such as oxytocin ${ }^{159}$. In addition, the growing foetus generates distention of the uterine wall, believed to give rise to increased production of inflammatory cytokines and remodelling of extracellular matrix, which could play a part in the initiation of parturition ${ }^{53}$.

\section{Cervical factors}

Finally, the cervix undergoes several changes during the course of pregnancy, which accelerate near term. The cervical collagen becomes less densely arranged, partly due to MMPs. In addition, the glycosaminoglycan composition changes and the water content increases; collectively supporting softening. Simultaneously, functional changes occur in the smooth muscle, epithelial, and fibroblast components ${ }^{53}$. The expression of pro- and anti-inflammatory cytokines undergo major changes during the labour process, irrespective of the gestational age, indicating that the pathogenesis of PTL might comprise dysregulation of the expression of anti-inflammatory cytokines in the cervix ${ }^{161}$.

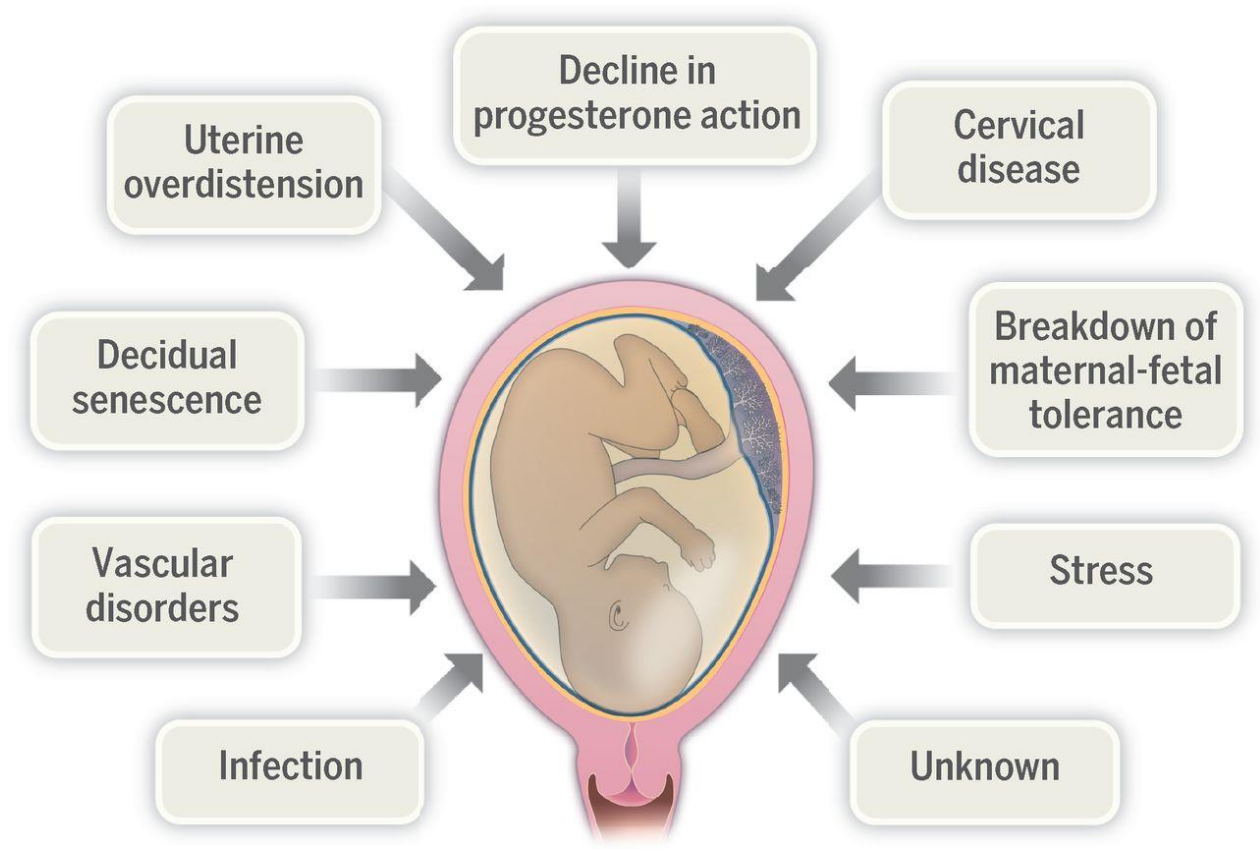

Figure 5. Proposed pathogenic mechanisms implicated in spontaneous preterm labour. . From [R. Romero, S.K. Dey, and S.J. Fisher (2014). Preterm labor: One syndrome, many causes. Science, 345 (6198), 760-765] $]^{7}$. Reprinted with permission from AAAS. 


\section{The Apgar score}

In 1953 the work of anaesthetist Virginia Apgar (Figure 6) "A proposal for a new method of evaluation of the newborn infant"162 was published, in which a scoring system was presented to evaluate resuscitation efforts in neonates, and as a basis for discussion and comparison of the results of obstetric interventions, including pain relief given to mothers. The original scoring system included assessment at one minute of age of heart rate, respiratory effort, reflex irritability (response to stimulation like suction in the oropharynx or nostrils), muscle tone, and skin colour. A rating of zero, one, or two was given to each sign depending on whether it was present or absent (Table 4). A score of ten indicated the best

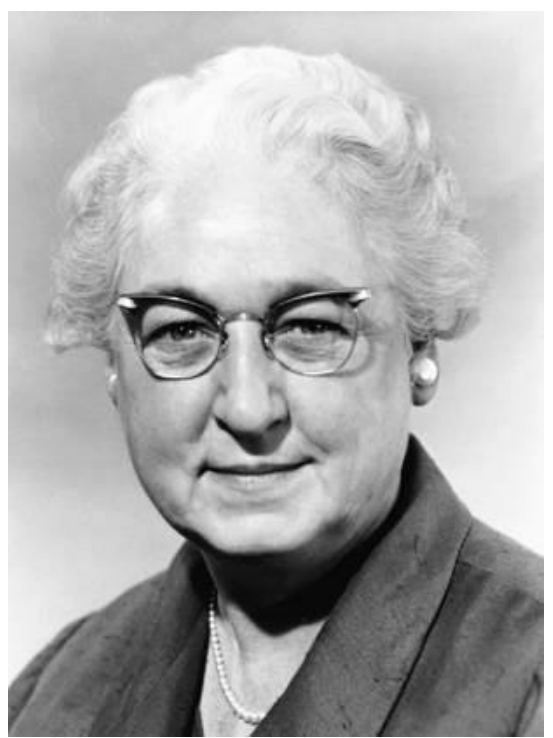

Figure 6. Virginia Apgar (1909-1974). Source:https://cfmedicine.nlm.nih.gov/phys icians/biography_12.html. Courtesy of the National Library of Medicine. possible condition.

Since the 1950s the scoring system has spread worldwide, and in clinical practice it includes assessment of the clinical signs at one, five, and ten minutes of age. Although the scoring system has been criticised because of inter- and intra-observer variability, and because a low score does not give information about the underlying conditions ${ }^{163}$, its simplicity and inexpensiveness provide many advantages. It is used to compare neonatal outcomes at different obstetric units and, despite other available methods such as measurement of umbilical cord acid base balance, defines the degree of birth asphyxia according to the International Statistical Classification of Diseases and Related Health Problems $11^{\text {th }}$ Revision (ICD-11) ${ }^{164}$.

An Apgar score $<7$ at 5 minutes $\left(\mathrm{AS}^{5 \min }<7\right)$ has been shown to be a risk factor for neonatal mortality ${ }^{165}$ and morbidity, such as respiratory distress and neurological conditions including cerebral palsy ${ }^{166-168}$, but is also associated with neurodevelopmental problems later in childhood ${ }^{169,170}$, as well as a higher prevalence of low cognitive performance in adult men ${ }^{171}$. Low Apgar scores are not only associated with neonatal mortality, but also with infant mortality up to one year of age ${ }^{165}$. Furthermore, there is an association between an Apgar score of 0-5 at five minutes of age and cancer diagnosed shortly after birth ${ }^{172}$. 
Table 4. The clinical signs included in the Apgar score.

\begin{tabular}{|l|c|c|c|}
\hline Score & $\mathbf{0}$ & $\mathbf{1}$ & $\mathbf{2}$ \\
\hline Heart rate & Absent & $<100$ & $>100$ \\
\hline Respiration & Absent & Slow, irregular & Strong, vigorous cry \\
\hline Skin colour & Blue & $\begin{array}{c}\text { Acrocyanosis } \\
\text { (blue extremities) }\end{array}$ & Normal \\
\hline Muscle tone & No movement, flaccid & $\begin{array}{c}\text { Some flexion } \\
\text { (arms and legs) }\end{array}$ & $\begin{array}{c}\text { Full body active } \\
\text { motion }\end{array}$ \\
\hline Reflex irritability* & No response & Grimace & Sneeze, cough \\
\hline
\end{tabular}

*response to catheter in nostrils

Several risk factors have been associated with $\mathrm{AS}^{5 \mathrm{~min}}<7$; they cover social, anthropometric, medical, and obstetric factors and comprise low socio-economic status and lower level of education ${ }^{173}$, single civil status ${ }^{174}$, overweight and obesity ${ }^{175,176}$, maternal shortness in stature $^{177}$, maternal age $>35$ years ${ }^{175}$, smoking ${ }^{178}$, nulliparity ${ }^{175,177}$, previous caesarean section ${ }^{177}$, operative and breech delivery in the current pregnancy, abnormal intrapartum cardiotocography (CTG), oxytocin augmentation, and intrauterine meconium release ${ }^{174}$. 


\section{Aims and Hypotheses}

\section{General aim}

The general aim of this thesis was to increase the knowledge of clinical and immunological factors in $\mathrm{SPTB}$, in particular to evaluate these factors as potential predictors for SPTB in early pregnancy or in relation to PTL and PPROM.

\section{Specific aims and hypotheses}

Study I: To identify risk factors prior to delivery for $\mathrm{AS}^{5 \mathrm{~min}}<7$ and to identify risk factors for PTB $<32$ weeks of gestation. An additional aim was to compare possible differences in risk factor profiles between secondary and tertiary levels of care.

We hypothesised that our study population would display risk factors for $\mathrm{AS}^{5 \min }<7$ and PTB $<32$ weeks in accordance with findings of previous studies. Furthermore, we hypothesised that the tertiary level of care would be associated with increased rates of $\mathrm{AS}^{5 \mathrm{~min}}<7$ and PTB $<32$ weeks.

Study II: To investigate whether chemokines/cytokines or a proximity extension assay (PEA)-based inflammatory biomarker panel in plasma, together with clinical variables, were able to predict time of delivery before or after 34 weeks of gestation, and delivery within or after 48 hours, in women with PTL before 34 weeks of gestation. An additional aim was to elucidate the cytokine and chemokine profiles in PTL and PPROM before 34 weeks of gestation compared to those of antenatal controls and controls in labour at term.

We hypothesised that a combination of several inflammation-associated proteins, mainly pro-inflammatory, would discriminate women with PTB $<34$ weeks from $>34$ weeks and women with delivery $<48$ hours from $>48$ hours with a clinically useful accuracy, possibly in combination with CL. Furthermore, we hypothesised that patterns of pro-inflammatory responses would be more evident in term labour > PTL > PPROM $>$ antenatal controls. 
Study III: To evaluate plasma oxylipin levels as a predictor for PTB <34 weeks of gestation and within 48 hours of admission to hospital in women with PTL before 34 weeks of gestation.

We hypothesised, that a combination of different plasma oxylipins would discriminate women with PTB $<34$ weeks from $>34$ weeks and women with delivery $<48$ hours from $>48$ hours with a clinically useful accuracy.

Study IV: To evaluate whether prediction of sPTB prior to 34 weeks of gestation was possible in a low-risk population of pregnant women, based on the levels of inflammation-associated plasma proteins in the first and second trimester, analysed by the high sensitivity PEA.

We hypothesised that combinations of inflammation-associated proteins from the first or second trimester, or in combinations of the trimesters, would demonstrate clinically useful predictive accuracy for PTB $<34$ weeks of gestation. 


\section{Material and Methods}

An overview of the studies included in this thesis is presented in Table 5.

Table 5. Overview of the studies included in the thesis.

\begin{tabular}{|c|c|c|c|c|}
\hline Study & I & II & III & IV \\
\hline Aim & $\begin{array}{l}\text { Identify risk factors } \\
\text { for Apgar score }<7 \text { at } \\
5 \text { ' and for PTB }<32 \\
\text { gw }\end{array}$ & $\begin{array}{l}\text { Evaluate } \\
\text { combinations of } \\
\text { plasma proteins for } \\
\text { prediction of PTB in } \\
\text { threatened PTB }\end{array}$ & $\begin{array}{l}\text { Evaluate plasma } \\
\text { oxylipins for } \\
\text { prediction of PTB in } \\
\text { PTL }\end{array}$ & $\begin{array}{l}\text { Evaluate } \\
\text { combinations of } \\
\text { plasma proteins in } \\
\text { early pregnancy for } \\
\text { prediction of SPTB }\end{array}$ \\
\hline Design & $\begin{array}{l}\text { Retrospective cohort } \\
\text { study }\end{array}$ & $\begin{array}{l}\text { Case-control study } \\
\text { and prospective } \\
\text { cohort study }\end{array}$ & $\begin{array}{l}\text { Prospective cohort } \\
\text { study }\end{array}$ & Case-control study \\
\hline Data collection & $2006-2010$ & 2014-2017, 2018* & 2014-2017, 2019* & 2011-2018, 2019* \\
\hline Data sources & $\begin{array}{l}\text { Digital medical } \\
\text { records Obstetrix }{ }^{\circledast}\end{array}$ & $\begin{array}{l}\text { Digital medical } \\
\text { records Obstetrix }{ }^{\circledR}\end{array}$ & $\begin{array}{l}\text { Digital medical } \\
\text { records Obstetrix }{ }^{\circledR}\end{array}$ & $\begin{array}{l}\text { Digital medical } \\
\text { records Obstetrix }{ }^{\circledR}\end{array}$ \\
\hline $\begin{array}{l}\text { Analytical } \\
\text { method }\end{array}$ & -- & MBA, ELISA, PEA & LC/MS-MS & PEA \\
\hline $\begin{array}{l}\text { Study } \\
\text { participants }\end{array}$ & $\begin{array}{l}\text { All live births } \\
\left(n=20,643 \text { ) at a } 2^{\circ}\right. \\
\text { and a } 3^{\circ} \text { level } \\
\text { hospital }\end{array}$ & $\begin{array}{l}80 \text { women with } \\
\text { PTL and } 40 \text { women } \\
\text { with PPROM <34 } \\
\text { gw }\end{array}$ & 80 women with PTL & $\begin{array}{l}45 \text { women with } 46 \\
\text { sPTBs <34 gw }\end{array}$ \\
\hline Controls & -- & $\begin{array}{l}44 \text { women at } \\
\text { antenatal visits, } 40 \\
\text { women in labour at } \\
\text { term }\end{array}$ & -- & $\begin{array}{l}46 \text { women with } \\
\text { normal } \\
\text { pregnancies and } \\
\text { delivery at term }\end{array}$ \\
\hline $\begin{array}{l}\text { Grouping } \\
\text { designation }\end{array}$ & $\begin{array}{l}\text { Apgar score }<7 \text { or }>7 \\
\text { at } 5^{\prime} \text { of age, birth } \\
<32 \text { gw }\end{array}$ & $\begin{array}{l}\text { PTB }<34 \text { gw or } \\
\text { within } 48 \mathrm{~h}\end{array}$ & $\begin{array}{l}\text { PTB }<34 \text { gw or } \\
\text { within } 48 \mathrm{~h}\end{array}$ & $\begin{array}{l}\text { PTB }<34 \text { gw or } \\
\text { term birth }\end{array}$ \\
\hline $\begin{array}{l}\text { Outcome } \\
\text { measures }\end{array}$ & $\begin{array}{l}\text { Maternal and } \\
\text { obstetric risk factors }\end{array}$ & $\begin{array}{l}\text { AUC for } \\
\text { combinations of } \\
\text { proteins predicting } \\
\text { PTB }\end{array}$ & $\begin{array}{l}\text { Oxylipin levels in } \\
\text { relation to time of } \\
\text { birth }\end{array}$ & $\begin{array}{l}\text { AUC for } \\
\text { combinations of } \\
\text { proteins predicting } \\
\text { PTB }\end{array}$ \\
\hline Statistics & $\begin{array}{l}\text { Student's t-test, } \\
\text { Chi2-test, univariate } \\
\text { and multivariate } \\
\text { logistic regression }\end{array}$ & $\begin{array}{l}\text { Kruskal-Wallis, } \\
\text { Mann-Whitney U- } \\
\text { test, Chi-2 test, } \\
\text { Fisher's exact test, } \\
\text { discriminant } \\
\text { analysis }\end{array}$ & $\begin{array}{l}\text { Chi-2 test, Fisher's } \\
\text { exact test, Mann- } \\
\text { Whitney } U \text {-test, } \\
\text { univariate and } \\
\text { multivariate } \\
\text { logistic quantile } \\
\text { regression }\end{array}$ & $\begin{array}{l}\text { Kruskal Wallis, Chi- } \\
2 \text { test, Fisher's } \\
\text { exact test, Mann- } \\
\text { Whitney U-test, } \\
\text { discriminant } \\
\text { analysis }\end{array}$ \\
\hline
\end{tabular}


Study designs, study populations, and outcomes

\section{Study 1}

Study I was a retrospective registry cohort study including all births $(\mathrm{n}=21,126)$ during 2006-2010 at a secondary level hospital and a tertiary level hospital in the southeast region of Sweden. The aim was to identify risk factors for $\mathrm{AS}^{5 \mathrm{~min}}<7$ and risk factors for PTB $<32$ weeks of gestation, and to evaluate differences between secondary and tertiary level of hospital care. Subjects were grouped according to Apgar score; $<7$ or $\geq 7$ at five minutes of age, and according to birth before or after 32 weeks of gestation. After exclusion of neonates who had not been assigned an Apgar score, stillbirths, neonates with lethal malformations, and one of two twins (or two of three triplets) the remaining study population was $n=20,643$. Outcomes were risk factors for $\mathrm{AS}^{5 \mathrm{~min}}<7$ and for risk factors for PTB $<32$ weeks of gestation estimated using logistic regression analysis.

\section{Study II}

Study II was both an observational multi-centre case-control study and a prospective cohort study, which included women with threatened PTB $<34$ weeks at three hospitals in the southeast region of Sweden during 2014-2017. Threatened PTB was defined as PTL, i.e. regular painful contractions and cervical change $(n=80)$, or PPROM $(n=40)$. As controls 44 women with normal pregnancies and subsequent deliveries at term were recruited at scheduled visits to an antenatal clinic. These women were matched for gestational age at inclusion to the women with threatened PTB. Another control group included 40 women with normal pregnancies in an early phase of active labour at term (cervical dilatation 5-6 cm) (Figure 7). Outcomes were AUC for combinations of inflammation-associated proteins predicting PTB $<34$ weeks and within 48 hours of hospital admission due to PTL, and differences in levels of chemokines and cytokines between groups.

\section{Study III}

The subjects in study III were the same 80 women with PTL before 34 weeks of gestation as those in the prospective cohort of Study II (Figure 7). Outcomes were ORs for oxylipins associated with PTB <34 weeks of gestation and ORs for oxylipins associated with delivery within 48 hours of hospital admission due to PTL. 


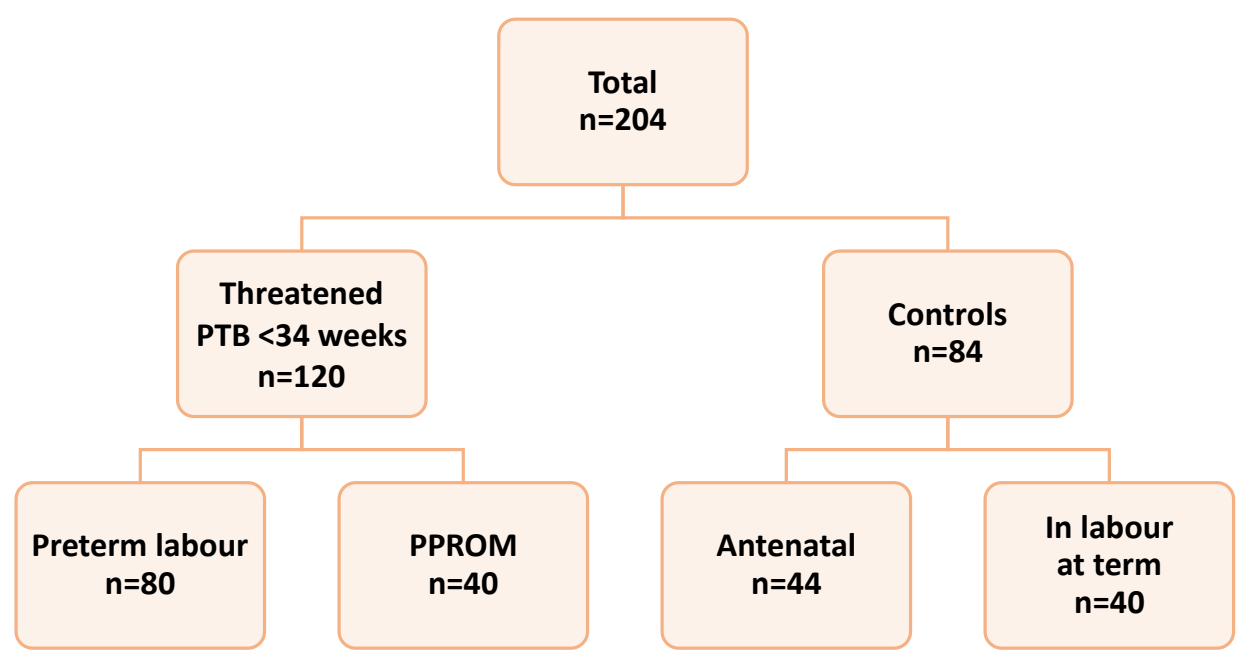

Figure 7. Flow chart of the women included in Study II. The 80 women in preterm labour were also included in Study III. PPROM=Preterm prelabour rupture of the membranes.

\section{Study IV}

Study IV was a retrospective case-control study based on the pregnancy biobank (Graviditetsbiobanken, GraBB), which was founded at the University of Linköping in collaboration with Linköping University Hospital with the purpose of prospectively collecting blood samples to enable research on pregnancy complications. Pregnant women received information about the research project when booking their first visit to the antenatal clinic. Two antenatal clinics in Region Östergötland were responsible for the recruitment of women, both clinics serving a population of predominantly low-risk women. Participation in the biobank required the donation of blood samples in the first trimester (8-11 weeks of gestation), second trimester (around 25 weeks of gestation), and intrapartum. Participation also included permitting access to present and future medical records for research purposes. If the partner of the pregnant woman also consented, blood samples were taken from the umbilical cord after delivery. During 2011-2018 a total of 8,027 women participated in the biobank. All pregnancies were dated, according to clinical routine, by transabdominal ultrasound measuring the biparietal diameter (21-55 $\mathrm{mm}$ ) at 12-22 weeks of gestation.

To perform a case-control study, all women with PTB 22-34 weeks of gestation ( $\mathrm{n}=108)$ were identified by linking the database of the biobank to the electronic medical records (Obstetrix $\left.{ }^{\circledR}\right)$ of the women. To identify cases of $\mathrm{sPTB}$, the medical records were scrutinised. Exclusion criteria were maternal age $<18(n=1)$, stillbirth $(n=9)$, multiple gestation $(n=17)$, emergency placental complications $(n=13)$, and medically indicated PTB due to preeclampsia, IUGR or other severe pregnancy complications (in total 
$\mathrm{n}=22$ ). After these exclusions, 46 pregnancies (in 45 women) were included (see flow chart in Figure 8). Of the included cases of sPTB 23 presented with PTL and 23 presented with PPROM.

As controls, 46 women with delivery at term were included. These controls were matched to the cases regarding parity, and the selection was based on the chronological order for inclusion in the biobank, i.e. the first woman enrolled in the biobank next after a case was selected, provided she fulfilled the inclusion criteria: delivery at term, blood samples from both first and second trimesters available, singleton pregnancy, age 1842, BMI 18-30, non-smoker, and uncomplicated current pregnancy. Exclusion criteria were intercurrent disease requiring medication, history of previous obstetric complications, and adverse outcomes in mother or child.

Outcomes were AUC for combinations of inflammation-associated proteins from the first and the second trimesters, separately or combined, for the prediction of PTB $<34$ weeks of gestation.

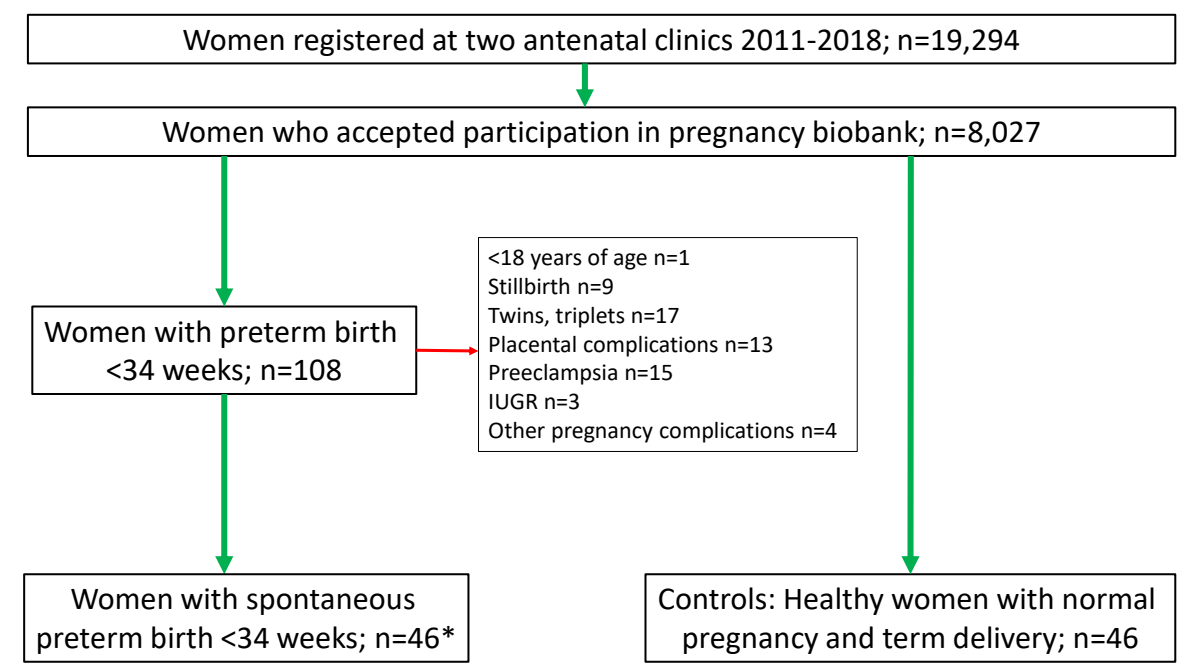

Figure 8. Flow chart of the study population in Study IV. * 46 pregnancies in 45 women.

\section{Data sources}

For all studies pre-pregnancy, pregnancy and delivery data was extracted from the Obstetrix ${ }^{\circledR}$ electronical medical records (Cerner Sweden Corp.). Detailed information on the women attending antenatal, intrapartum, and postpartum care in the South-East region of Sweden is registered in Obstetrix ${ }^{\circledR}$ and includes diagnoses, pregnancy outcomes of mother and child, as well as maternal general health data. 


\section{Analytical methods}

\section{Handling of blood samples}

For study II, III, and IV EDTA tubes were used. The tubes were centrifuged at $2500 \mathrm{~g}$, in study II and III after one-two hours, and in study IV after 30-60 minutes. The plasma was then aliquoted and frozen immediately at $-70^{\circ} \mathrm{C}$ until use.

\section{Enzyme-linked immunosorbent assay (ELISA)}

In study II levels of the Th2associated chemokine $\mathrm{C}-\mathrm{C}$ motif ligand (CCL) 18 were analysed by an in-house sandwich ELISA adapted from Sandberg $e t a l^{179}$. The method is described in detail in Paper II, and a principal (schematic) overview is provided here (Figure 9).

A 96-microtiter well plate is coated with capture antibodies against the target antigen, in this case CCL18, after which the diluted sample is added, in duplicates in this case. The capture antibodies will bind any antigens present in the sample. After

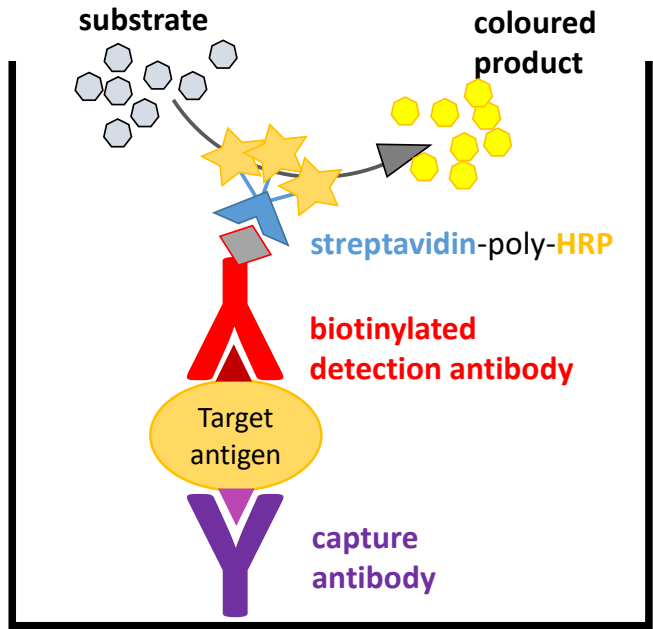

Figure 9. Schematic overview of Enzyme-Linked Immunosorbent Assay (ELISA). HRP=horse radish peroxidase.

washings to remove unspecifically bound antigens, a biotinylated detection antibody is added in order to bind to another epitope of the antigen.

After repeated additional washings, streptavidin-poly-horse radish peroxidase (HRP) is added. The streptavidin binds to the biotin. The enzymatic activity of the HRP transforms the substrate into a coloured product. The more enzyme present, the stronger colour. Hence, the colour intensity reflects the abundance of antigen. The enzymatic reaction is stopped by adding a solution of sulphuric acid. To assess the concentration in the sample, the optical density of the colour reaction is measured and compared to that of a standard curve, with known concentrations, also present on the plate. 


\section{Multiplex bead analysis}

In study II, multiple bead analysis (Luminex) was used to determine concentrations of chemokines and cytokines representing different types of immune responses; Th1 (CXCL10, CXCL11), Th2 (CCL2, CCL17), Th17 (CCL20, CXCL1), inflammation (CXCL8, Granulocyte Macrophage-Colony Stimulating Factor (GM-CSF), IL-6), and B-cell recruitment (CXCL13). The analysis was performed as described by Håkansson et al ${ }^{180}$ and is described in detail in Paper II.

The principle of the multiple bead analysis is similar to that of ELISA, but permits simultaneous measuring of multiple antigens in one sample (Figure 10). Instead of coating wells with capture antibodies, colour-coded (dyed red and infrared in different concentrations) micro-spheres (beads) coated with capture antibodies against the antigen of interest are placed in the wells. The antigens bind to the capture antibodies, like in ELISA. Next, a biotinylated detection antibody is added, and thereafter a solution with phycoerythrin-conjugated streptavidin, which binds to the biotin. Phycoerythrin is a fluorochrome that emits light of a certain wavelength when hit by a laser beam. The colour-codes of the beads and the fluorescence signal from the detection antibodies are then simultaneously read after exposure by a dual laser beam. One laser identifies the colour-coded bead that represents the antigen, whereas the other laser determines the magnitude of the fluorescence signal from the detection antibody, thus representing the concentration of the antigen in the sample. Also here, the signal (in this case fluorescence instead of optical density in ELISA) is related to a standard curve to obtain the concentration.

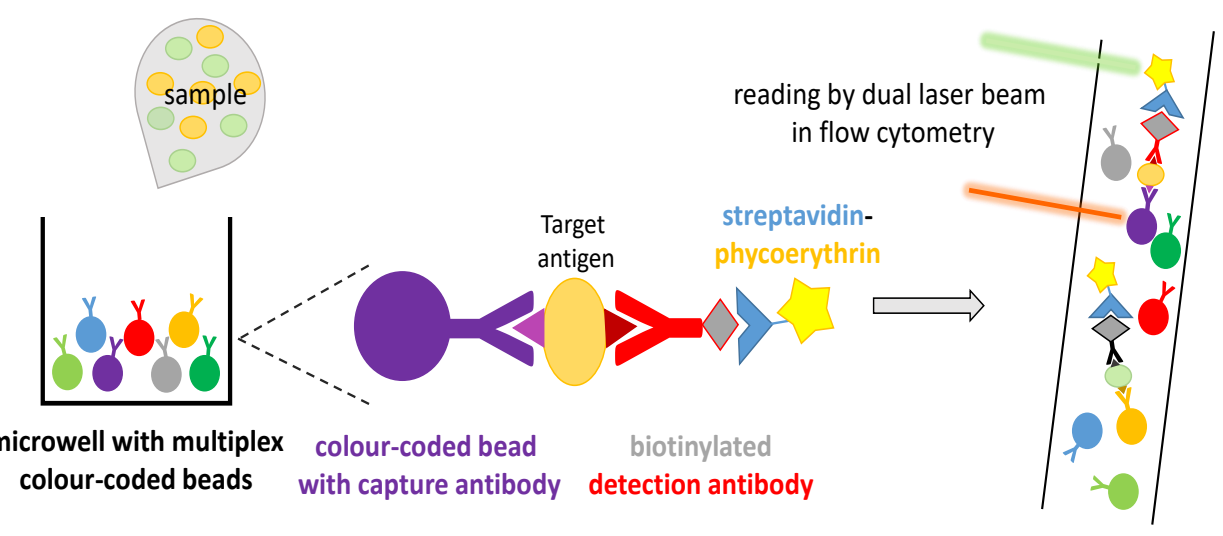

Figure 10. Schematic overview of the multiplex bead assay. 
In study II and IV PEA was performed; for study II in 2018 and for study IV in 2019. In preparation for analysis, aliquots were thawed slowly on ice, centrifuged during 5 min at $2,000 \mathrm{~g}$ at $+4^{\circ} \mathrm{C}$ to remove potential precipitates, then pipetted into a 96microwell plate, frozen at $-70^{\circ} \mathrm{C}$ and shipped on dry ice to the Clinical Biomarkers Facility, Science for Life Laboratory, Uppsala University, Uppsala, Sweden, where the analysis was carried out.

The multiplex PEA technology (Olink Bioscience, Uppsala, Sweden) was used to measure 92 inflammation-associated proteins using the Olink Inflammation panel (https://www.olink.com/products/inflammation) (Appendix 1).

A brief description of the main steps of the PEA technology is presented (Figure 11): The samples are incubated with oligonucleotide-labelled antibodies, which pair-wise bind to two different epitopes of the target protein. Next, if the oligonucleotides are in close proximity they are hybridized and then extended by DNA polymerization, which forms a new polymerase chain reaction (PCR) target sequence. Real-time PCR is then used to detect, amplify and quantify the PCR target. The data is presented as Normalized Protein eXpression (NPX) values, i.e. arbitrary units in a Log2 scale, in order to minimize intra- and inter-assay variation, and used for relative quantification only. Hence, NPX values for two different analytes are not comparable. The requirement of binding two epitopes secures a high specificity, and the PCR-based amplification step secures a high sensitivity.

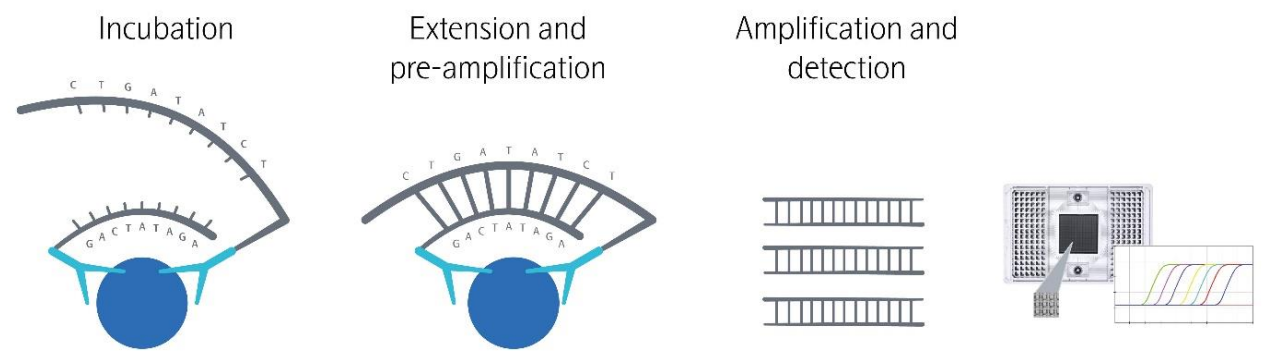

Figure 11. Overview of the proximity extension assay technology. Image courtesy of Olink Proteomics $\mathrm{AB}$. 
In study III, during 2019, high performance liquid chromatography coupled to tandem mass spectrometry (HPLC/MS-MS) was used to quantify concentrations of 67 individual oxylipins (Figure 12). The explanations of the abbreviations of the individual oxylipins are listed in Appendix 2. The procedure of HPLC/MS-MS is described in detail in Paper III according to a protocol published by Späth et $a l^{181}$ using external calibration curves, also previously described ${ }^{182}$.

HPLC-MS/MS is optimal for simultaneous multi analyte quantification to obtain oxylipin profiles in biological samples ${ }^{183}$. Briefly, HPLC methodology can separate analytes dissolved in liquid, which are transferred to the MS system via an interface. The MS system then identifies and quantifies the analytes.

First, the analytes are extracted from the sample (in our case with solid phase extraction), injected on the HPLC-column, and then pumped under pressure through the column with the mobile phase (a gradient of water $(0.1 \%$ acetic acid) and acetonitrile: isopropanol (90:10)). In the reversed phase set-up, the analytes are separated based on their polarity due to their different affinities for the stationary phase of the column. Retention time in this set-up is longer for lipophilic analytes compared to more polar analytes, which results in a chromatogram with PG-like compounds eluting earlier than for instance fatty acid epoxides.

For quantification purposes the HPLC is connected with the MS via an interface (in this case an ion source operating in negative electrospray ionisation mode) generating ions, making introduction into the mass spectrometer in the gas phase possible, so that they can be separated in the mass analyser according to their mass/charge ratio and then detected. A triple quadropole was used, in which the first and last quadropoles are mass filters, while the one in the middle is used as a collision cell for fragmentation of the ions. The data is computer processed, whereby a mass spectrum is generated and compiled into a chromatogram allowing quantifications of the analytes (Figure 13). 


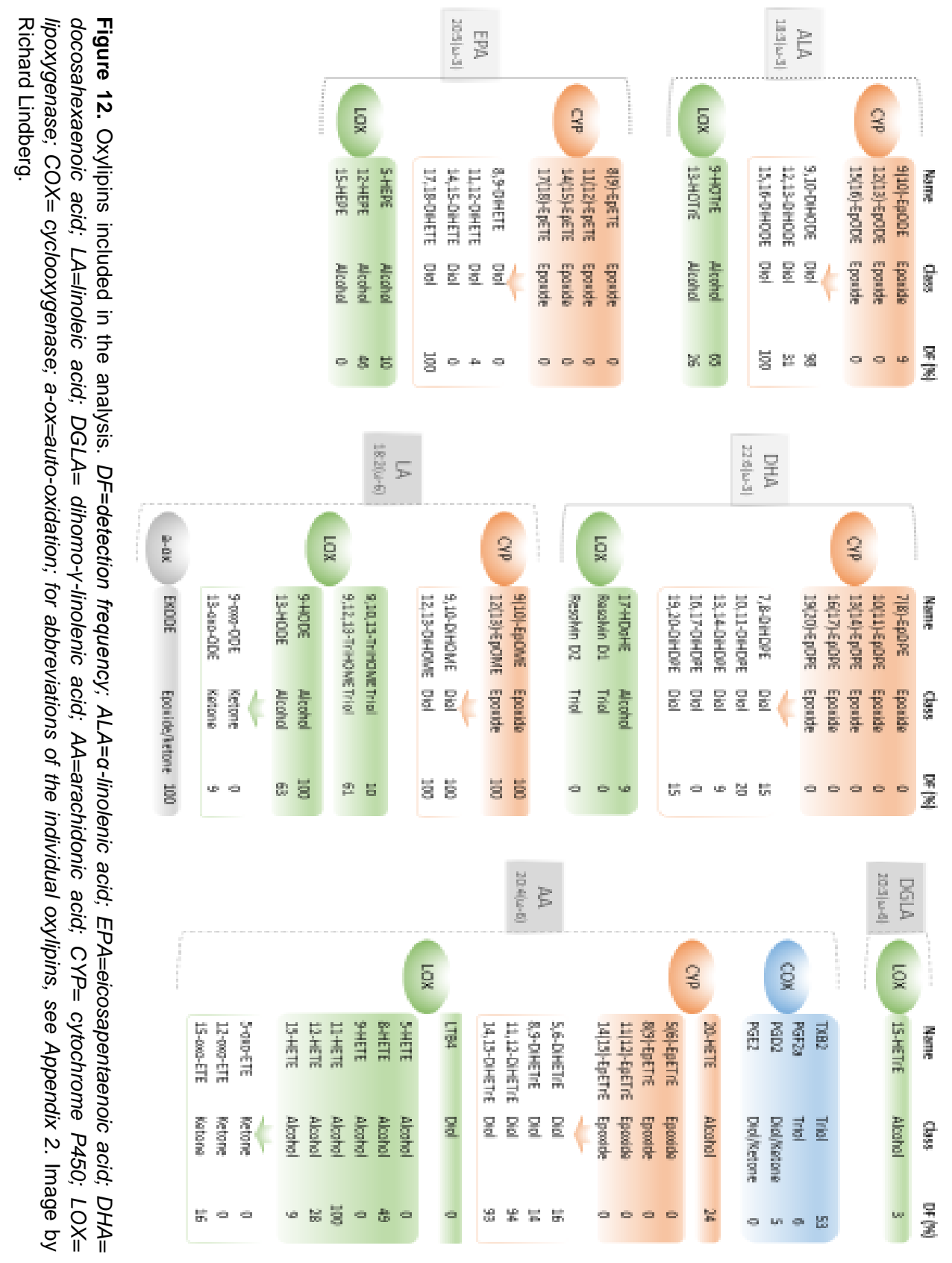




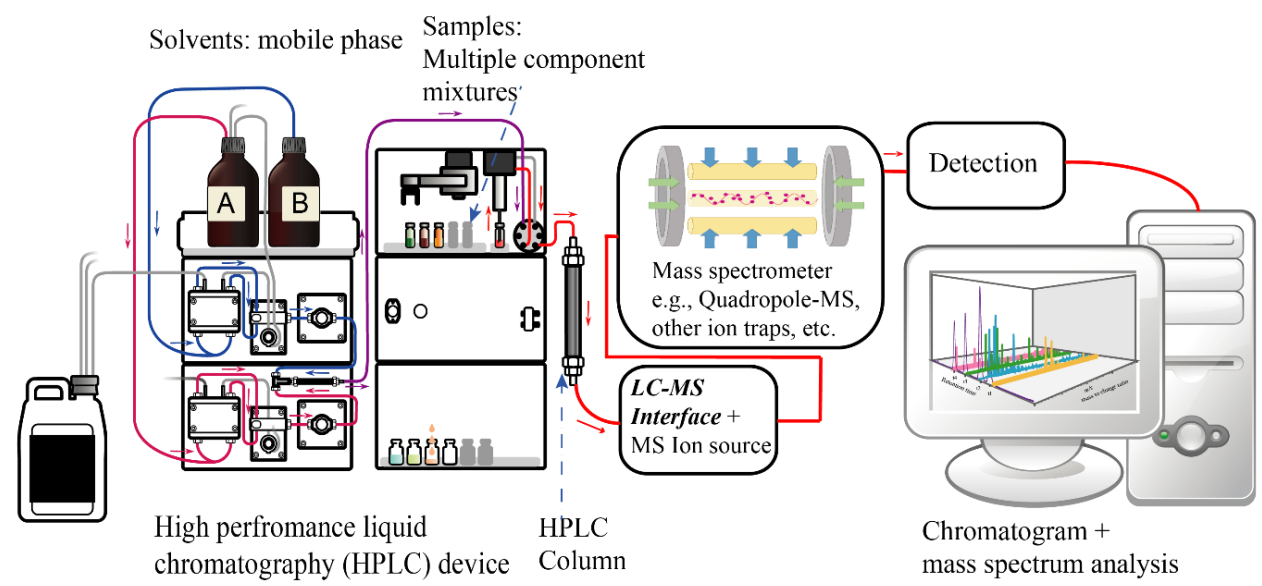

Figure 13. Diagram of liquid chromatography coupled to tandem mass spectrometry. Author: Daniel Norena-Caro, 2017. Created in Illustrator C6. Downloaded from https://en. wikipedia.org/w/index.php?curid=53483681, available under the Creative Commons CC0 1.0 Universal Public Domain Dedication.

\section{Statistics}

\section{Sample size calculation}

In Study I no sample size calculation was performed since it was a descriptive retrospective registry study.

For Study II-IV a priori analysis showed that a sample size of 70 women was sufficient to detect a $40 \%$ decrease or increase in an immunological parameter (CXCL10) with a power of $80 \%$ and an alpha value of 0.05 . Hence, 35 women in each group would be appropriate. This was also supported by findings in previous studies detecting differences between groups regarding immunological parameters in pregnancy complications ${ }^{85,184}$. Therefore, in Study II inclusions of women continued until there were at least 40 women in each group. Study III was based on a sub-cohort of the women included in Study II.

In Study IV, a total of 46 women with SPTB were identified in the pregnancy biobank. Since at least 35 women in each group were required according to the a priori analysis, we decided to include all women with SPTB as the number of cases with sPTB did not substantially exceed 35 . As control group, the same number of women as the cases were included according to the a priori analysis. 


\section{Descriptive statistics}

In Study I, mean value (mean), standard deviation (SD), and range (first-third quartile (Q1-Q3); interquartile range (IQR)) were presented for continuous variables, and differences between groups were analysed with Student's $t$-test adjusted for unequal variances. Categorised descriptive data was presented as numbers and percentages. Chi2-test was used for the comparison of frequencies.

In Study II, III, and IV mean/SD and median/range (min-max or IQR) were presented for continuous variables. Differences between several groups were analysed with Kruskal-Wallis test, and in case of $\mathrm{p}<0.05$ followed by a Mann-Whitney $U$-test. Numbers and proportions were presented for categorical variables and differences between groups were analysed by Chi- 2 test or Fisher's exact test.

\section{Analyses of outcomes}

In Study I ORs for $A S^{5 m i n}<7$ and PTB $<32$ weeks of gestation, associated to the risk factors for the respective outcomes, were calculated with univariate and multivariate logistic regression analysis. The multivariate analysis included all variables with significant associations with the respective outcomes in the univariate analysis, and maternal age.

In Study II differences in concentrations of chemokines and cytokines between the cases and control groups at baseline were assessed with Kruskal-Wallis test, and in case of $\mathrm{p}<0.05$ followed by Mann-Whitney $U$-test. In women with PTL, differences in levels of inflammation-associated proteins in association with time of delivery were calculated with the Mann Whitney $U$-test. Discriminant analysis was performed to evaluate associations between inflammation-associated proteins and time of PTB. Receiver operating characteristic (ROC) curves using the results from the discriminant function analysis were defined.

In Study III the Mann-Whitney $U$-test, or Chi-2 test when appropriate, was used for screening of differences in oxylipin concentrations between groups. Oxylipins with a difference in concentrations between groups at a $p$-value $<0.1$ were further analysed with logistic quantile regression in univariate and multivariate models.

In Study IV, initially a Mann-Whitney $U$-test was performed to screen for proteins associated with PTB $<34$ weeks of gestation. Proteins with significant differences at a p-value level $<0.1$ were included in a discriminant analysis to evaluate associations between inflammation-associated proteins and SPTB before 34 weeks of gestation. Only proteins with a p-value $<0.05$ were accepted in the final discriminant analysis. ROC curves were then defined using the results from the discriminant function analyses. 


\section{Ethical approval and considerations}

The Regional Ethical Review Board in Linköping, Sweden, approved the studies in this thesis (Study I; Dnr 2012/195-31, Study II and III; Dnr 2013/417-31 and Dnr 2016/42132 (amendment), and Study IV; Dnr 2010/296-31 and Dnr 2019-00424 (amendment)).

Study I was a registry study, in which no informed consent was obtained. Because of the retrospective and observational study design and the nature of the study with data electronically collected from thousands of women, the Swedish Ethical Review Authority did not demand informed consent. The study had no impact on the participants' health, but might add important knowledge that future parturients may benefit from.

In Studies II-IV, all participating women gave written informed consent after receiving oral and written information. They consented to donating blood samples and to giving access to their medical records for research purposes.

In Study II, as well as in Study III, which was based on a sub-cohort of the women participating in Study II, the women in the case group were admitted to hospital due to threatened PTL, which might be an emergency condition. However, information about the study did not delay any medical examination or the start of treatment. Blood sampling for research purposes did not cause any additional discomfort for the women, as this was done in conjunction with clinically indicated procedures, such as the insertion of a peripheral vein catheter. Study II included two control groups: one comprising women in labour at term and one comprising women at scheduled antenatal visits. For the women in labour at term, information about the study neither caused delay regarding medical examinations nor affected the care given to the women. The insertion of a peripheral vein catheter is a routine procedure at the labour wards from which the women were recruited to the study, meaning that the blood sampling for the study caused no additional discomfort. For the women in the antenatal control group, participation in the study entailed blood sampling at a time point when it was not clinically indicated, causing some additional discomfort. However, the oral and written information clearly gave the women the opportunity to carefully consider whether they would consent or not. Also, the amount of extra blood taken, about $20 \mathrm{~mL}$, did not cause any health problems. In Study IV, extra blood samples were donated on three occasions, which also can be regarded as safe. The sampling times were scheduled to coincide with routine blood sampling.

To study risk factors of PTB in early pregnancy raises ethical concerns. To date, there are no obvious preventive strategies to offer women with an increased risk of PTB based on biomarker information. However, in Study IV, data is processed on a group level and no information is retrieved about individual women. Moreover, Study IV is 
retrospective, meaning that the women have already delivered preterm. Hence, it is already known that these women are at an increased risk of PTB and will be treated accordingly in a subsequent pregnancy, irrespective of the findings in this study. Further ethical issues regarding these studies are discussed in the section Future Perspectives. When the possible negative ethical aspects of the studies are compared to the benefits of gaining more knowledge regarding the understanding and prediction of PTB, the positive aspects dominate. 


\section{Results and Discussion}

\section{Risk factors for Apgar score $<7$ at five minutes of age}

Because the Apgar score is an important predictor for child mortality and morbidity, as well as for medical and cognitive problems later in life, the aim of Study I was to identify risk factors for $\mathrm{AS}^{5 \mathrm{~min}}<7$ in a cohort of women giving birth to 21,126 infants, of which 99.4\% had been assigned an Apgar score at 5 minutes of age. Stillbirths $(n=72)$, neonates with lethal malformations ( $\mathrm{n}=3$ ), and, in case of multiple gestations $(\mathrm{n}=619)$, one of two of twins (or two of three of triplets) were excluded. The reason for exclusion of one of two twins was in order not to register maternal risk factors more than once in the same pregnancy. The settings were a tertiary level hospital $(\mathrm{n}=13,632)$ and a secondary level hospital $(n=7,011)$ with a rate of $\mathrm{AS}^{5 \min }<7$ of $2.00 \%$ and $1.37 \%$ respectively.

The most evident risk factor for $\mathrm{AS}^{5 \mathrm{~min}}<7$ was PTB with a clear trend of the rate of $\mathrm{AS}^{5 \mathrm{~min}}<7$ across the strata of gestational ages; compared to delivery at term PTB at 2831 weeks had an OR for $\mathrm{AS}^{5 \mathrm{~min}}<7$ of 8 (95\% CI 5-12), and at $<28$ weeks of gestation the OR was 15 (95\% CI 8-29) with a rate of $\mathrm{AS}^{5 \mathrm{~min}}<7$ of $56 \%$ at $<28$ weeks compared to $1.13 \%$ at term (Table 6). This is in line with previous findings of associations between low gestational age and very low birth weight and low Apgar scores ${ }^{185}$. Moreover, it has been shown that preterm born infants, who are assigned lower Apgar scores, have higher RRs of neonatal death ${ }^{186}$. However, postterm birth (>42 weeks of gestation) was also associated with $\mathrm{AS}^{5 \mathrm{~min}}<7$, although the risk increase was less evident than for PTB (OR 2.0 (95\% CI 1.7-2.3)) (Table 6).

The anthropometric risk factors that were multivariately associated with $\mathrm{AS}^{5 \mathrm{~min}}<7$ were short stature $(\leq 158 \mathrm{~cm}$ ), overweight (BMI 25-29), and obesity (BMI $\geq 30$ ) (Table 6). Similar findings were made by others ${ }^{175,176,187,188}$. Interestingly, Berglund et al found an association between short stature and the risk for asphyxia associated with substandard care during labour ${ }^{177}$. Obesity is a risk factor for a number of pregnancy complications, such as gestational diabetes and preeclampsia ${ }^{189,190}$, and it is possible that these conditions cause adverse neonatal outcomes. However, in this study there was no multivariate association between preeclampsia and $\mathrm{AS}^{5 \mathrm{~min}}<7$, although there was an association in the univariate analysis (Table 3, Paper I). Data on gestational diabetes was not available.

Factors related to obstetric history and current pregnancy characteristics that were associated with $\mathrm{AS}^{5 \min }<7$ were nulli-parity, previous caesarean section, multiple pregnancy, and non-normal admission CTG (Table 6), which correspond to previous findings ${ }^{175,177}$. 
An additional aim was to investigate whether the level of care (secondary or tertiary hospital) was a risk factor for $\mathrm{AS}^{5 \mathrm{~min}}<7$. The two clinics in this study work in collaboration according to shared guidelines, and some of the obstetric high-risk patients are referred from the secondary to the tertiary level hospital. Therefore, it is important to continually evaluate potential differences in obstetric care and outcomes. According to the univariate logistic regression analysis there was an association between $\mathrm{AS}^{5 \mathrm{~min}}<7$ and tertiary level care, however in the multivariate analysis, adjusted for PTB and other variables, there was no significant difference (Table 6). Thus, there seems to be no difference in outcomes at the different levels of care, when taking differences in diagnoses into account.

Table 6. Risk factors for Apgar score $<7$ at 5 minutes. Analyses performed by univariate and multivariate logistic regression.

\begin{tabular}{|c|c|c|c|c|c|c|c|c|c|}
\hline & \multicolumn{3}{|c|}{ Apgar $<7$} & \multicolumn{3}{|c|}{$\begin{array}{l}\text { Univariate logistic } \\
\text { regression }\end{array}$} & \multicolumn{3}{|c|}{$\begin{array}{l}\text { Multivariate logistic } \\
\text { regression }\end{array}$} \\
\hline & Total & $\mathbf{n}$ & $(\%)$ & OR & 95\% C.I. & p & OR & 95\% C.I. & $\mathbf{p}$ \\
\hline \multicolumn{10}{|l|}{ Level of Care } \\
\hline Secondary & 7,011 & 96 & 1.37 & 1.00 & & & 1.00 & & \\
\hline Tertiary & 13,632 & 273 & 2.00 & 1.48 & $1.17-1.87$ & 0.001 & 1.21 & $0.90-1.61$ & 0.203 \\
\hline \multicolumn{10}{|l|}{ Height $(\mathbf{c m})$} \\
\hline$\geq 175$ & 1,800 & 17 & 0.94 & 1.00 & & & 1.00 & & \\
\hline $159-174$ & 14,992 & 229 & 1.53 & 1.83 & $1.44-2.32$ & & 2.06 & $1.56-2.72$ & \\
\hline$\leq 158$ & 2,084 & 60 & 2.88 & 3.34 & $2.06-5.39$ & $<0.001$ & 4.23 & $2.43-7.39$ & $<0.001$ \\
\hline \multicolumn{10}{|l|}{ BMI $\left(\mathrm{kg} / \mathrm{m}^{2}\right)$} \\
\hline$<25$ & 11,359 & 156 & 1.37 & 1.00 & & & 1.00 & & \\
\hline $25-29.9$ & 4,862 & 84 & 1.73 & 1.38 & $1.19-1.60$ & & 1.29 & $1.08-1.54$ & \\
\hline$\geq 30$ & 2,319 & 61 & 2.63 & 1.91 & $1.43-2.56$ & $<0.001$ & 1.67 & $1.17-2.36$ & 0.004 \\
\hline \multicolumn{10}{|l|}{ Parity } \\
\hline 0 & 8,418 & 191 & 2.27 & 1.00 & & & 1.00 & & \\
\hline$\geq 1$ & 10,602 & 117 & 1.10 & 0.48 & $0.38-0.60$ & $<0.001$ & 0.34 & $0.25-0.48$ & $<0.001$ \\
\hline \multicolumn{10}{|c|}{ Gestational age (weeks) } \\
\hline $37+0-41+6$ & 18,251 & 206 & 1.13 & 1.00 & & & 1.00 & & \\
\hline$\geq 42+0$ & 1,080 & 26 & 2.41 & 2.8 & $2.6-3.1$ & & 2.0 & $1.7-2.3$ & \\
\hline $32+0-36+6$ & 1,026 & 45 & 4.39 & 8.0 & $6.8-9.4$ & & 3.9 & $2.9-5.3$ & \\
\hline $28+0-31+6$ & 149 & 27 & 18.1 & 23 & $18-29$ & & 8 & $5-12$ & \\
\hline$<28+0$ & 111 & 62 & 55.9 & 64 & $46-88$ & $<0.001$ & 15 & $8-29$ & $<0.001$ \\
\hline \multicolumn{10}{|c|}{ Previous caesarean section } \\
\hline No & 17,796 & 271 & 1.52 & 1.00 & & & 1.00 & & \\
\hline Yes & 1,224 & 37 & 3.02 & 2.01 & $1.42-2.84$ & $<0.001$ & 3.66 & $2.31-5.81$ & $<0.001$ \\
\hline \multicolumn{10}{|c|}{ Multiple pregnancy } \\
\hline No & 20,338 & 336 & 1.65 & 1.00 & & & 1.00 & & \\
\hline Yes & 305 & 33 & 10.82 & 7.20 & $4.95-10.49$ & $<0.001$ & 3.57 & $1.81-7.05$ & $<0.001$ \\
\hline \multicolumn{10}{|c|}{ CTG at admission } \\
\hline normal & 16,524 & 214 & 1.30 & 1.00 & & & 1.00 & & \\
\hline non normal & 1,176 & 36 & 3.06 & 2.47 & $1.73-3.53$ & $<0.001$ & 1.95 & $1.45-2.62$ & $<0.001$ \\
\hline
\end{tabular}




\section{Risk factors for preterm birth $<32$ weeks of gestation}

Our second aim in Study I was to investigate risk factors for PTB $<32$ weeks of gestation among the maternal and obstetric variables available in the database. The database included 260 infants born at $<32$ weeks of gestation, corresponding to a rate of $1.26 \%$. The total rate in Sweden during the same time period was $1.0 \%{ }^{9}$. The slightly higher rate in our study population is due to referrals of preterm deliveries to the tertiary level hospital, also from other secondary level hospitals, as mentioned above.

Pre-existing thyroid disease and epilepsy, as well as smoking were multivariately significant risk factors for PTB <32 weeks of gestation (Table 7), while type 1 diabetes mellitus and IBD did not convey an increased risk of PTB (Table 4, Paper I). The number of cases with thyroid disease or epilepsy are few ( $n=10$ and $n=4$, respectively) in the PTB group. Therefore, this finding must be interpreted cautiously. Focusing on smoking cessation in pregnant women through information campaigns and through offering therapies is an important measure for prevention of PTB, but also for other pregnancy complications associated with smoking, such as IUGR ${ }^{191}$.

Significant obstetric risk factors for PTB $<32$ weeks were preeclampsia $(\mathrm{OR}=5.5(95 \%$ CI 3.4-8.9)) and multiple gestation ( $\mathrm{OR}=15$ (95\% CI 10-24)). According to Swedish guidelines in assisted reproductive techniques, the standard procedure is to insert a single embryo due to the increased risk of multiple gestations, a risk that was confirmed in our study. An inverse association was noted between PTB $<32$ weeks and parity, as parous women had a lower risk for PTB than nulli-parous women (OR 0.68 (95\% CI 0.47-0.98)), in line with previous findings ${ }^{6,34,35}$ (Table 7). 
Table 7. Risk factors for preterm birth before 32 weeks of gestation; analysed by univariate and multivariate logistic regression.

\begin{tabular}{|c|c|c|c|c|c|c|c|c|c|}
\hline & \multirow[b]{2}{*}{ Total } & \multicolumn{2}{|c|}{$\begin{array}{c}\text { PTB }<32 \\
\text { weeks }\end{array}$} & \multicolumn{3}{|c|}{$\begin{array}{l}\text { Univariate logistic } \\
\text { regression }\end{array}$} & \multicolumn{3}{|c|}{$\begin{array}{c}\text { Multivariate logistic } \\
\text { regression }\end{array}$} \\
\hline & & $\mathbf{n}$ & $(\%)$ & OR & 95\% C.I. & $\mathbf{p}$ & OR & 95\% C.I. & $\mathbf{p}$ \\
\hline \multicolumn{10}{|l|}{ Smoking } \\
\hline $\mathrm{No}$ & 15,784 & 108 & 0.68 & 1.00 & & & 1.00 & & \\
\hline Yes & 3,236 & 34 & 1.05 & 1.54 & $1.05-2.27$ & 0.029 & 1.61 & $1.07-2.41$ & 0.022 \\
\hline \multicolumn{10}{|c|}{ Thyroid disease } \\
\hline No & 18,379 & 131 & 0.71 & 1.00 & & & 1.00 & & \\
\hline Yes & 550 & 10 & 1.82 & 2.58 & $1.35-4.93$ & 0.004 & 2.32 & $1.17-4.57$ & 0.015 \\
\hline \multicolumn{10}{|l|}{ Epilepsy } \\
\hline No & 18,798 & 137 & 0.73 & 1.00 & & & ' 1.00 & & \\
\hline Yes & 158 & 4 & 2.53 & 3.54 & $1.29-9.67$ & 0.014 & 3.14 & $1.13-8.78$ & 0.029 \\
\hline \multicolumn{10}{|l|}{ Parity } \\
\hline 0 & 8,418 & 82 & 0.97 & 1.00 & & & 1.00 & & \\
\hline$\geq 1$ & 10,602 & 60 & 0.57 & 0.58 & $0.41-0.81$ & 0.001 & 0.68 & $0.47-0.98$ & 0.036 \\
\hline \multicolumn{10}{|c|}{ Multiple pregnancy } \\
\hline No & 20,314 & 216 & 1.06 & 1.00 & & & 1.00 & & \\
\hline Yes & 303 & 44 & 14.52 & 15.8 & $11.2-22.3$ & $<0.001$ & 15 & $10-24$ & $<0.001$ \\
\hline \multicolumn{10}{|c|}{ Preeclampsia } \\
\hline No & 20,067 & 214 & 1.07 & 1.00 & & & 1.00 & & \\
\hline Yes & 550 & 46 & 8.36 & 8.47 & $6.09-11.8$ & $<0.001$ & 5.48 & $3.39-8.86$ & $<0.001$ \\
\hline
\end{tabular}


Complex immune profiles in preterm labour, PPROM, labour at term, and antenatal controls

With the aim to elucidate the immune profiles of PTL and PPROM in comparison to the antenatal pregnant state, and to labour at term, in total 204 women were included in a case-control study, as shown in Figure 14. The study group comprised of 120 women with threatened PTB (PTL $(n=80)$ and PPROM $(n=40)$ ), and the control groups consisted of 44 pregnant women before labour, recruited at scheduled visits to an antenatal clinic, and 40 women in labour at term. Despite the intention to match for gestational age at inclusion there was a slight (medians 30 versus 32 weeks), but statistically significant $(\mathrm{p}=0.048)$ difference between the antenatal control group and the women with PTL (Table 1, Paper II). Although unlikely, a minor influence on protein levels cannot be excluded. Regarding age, BMI, and parity, there were no significant differences between any of the groups. There was, as anticipated, a statistically significant difference in gestational age at inclusion and gestational age at delivery. There was also a significant difference in CL at inclusion comparing women with PTL (median $15 \mathrm{~mm}$ ) and women with PPROM (median $21 \mathrm{~mm} ; \mathrm{p}=0.008$ ) (Table 1, Paper II).

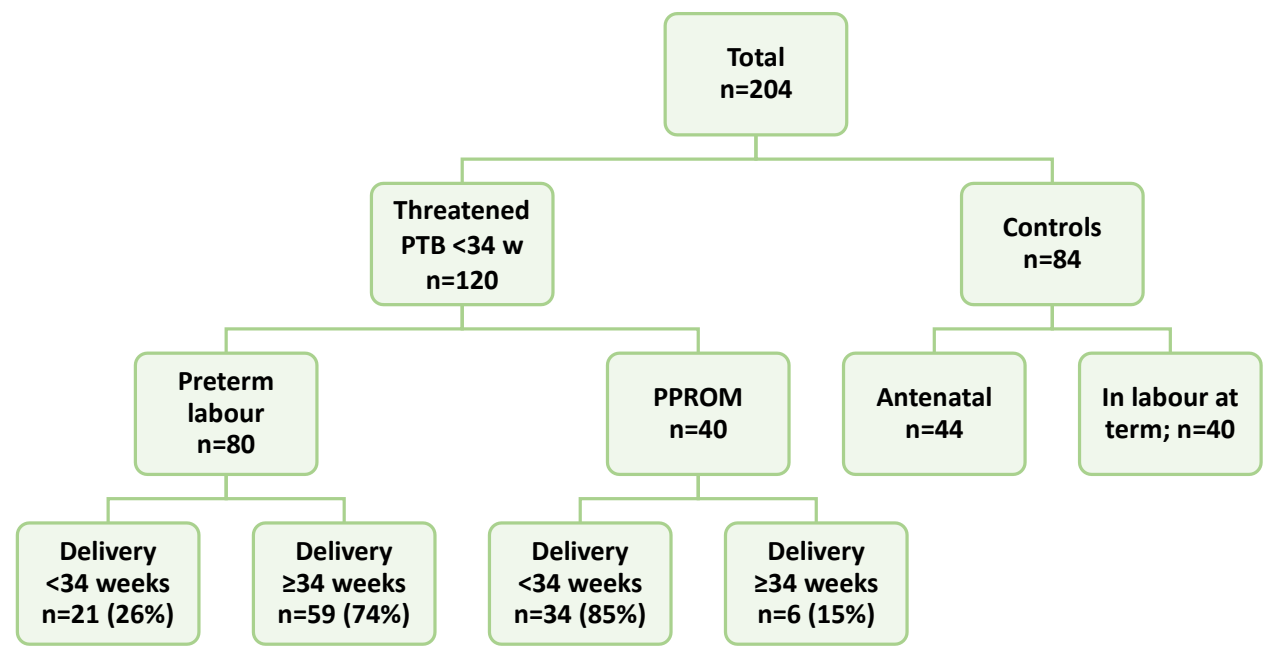

Figure 14. Flow chart of the women in Study II. PPROM=Preterm prelabour rupture of the membranes. 
Analysis of plasma samples with multiplex bead assay and ELISA showed a complex pattern of chemokines and cytokines when comparing PTL, PPROM, antenatal controls, and controls in term labour. CCL17, CXCL1, CXCL8, and IL-6 were the cytokines and chemokines that differed. The highest level of inflammation was found in labour at term, which was expected considering the known pro-inflammatory state of labour ${ }^{143}$. Women in labour at term had higher plasma levels of the Th17-associated chemokine CXCL1, and pro-inflammatory CXCL8 and IL-6 compared with PTL ( $\mathrm{p}=0.007,0.003$, and 0.013, respectively). Women in labour at term also displayed higher levels of the Th2associated chemokine CCL17, CXCL1 and IL-6 (all p<0.001) compared with the antenatal controls.

Women with PTL had higher inflammatory activity than controls before labour with higher levels of CCL17 ( $\mathrm{p}=0.002)$ and CXCL1 $(\mathrm{p}<0.001)$. Women with PPROM also had higher inflammatory activity than the antenatal controls with higher levels of CXCL1 ( $p<0.001)$ and IL-6 ( $\mathrm{p}=0.005)$. However, there were no significant differences between PTL and PPROM. The finding of significantly higher levels of CXCL1 in the groups with labour (preterm and at term), as well as in PPROM, indicates that Th17associated immunity has a role in parturition. The origin of PPROM is supposed to involve degenerative and inflammatory processes in foetal membranes ${ }^{25}$. Our findings support such a pro-inflammatory component in PPROM.

Interestingly, the Th2-associated chemokine CCL17 was higher in PTL and term labour compared to antenatal controls, suggesting that the inflammatory process in labour is complex and not confined to the previous dogma of high Th1 and low Th2 (Table 8). 


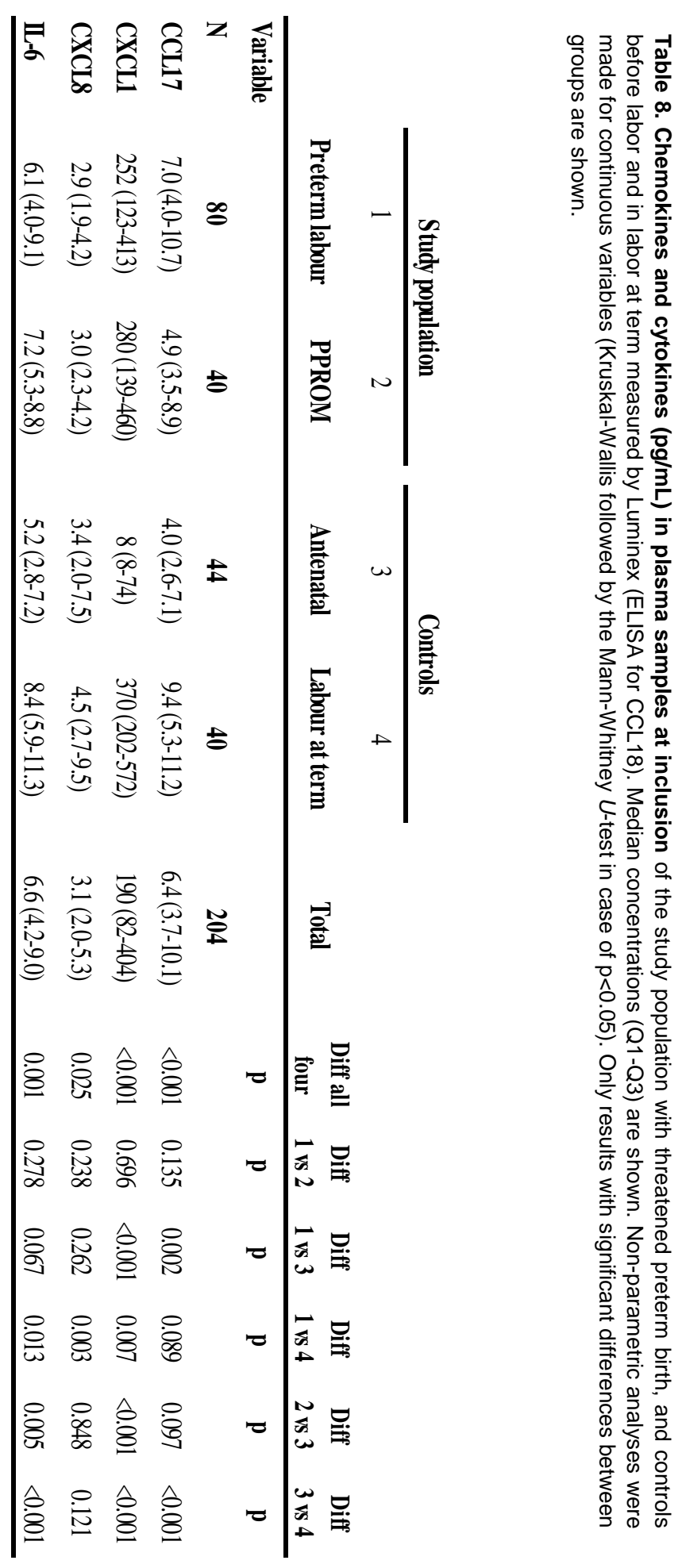


Another aim was to evaluate chemokines, cytokines and other inflammation-associated compounds, such as the fatty acid metabolites oxylipins, as predictors for PTB <34 weeks of gestation and for PTB within 48 hours of hospital admission due to PTL $<34$ weeks. Of the 80 women with PTL, only 21 (26\%) delivered before 34 weeks of gestation, whereas of the 40 women with PPROM, a majority (34 (85\%)) delivered before 34 weeks of gestation (Figures 14, 15A, 15C). This supports previous findings of a majority of women with PTL delivering at term, while the risk of subsequent PTB after PPROM is significantly higher than after $\mathrm{PTL}^{6,7}$.
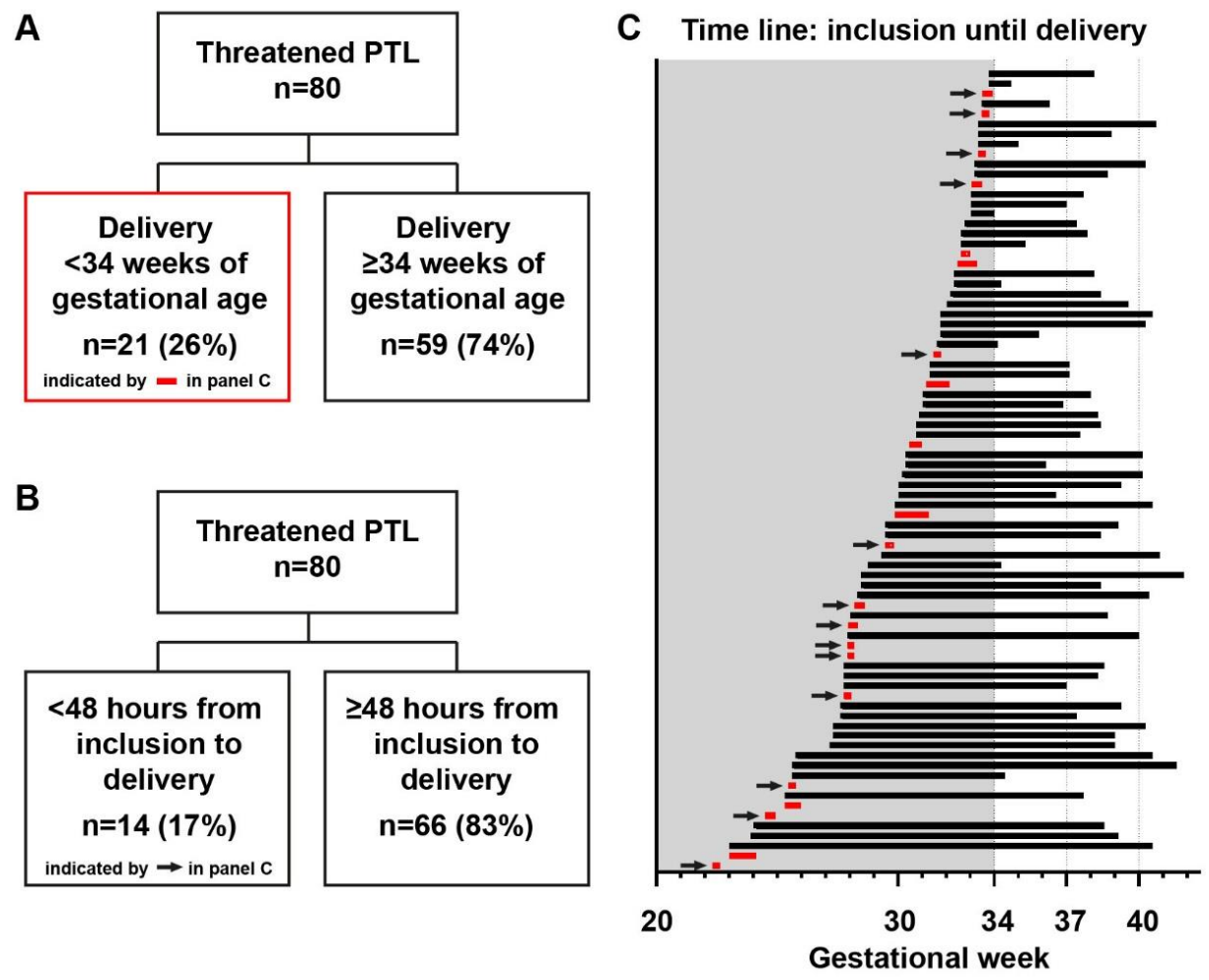

Figure 15. Flow chart (panels $A$ and $B$ ) and inclusion chart (panel $C$ ) of women with preterm labour. The bars in panel $C$ represent gestational age at inclusion and at delivery for individual women. The red bars represent those who delivered before 34 weeks. The arrows indicate delivery within 48 hours of hospital admission. Image by Johanna Raffetseder. 
Moreover, delivery within 48 hours of hospital admission due to PTL occurred in 14 $(17 \%)$ of the 80 women (Figures 15B, 15C). That is a small proportion, but clinically the most important group of women to identify, since they are the ones most in need of medical treatment and referral to tertiary centres. However, the rather small sample size might negatively affect the predictive power of the study.

Regarding maternal and obstetrical characteristics, delivery before 34 weeks was associated with a higher BMI (median 25 (20-46)) than in the group who delivered after 34 weeks (median $22(16-41), \mathrm{p}=0.011)$. This finding is noteworthy as obesity is not generally associated with $\mathrm{sPTB}^{192}$, but rather with medically indicated PTB due to pregnancy complications like preeclampsia and gestational diabetes mellitus. Nonetheless, this was not a surprising finding, given the association between obesity and inflammation ${ }^{193,194}$. Furthermore, as expected, CL differed significantly both for delivery before or after 34 weeks of gestation (median $7(0-40)$ and $16(4-40) ; \mathrm{p}<0.001)$ ) and for delivery within or after 48 hours $(\mathrm{p}=0.008)$. Additionally, there was a significantly higher proportion of nulli-parous women among the women with preterm delivery before 34 weeks of gestation compared to later ( $81 \%$ vs $45.8 \%$; $\mathrm{p}=0.01$ ), but no significant difference between women with delivery within 48 hours compared to after 48 hours $(\mathrm{p}=0.24)$. There were no significant differences between groups regarding maternal age, prevalence of smoking, or gestational age at inclusion (Table 3, Paper II).

Combinatory prediction model for preterm birth with IL-6, IL-17C, IL-10RB, FGF-23, and cervical length

In Study II, all chemokines and cytokines analysed with multiplex bead assay or ELISA were investigated as predictive markers together with a PEA-based inflammatory biomarker panel of 92 proteins. The proteins with the most significant differences between women with delivery before or after 34 weeks of gestation, according to the $\mathrm{p}$ values, were IL-6 ( $<<0.001)$, CXCL8 $(<0.001)$, M-CSF ( $<<0.001)$, OSM ( $\mathrm{p}=0.002)$, IL$17 \mathrm{C}(\mathrm{p}=0.003)$, and CCL3 ( $\mathrm{p}=0.005)$ (Figure 16, Table 4, Paper II). Interestingly, all these highly significant differences originated from the high-sensitivity and highspecificity PEA technique. A few significant differences in chemokine and cytokine levels were also detected with the multiplex bead assay, however not as convincingly as with the PEA. The only protein measured by multiplex bead assay that showed a significant difference between women with delivery before or after 34 weeks of gestation was CXCL8 ( $\mathrm{p}=0.040)$. Regarding women with delivery within or after 48 hours of hospital admission CXCL8 ( $\mathrm{p}=0.020)$, GM-CSF ( $\mathrm{p}=0.017)$ and IL-6 ( $\mathrm{p}=0.034)$ differed between groups (supplementary Table 1, Paper II). 
IL-6

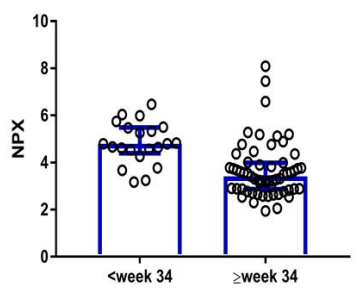

OSM

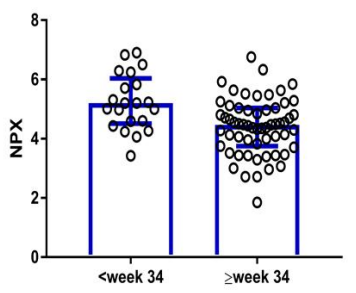

CXCL8

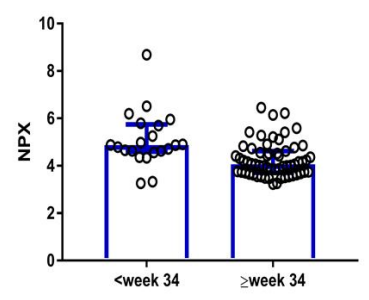

IL-17C

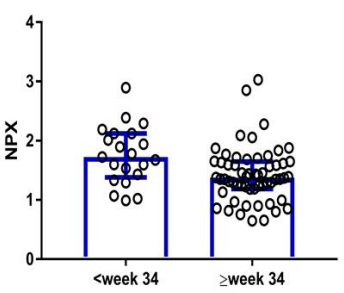

M-CSF

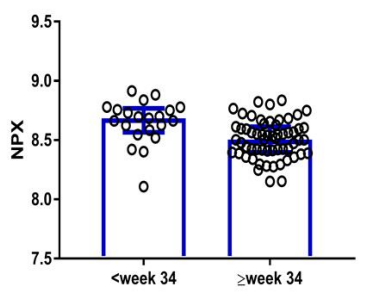

CCL3

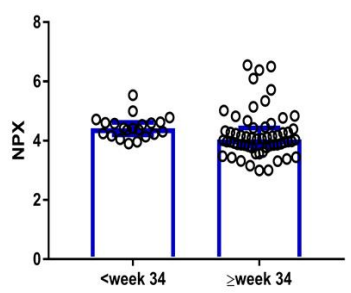

Figure 16. Inflammation-associated proteins in the sub-cohort of women with preterm labour $(n=80)$ for those who delivered $<34$ weeks and $\geq 34$ weeks. The proteins with the most significant differences according to the p-value (Mann Whitney U-test) are shown. NPX (Normalised Protein eXpression) levels are arbitrary units on a log2 scale (one unit increase equals a doubling of concentration). Image by Johanna Raffetseder.

Furthermore, a discriminant function analysis, including all proteins with a p-value $<0.1$ in an initial Mann-Whitney $U$-test, was performed in order to find out which combination of proteins that was most strongly associated with time of PTB. IL-6, IL17C, IL-10 receptor subunit beta (IL-10RB), and fibroblast growth factor (FGF) 23 were found to be most strongly associated with delivery $<34$ weeks, whereas IL-6 and IL-17C were most strongly associated with delivery within 48 hours. Thereafter, ROC curves using the results from the discriminant function analysis were defined, creating a prediction model for delivery <34 weeks and within 48 hours, respectively (Figure 17).

When adding data on CL to the protein findings, and adjusting for BMI and age in the model, the prediction accuracy was slightly improved compared with protein data only (Figure 17). BMI did not on its own influence the prediction model. With the combined model, delivery before 34 weeks was predicted with an AUC of 0.90 , at a sensitivity level of $90 \%$ with a specificity of $74 \%$. These cut-off levels were chosen to obtain a high NPV (96\%), with a corresponding PPV of 54\%. Delivery within 48 hours was predicted with an AUC of 0.88 , with a sensitivity level of $100 \%$ and a specificity of $71 \%$. The corresponding NPV was $100 \%$, and PPV was $39 \%$. 

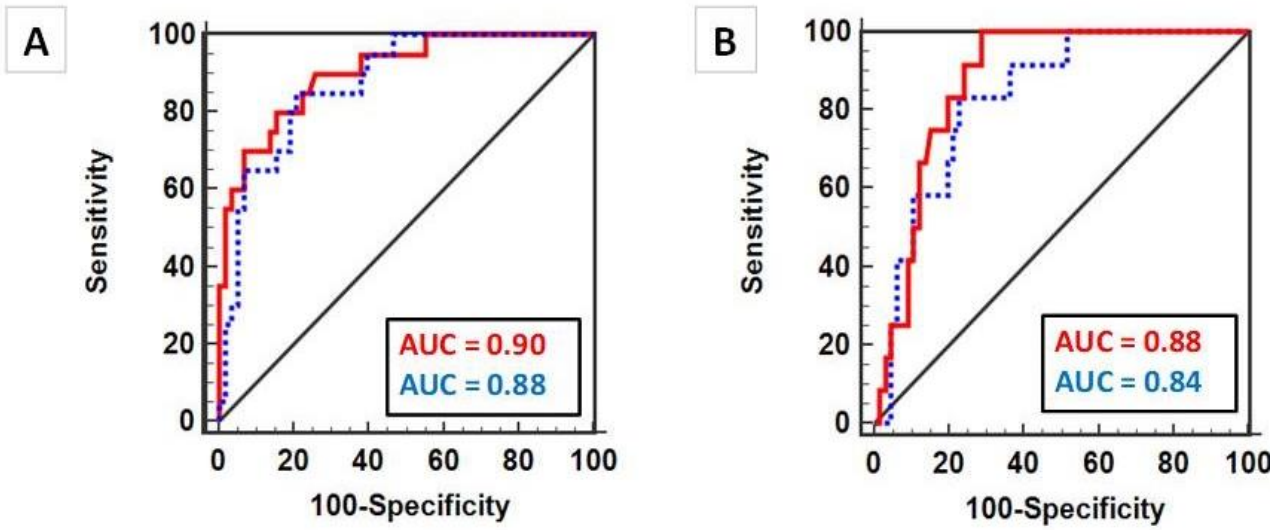

Figure 17. Index for preterm delivery. Receiver operating characteristic $(R O C)$ curves resulting from the discriminant function analyses. The left panel (a) shows the weighted combination of proteins that significantly discriminated between women who delivered at $<34$ weeks of gestation $(n=21)$ and women who delivered after 34 weeks $(n=59)$ and the right panel (b) shows corresponding ROC curves for the women who delivered within 48 hours of study inclusion $(n=14)$ compared to women who delivered after 48 hours $(n=66)$. The red solid line is proteins in combination with cervical length, and adjusted for age and body mass index. The blue dotted line is proteins only, in panel (a) IL-6, IL-17C, IL-10RB, and FGF-23, and in panel (b) IL-6 and IL-17C. Image by Lars Brudin,
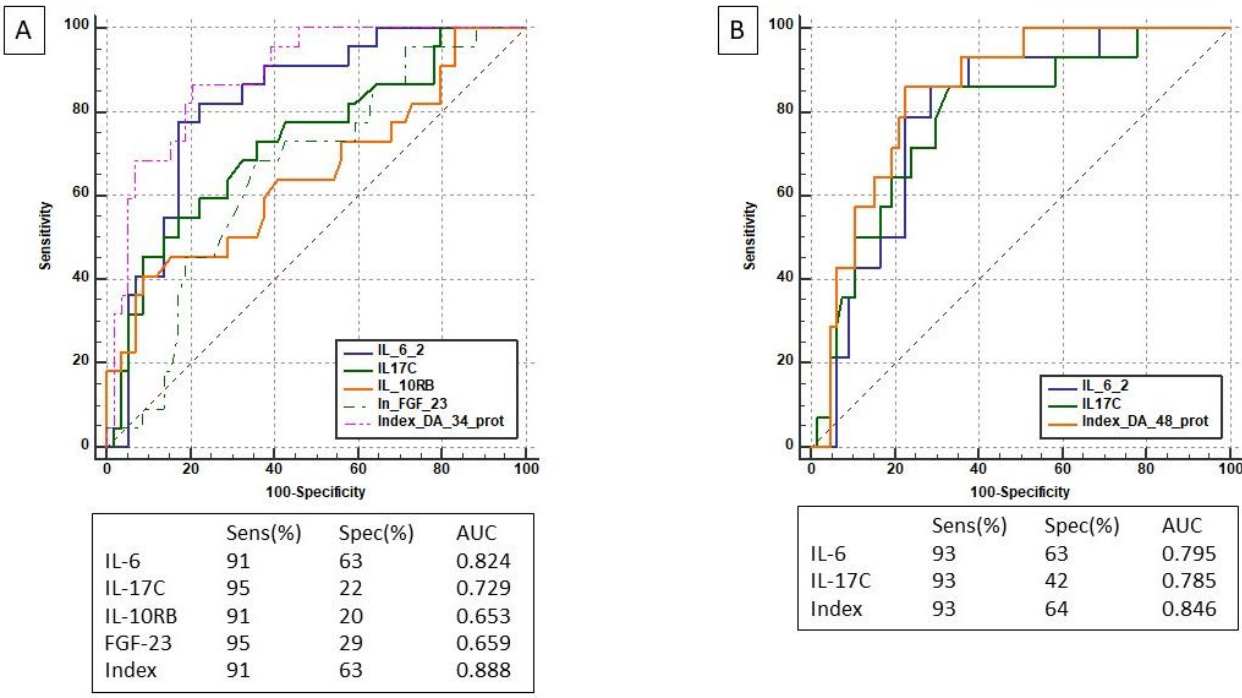

Figure 18. Receiver operating characteristic $(R O C)$ curves from the discriminant function analyses showing the proteins and the protein index that significantly discriminated between women who delivered at $<34$ weeks of gestation and women who delivered after 34 weeks (panel A) and the corresponding ROC curves for the women who delivered within 48 hours from study inclusion compared to women who delivered after 48 hours (panel B). Sens=Sensitivity; Spec=Specificity; $A U C=A r e a$ under the curve. Image by Lars Brudin. 
The cut off-values and ROC curves for the individual proteins included in the prediction models are shown in Figure 18. Since CL $<25 \mathrm{~mm}$ was not an absolute inclusion criterion, the study included three women with PTL and a CL >25 mm. Exclusion of these three women did not affect the results.

The sets of proteins that predicted delivery $<34$ weeks of gestation or delivery within 48 hours comprise both inflammatory (IL-6, IL-17C, FGF-23) and anti-inflammatory (IL$10 \mathrm{RB}$ ) compounds, indicating that inflammation is paralleled by a counteracting antiinflammatory response, as a negative feedback mechanism.

IL-6 is one of the most studied biomarkers in relation to $\mathrm{PTB}^{93}$ and has previously been associated with PTB subsequent to PTL in samples obtained from amniotic fluid $^{82,83,87,89,195}$, blood ${ }^{87,196}$, and cervicovaginal fluid ${ }^{86}$. Our finding therefore is in line with previous studies, and the importance of IL- 6 is further emphasised by the association of IL- 6 with both delivery $<34$ weeks and with delivery within 48 hours.

Three novel findings regarding association between PTB and inflammation-associated proteins were made; IL-17C was associated both with PTB $<34$ weeks and with delivery within 48 hours. IL-17C is a pro-inflammatory cytokine belonging to the IL17-family. Except for a role in the pro-inflammatory response, IL-17C is also involved in epithelial tissue homeostasis ${ }^{197,198}$. Previous work on IL-17 has shown contradicting results; lower serum levels have been associated with PTL ${ }^{199}$, but higher amniotic fluid levels of IL$17 \mathrm{C}$ were found in PTL and PPROM ${ }^{200}$. However, it was not stated ${ }^{199,200}$ which subgroup of IL-17 that was investigated, thus it is likely to have been IL-17A, the most studied IL-17 family member. There are no previous findings reported on IL-17C and PTB specifically.

Another novel finding was the association of IL-10RB with PTB $<34$ weeks of gestation. IL-10RB is one of the subunits of the IL-10 receptor and is required for IL-10 signal transduction $^{201,202}$. To our knowledge it has not previously been associated with PTB. Our findings support an important role in PTB for the cytokine IL-10, in line with previous findings of associations between IL-10 and PTB ${ }^{84,196}$.

The third novel finding was the association of FGF- 23 with PTB $<34$ weeks of gestation. FGF-23 has several endocrine functions ${ }^{203}$ and is involved in phosphate and vitamin D homeostasis ${ }^{204}$. The finding of low FGF-23 levels in gestational diabetes supports its importance in endocrine functions and suggests it has a role in pregnancy related complications ${ }^{205}$. 

preterm birth

In order to further investigate inflammatory profiles as predictive biomarkers for PTB in PTL, plasma levels of 67 oxylipins were analysed with HPLC-MS/MS in the subcohort of 80 women with PTL (Figures 14, 15) (Study III).

According to an initial non-stringent $(\mathrm{p}<0.1)$ screening, using a Mann-Whitney $U$-test (supplementary Table S2, Paper III), women with delivery before 34 weeks of gestation had lower concentrations of 9-HOTrE, 9,10-DiHOME, and 9,10-DiHODE, while higher concentrations of 8-HETE and 11,12-DiHETrE compared to women with delivery after 34 weeks (Figure 19). Furthermore, women with delivery within 48 hours of hospital admission displayed higher concentrations of 8-HETE and lower concentrations of 9,12,13-TriHOME, 9,10-DiHOME, and 9,10-DiHODE compared to women with delivery after 48 hours (Figure 20). The association between these oxylipins and time of delivery was further analysed with univariate and multivariate logistic regression. Results from the univariate analyses are shown in Table 2 and Table 3 in Paper III.

Multivariately, an association was found between lower concentrations of 9,10DiHODE and PTB <34 weeks of gestation; $40 \%$ of women with concentrations of 9,10DiHODE in the lowest two concentration quartiles delivered <34 weeks compared to $10 \%$ of women with concentrations in the highest quartile (adjusted (a) OR $0.12(0.024-$ $0.62) ; \mathrm{p}=0.012$ ). In addition, there was an association between higher concentrations of 11,12-DiHETrE and PTB <34 weeks; $15 \%$ of women with concentrations in the lowest quartile delivered $<34$ weeks compared to $45 \%$ of women with concentrations of 11,12 DiHETrE in the highest quartile (aOR 6.19 (1.17-32.7); $\mathrm{p}=0.032$ ) (Table 2, Paper III). Data for all quartiles is shown in supplementary Tables S3 and S4 in Paper III. Thus, 9,10-DiHODE and 11,12-DiHETrE seemed to have opposite effects in relation to PTB $<34$ weeks; 9,10-DiHODE appearing to be protective while 11,12-DiHETrE was associated with an increased OR of PTB.

Regarding delivery within 48 hours of hospital admission, the oxylipins showing significant associations in the multivariate analysis were 9,10-DiHODE and 8-HETE. Again, lower concentrations of 9,10-DiHODE was associated with delivery within 48 hours; $28 \%$ of women with concentrations in the two lowest quartiles delivered within 48 hours compared to $5 \%$ of women with concentrations in the highest quartile (aOR 0.13 (0.019-0.93); $\mathrm{p}=0.042$ ). The corresponding numbers for 8 -HETE were $7 \%$ delivery within 48 hours in the two lowest quartiles and $28 \%$ in the two highest quartiles (aOR 5.01 (1.13-22.14); $\mathrm{p}=0.034$ ) (Table 3, Paper III). Hence, regarding delivery within 48 hours of hospital 9,10-DiHODE appeared to be protective, while 8-HETE was associated with an increased risk of delivery within 48 hours. 

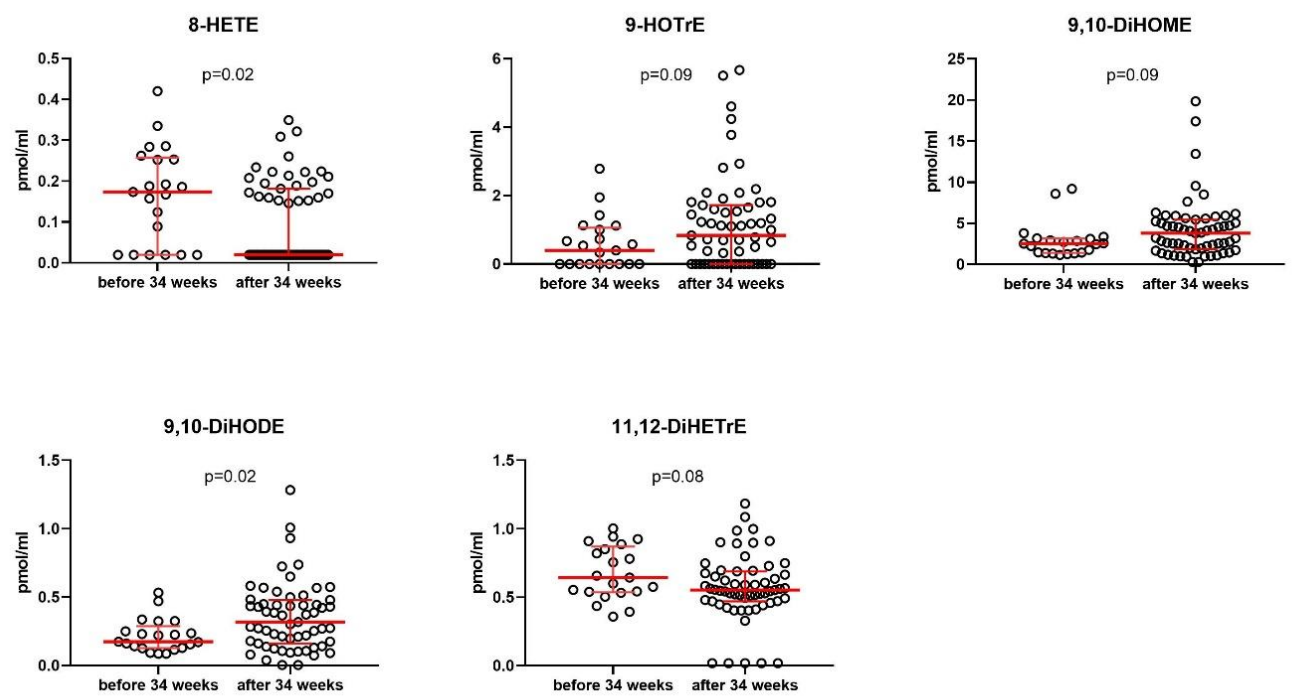

Figure 19. Oxylipins associated with delivery before $(n=21)$ and after $(n=59) 34$ weeks of gestation. A non-parametric Mann-Whitney $U$-test was used. Results are shown for oxylipins with $p$-values $<0.1$. Medians and inter-quartile ranges are noted. Image by Johanna Raffetseder.
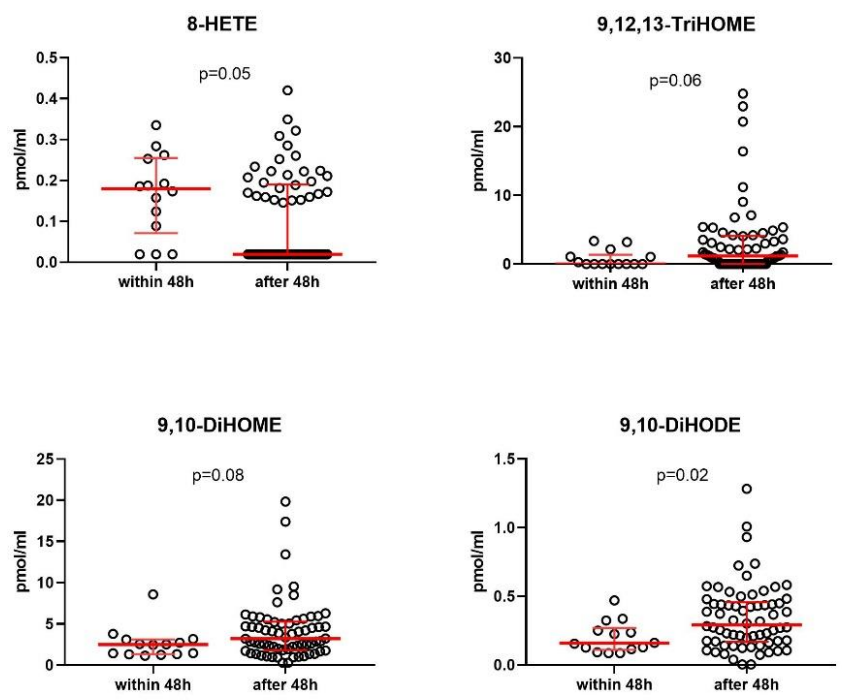

Figure 20. Oxylipins associated with delivery within $(n=14)$ and later than $(n=66) 48$ hours after study inclusion. A non-parametric Mann-Whitney U-test was used. Results are shown for oxylipins with $\mathrm{p}$ values $<0.1$. Medians and inter-quartile ranges are noted. Image by Johanna Raffetseder. 
Thus, 9,10-DiHODE, which is an ALA-derived dihydroxy fatty acid produced via the CYP pathway, seemingly has a protective effect in relation to both PTB $<34$ weeks of gestation and to delivery within 48 hours. 9,10-DiHODE has previously been associated with pregnancy in analyses of bovine corpora lutea ${ }^{206}$. Interestingly, in a prospective study by Aung et al on asymptomatic women, several CYP products (together with LOX products) had best discriminative capacity among the oxylipins for overall and sPTB $<37$ weeks of gestation ${ }^{207}$, although 9,10-DiHODE was not included in that study. DiHODEs are not commercially available, which in part may have held back investigations of their role in PTB. The need for a comprehensive panel of analytes in studies of PTL and PTB is emphasised by our findings.

Aung et al furthermore found that among asymptomatic women another dihydroxy fatty acid; 11,12-DiHETrE (also known as 11,12-DHET); derived from AA via the CYP pathway was associated with overall $\mathrm{PTB}^{207}$. In accordance, our results imply that $11,12-$ DiHETrE increases the risk of PTB also in women with PTL, as we found that high levels of 11,12-DiHETrE were associated with PTB <34 weeks of gestation.

The finding of 9,10-DiHODE and 11,12-DiHETrE having opposite effects on the risk of sPTB is really interesting. The finding is in contrast to the inflammation-associated proteins, which were all elevated in association with PTB. In the context of oxylipins, high levels of 9,10-DiHODE instead seem to have a protective effect. This highlights that oxylipins have both pro- and anti-inflammatory properties, despite that these two compounds are catalysed by the same enzyme (CYP).

Furthermore, the precursor fatty acid might be of importance; 11,12-DiHETrE is omega6 AA-derived, while 9,10-DiHODE is omega-3 ALA-derived. Omega-3 supplementation has been associated with decreased risk of $\mathrm{PTB}^{103,207}$, and low plasma concentration of omega-3 EPA and DHA is a distinct risk factor for PTB ${ }^{153}$. Additionally, it has been shown that omega-3 supplementation (DHA and EPA) in singleton pregnancies in women with low total omega-3 PUFA status reduced the risk of PTB. This illustrates that PUFA status is of clinical importance in relation to PTB, although this finding was demonstrated in asymptomatic women and not women in PTL $^{208}$.

In addition, we found high levels of 8-HETE in association with delivery within 48 hours of hospital admission. In the univariate logistic regression analysis high levels of 8HETE also correlated with PTB <34 weeks of gestation. 8-HETE is a monohydroxy fatty acid derived from non-enzymatic oxidation of AA, or via the LOX pathway. It was included in the study of Aung et $a l^{207}$ but was not associated with PTB. In the study by Ramsden et al 8-HETE was not included ${ }^{152}$. To our knowledge there are no previous reports on an association between 8-HETE and PTB. 
In conclusion, we made some novel findings regarding associations between specific oxylipins and PTB $<34$ weeks and delivery within 48 hours subsequent to PTL. The oxylipins seem to have both protective and harmful effects on the risk of PTB. However, we did not estimate the results strong enough for the studied oxylipins to be clinically useful as predictive biomarkers for PTB at present.

\section{Early prediction of preterm birth $<34$ weeks of gestation based on first and second trimester plasma levels of MMP-10, sCD40, M-CSF, Flt3L, and FGF-21}

In Study IV the aim was to identify plasma biomarkers in early pregnancy predictive for PTB before 34 weeks of gestation, based on samples from a group of women with sPTB $(n=46)$ and a group of healthy women with normal pregnancies and delivery at term $(n=46)$, selected from a prospectively collected biobank with samples from both the first and the second trimesters (flow chart in Figure 8).

Regarding maternal characteristics there was, as expected, a significant difference $(p<0.001)$ in gestational age at delivery comparing cases (median w 32 (range 23-34)) and controls (w40 (37-42)). The median gestational age at first trimester sampling was $10+4$ weeks (range $7+1-16+3$ ) and at second trimester sampling $25+3$ weeks (range $23+2-30+3)$. Furthermore, there was a significantly higher rate of deliveries by caesarean section in PTB <34 weeks of gestation than in term deliveries $(26.1 \%$ and $4.3 \%$, respectively; $\mathrm{p}=0.007$ ). Age, BMI, smoking, and gestational age at the time for blood sampling did not differ between groups (Table 1, Paper IV).

Concerning plasma levels of inflammation-associated proteins, differences in NPX values between the women with PTB $<34$ weeks and women with delivery at term were evaluated both for the respective trimester and for the difference between the trimesters (change). In the first trimester, higher levels of seven inflammation-associated proteins were significantly associated $(\mathrm{p}<0.05)$ with subsequent PTB $<34$ weeks (Table 2, Paper IV). In the second trimester, plasma samples were available from 31 of the 46 women with PTB before 34 weeks of gestation. We found significantly higher $(\mathrm{p}<0.05)$ levels of 26 proteins associated with PTB $<34$ weeks (Table 3, Paper IV). The change in NPX values between the first and the second trimester samples revealed five proteins that differed significantly between PTB $<34$ weeks and term delivery (Table 4, Paper IV). The proteins with significant differences in the different comparisons partially overlapped.

Thereafter, a discriminant function analysis, including all protein data, revealed which combination of proteins that was most strongly associated with PTB $<34$ weeks of gestation. The included proteins were soluble cluster of differentiation (sCD) 40 and 
MMP-10 from the first trimester, and M-CSF and FMS-like tyrosine kinase 3 ligand (Flt3L) from the second trimester. FGF-21 and CXCL10 were the proteins whose change between the first and second trimesters correlated most to PTB $<34$ weeks. Moreover, the total combination of proteins from the first trimester, the second trimester, and the change in protein level that most accurately discriminated PTB $<34$ weeks of

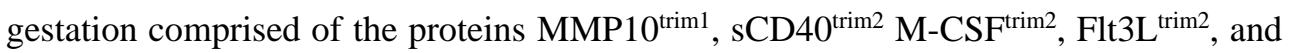
FGF-2 $11^{\text {diff. }}$

The inclusion of FGF-21 plasma level change in the prediction model for PTB $<34$ weeks among asymptomatic women is very interesting. In the second trimester samples FGF-21 was significantly higher in PTB $<34$ weeks $(\mathrm{p}=0.024)$. FGF-21 is a fibroblast growth factor with metabolic, but no proliferative, activity ${ }^{203}$. Its importance in pregnancy is implicated by findings of decreasing levels of FGF-21 in the postpartum period compared to during pregnancy ${ }^{209}$. Intriguingly, in Study II, FGF-23, which belongs to the same endocrine subfamily as FGF- $21^{203}$, was included in the prediction model for PTB $<34$ weeks of gestation, further strengthening an association between this subfamily of FGFs and PTB. Besides this, to our knowledge, there are no previous reports on the association between FGF-21 and PTB.

Another similarity between the results of Study II and IV is the significance of high levels of M-CSF. In Study IV, M-CSF was associated with PTB with significantly higher levels of this cytokine in both the first and the second trimester ( $\mathrm{p}=0.011$ and $\mathrm{p}<0.001$, respectively), although only the second trimester value qualified for inclusion in the prediction model. In Study II, levels of M-CSF were significantly higher in women with PTL who delivered $<34$ weeks of gestation (Figure 16) and within 48 hours of hospital admission (Table 4, Paper II), although in Study II M-CSF did not qualify for the prediction model. M-CSF has previously been associated with other pregnancy complications, although in diverging ways. Low levels of M-CSF at the foetal maternal interface have been associated with pregnancy $\operatorname{loss}^{210}$, which is not surprising given its importance for the induction of decidual macrophages ${ }^{132,133}$. However, in preterm deliveries and gestational diabetes M-CSF levels in the maternal circulation are reportedly increased ${ }^{211}$. The diverging results of M-CSF may be partly explained by low levels of M-CSF contributing to immune dysregulation, while high levels of M-CSF can be viewed as an attempt to balance an increase in inflammation.

Other proteins that have been previously associated with pregnancy complications are the MMPs, involved in tissue remodelling in the endometrium, cervix and vascular tissue during pregnancy ${ }^{53,212,213}$. Increased levels of MMP- 8 in amniotic fluid have been associated with PTB within seven days in twin pregnancies complicated by PTL $<35$ weeks of gestation ${ }^{214}$, whereas decreased levels of MMP-2 and MMP-9 have been associated with preeclampsia and preterm labour ${ }^{213}$. In this study, MMP-10 in the first 
trimester was also lower in women with subsequent PTB than in women with term delivery, although the difference was not statistically significant $(\mathrm{p}=0.068$, supplementary Table 1, Paper IV). However, according to the discriminant analysis (where all proteins with a p-value $<0.1$ were tested), MMP-10 did have a discriminative capability in association with sCD40, which was, on the other hand, significantly higher in cases than in controls, both in the first trimester and in the second trimester $(\mathrm{p}=0.002$; Table 2, Paper IV, and $\mathrm{p}<0.001$; Table 3, Paper IV, respectively). CD40 is a costimulatory trans-membrane protein, expressed on various antigen-presenting cells, and involved in cell activation ${ }^{215}$. Regarding its presumptive involvement in pregnancy complications and inflammatory dysregulation in pregnancy, increased levels of CD40 ligand $(\mathrm{CD} 40 \mathrm{~L})$ on cord blood platelets have been reported in chorioamnionitis ${ }^{216}$, which is strongly associated with PTB. In addition, activation of the CD40-CD40L system has been associated with preeclampsia ${ }^{217}$. In Study II MMP-10 was not associated either with PTB $<34$ weeks of pregnancy or with delivery within 48 hours, whereas higher levels of sCD40 was significantly associated with PTB $<34$ weeks of gestation ( $\mathrm{p}=0.023$, data not shown) but not with delivery within 48 hours. $\mathrm{sCD} 40$ was not included in the prediction model in Study II.

Furthermore, higher second trimester levels of the Th1-associated chemokine CXCL10 was associated with PTB <34 weeks of gestation ( $\mathrm{p}=0.003$; Table 3, Paper IV), as well as was the change between the first and second trimesters ( $\mathrm{p}=0.049$; Table 4, Paper IV), although CXCL10 was not included in the combinatory prediction model. For comparison, in Study II CXCL10 did not significantly differ between groups of PTL, PPROM, antenatal controls and controls in labour at term, neither analysed by multiplex bead assay nor by PEA. Elevated levels of CXCL10 have previously been associated with preeclampsia ${ }^{218-220}$, in accordance with the inflammatory properties of CXCL10. Regarding PTB, previous studies have not demonstrated clear associations with levels of CXCL10 220,221 although CXCL10 has been found to be increased in inflammatory conditions of the placenta ${ }^{222}$ which might precede PTB.

Finally, also higher second trimester levels of Flt3L were associated with PTB $<34$ weeks. Interestingly, Flt3L, which is a growth factor, is structurally related to M-CSF and involved in the maturation and growth of B cells $\mathrm{s}^{223}$ and dendritic cells $\mathrm{s}^{224}$. Flt3 binds to the cytokine receptor Flt3, belonging to the tyrosine kinase receptors family, including, among others, also the Flt1 receptor ${ }^{225}$. To our knowledge, no associations between Flt3L and pregnancy complications have been reported before, but there are evident associations between increased levels of sFlt-1 and the development of preeclampsia $^{226-228}$. In Study II there was no association between Flt3L and PTB $<34$ weeks or with delivery within 48 hours in PTL. 
To create a prediction model for PTB $<34$ weeks of gestation we used the results from the discriminant function analyses to define ROC curves. The AUC for the prediction models of the respective blood sampling time points was 0.764 in the first trimester, 0.799 in the second trimester, and 0.757 for the difference between the first and the second trimester. The combinatory model of proteins predicted PTB before 34 weeks of gestation with an AUC of 0.902 (Figure 21).

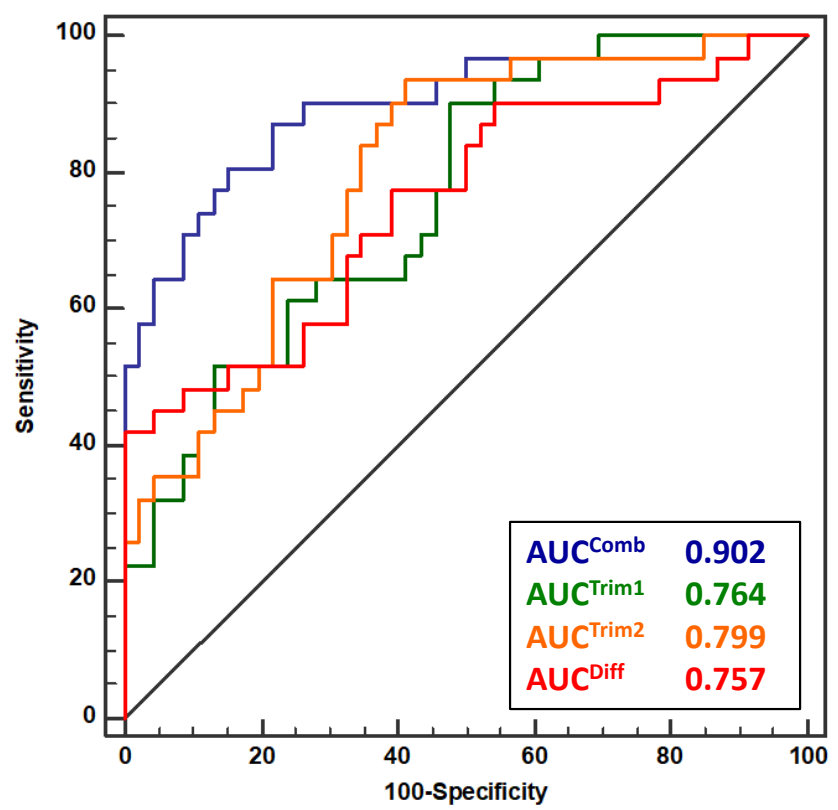

\section{Comb: MMP10 trim1, sCD40 trim2, M-CSFtrim2 Flt3L $^{\text {trim2 }}$, FGF-21 diff Trim 1: sCD40, MMP10 \\ Trim 2: M-CSF, Flt3L Diff ${ }^{\mathrm{T} 1-\mathrm{T}}$ : FGF-21, CXCL10}

Figure 21. Index for PTB before 34 weeks of gestation. Receiver operating characteristic curves resulting from the discriminant function analyses and their respective areas under the curve (AUC) for the total combination (Comb) of proteins (blue line), the first trimester (Trim1 (T1), green line), the second trimester (Trim 2 (T2), orange line), and the change in protein levels between Trim1 and Trim2 (Diff, red line). Proteins were measured by proximity extension assay in plasma longitudinally sampled from women with PTB before 34 weeks of gestation $(n=46$ in Trim1, $n=31$ in Trim2) compared with women with delivery at term ( $\mathrm{n}=46$ in both trimesters). The proteins included in each index are listed in the box. Image by Lars Brudin and Maria Svenvik.

Our findings that levels of inflammation-associated proteins in early pregnancy plasma are of importance for subsequent PTB is confirmed by Lynch et al, who investigated early pregnancy plasma with a proteomic approach and found that the most relevant 
pathways for PTB <37 weeks of gestation were the complement cascade, the immune system, and the clotting cascade ${ }^{229}$.

Furthermore, the predictive ability of our combined model with an AUC of 0.902 is reasonably good compared to previous work. In another study based on circulating proteins measured at 17-28 weeks of gestation, a prediction model for sPTB <37 weeks using insulin-like growth factor binding protein 4 and sex hormone binding globulin had an AUC of 0.75 . However, the study involved both a discovery and a validation $\operatorname{design}^{230}$, which is an advantage compared to our study with discovery cohort only. Regarding other circulating compounds than proteins, Ngo et al ${ }^{99}$ presented an AUC of 0.81 based on transcripts in maternal blood in a rather small $(n=23)$ validation cohort of women with a high risk of PTB. So far, the predictive model presenting the highest AUC seems to be different combinations of circulating microparticles where the top 20 combinations predicted sPTB before 34 weeks with an AUC ranging from 0.861 to $0.892^{231}$. However, the method used by us offers a fast and feasible way of measuring circulating biomarkers without the need for extraction of RNA or microparticles.

In summary, the protein findings in Studies II and IV showed both similarities and differences regarding associations between certain elevated inflammation-associated proteins in early pregnancy and in PTL with subsequent PTB. The proteins that were included in any of the individual prediction models are shown in Table 9.

Table 9. Inflammation-associated proteins included in a prediction model for PTB $<34$ weeks of gestation either in Study II (PTL) or Study IV (early pregnancy). P-values $<0.1$ are shown for protein associations with PTB $<34 \mathrm{gw}$ and within 48 hours of hospital admission (Study II) and for associations between proteins analysed in the first (Trim 1 (T1)) and second trimester (Trim2 (T2)), and the change in protein levels between T1 and T2, with PTB (Study IV). Incl. indicates which prediction model the protein was included in.

\begin{tabular}{|c|c|c|c|c|c|c|c|}
\hline & \multicolumn{3}{|c|}{ Study II PTL } & \multicolumn{4}{|c|}{ Study IV early pregnancy } \\
\hline & $34 \mathrm{gw}$ & $48 \mathrm{~h}$ & Incl. & Trim 1 & Trim 2 & Diff $^{\text {T1-T2 }}$ & Incl. \\
\hline Protein & $\mathbf{p}$ & $\mathbf{p}$ & & $\mathbf{p}$ & p & $\mathbf{p}$ & \\
\hline sCD40 & 0.023 & ns & - & 0.002 & $<0.001$ & ns & Comb, T1 \\
\hline CXCL10 & 0.057 & 0.086 & - & ns & 0.003 & 0.049 & Diff \\
\hline FGF-21 & ns & ns & - & ns & 0.024 & $<0.001$ & Comb, diff \\
\hline FGF-23 & 0.034 & ns & $34 \mathrm{gw}$ & ns & ns & ns & - \\
\hline Flt3L & 0.082 & ns & - & ns & 0.007 & ns & Comb, T2 \\
\hline IL-6 & $<0.001$ & $<0.001$ & $34 \mathrm{gw}, 48 \mathrm{~h}$ & ns & $<0.001$ & 0.024 & - \\
\hline IL-10RB & 0.021 & 0.079 & 34gw & ns & 0.044 & ns & - \\
\hline IL-17C & 0.003 & $<0.001$ & $34 \mathrm{gw}, 48 \mathrm{~h}$ & ns & $\mathrm{ns}$ & ns & - \\
\hline M-CSF & $<0.001$ & 0.007 & - & 0.011 & $<0.001$ & ns & Comb, T2 \\
\hline MMP-10 & ns & ns & - & 0.068 & ns & 0.087 & Comb, T1 \\
\hline
\end{tabular}

PTL=preterm labour; $\mathrm{gw}=$ gestational week; $\mathrm{h}=$ hours; Incl.=inclusion in prediction model; Trim1=first trimester; Trim2=second trimester; Diff ${ }^{\mathrm{T} 1-\mathrm{T} 2}=$ change in protein level Trim1-Trim2. 


\section{Methodological considerations}

All four studies have strengths and limitations in their research methodology.

In Study I we investigated risk factors for low Apgar scores and for PTB $<32$ weeks of gestation. As previously pointed out, a low Apgar score does not provide information about the underlying cause of the neonate's ill condition ${ }^{163}$. Thus, the analysis of umbilical cord $\mathrm{pH}$ and base excess would have been valuable in order to possibly correlate metabolic acidosis to findings of low Apgar scores. However, this data was not available. It has previously been shown that only about half of infants with low Apgar scores or asphyxia have metabolic acidosis ${ }^{232,233}$, and not all neonates with metabolic acidosis have low Apgar scores ${ }^{233,234}$. As a low Apgar score at five minutes of age identifies infants in need of intensified medical care, it has advantages over the diagnosis of metabolic acidosis in that a vast majority (99.4\%) of the neonates in this study were assigned an Apgar score at five minutes of age, whereas umbilical cord blood gases were completely recorded in only $70-75 \%$.

A possible limitation of Study I is that the cases with $\mathrm{AS}^{5 \min }<7$ were rather few ( $\mathrm{n}=367$; $1.98 \%)$. However, as the total study population included a larger number of infants with AS $\geq 7 \quad(n=20,274)$, the risk factor analysis may be considered solid. Furthermore, the rate of PTB $<37$ weeks was $7.7 \%$ in our study population, compared to $6.2 \%$ in the general Swedish population for the same time period ${ }^{9}$. The corresponding numbers for PTB $<32$ weeks were $1.3 \%$ in the study population versus $1.0 \%$ in the general population ${ }^{9}$. The slightly higher rate of PTB in our study population than in the general population can be explained by the referrals of preterm deliveries to the tertiary level hospital from the other six hospitals in the southeast region. Thus, it might be considered that we focused on risk factors for PTB associated with a tertiary level of care. However, as the risk factors for PTB $<32$ weeks of gestation that were demonstrated in this study have been confirmed by others, we believe that our findings are not particularly biased by the slightly higher rate of PTB at the tertiary level hospital. Moreover, our data did not allow investigation of whether the cases of PTB were spontaneous or medically indicated. However, from a clinical point of view it is likely that the majority of PTBs among preeclamptic women were medically indicated. The rate of medically indicated versus $\mathrm{SPTB}$ in multiple gestations was also unclear in our study, which is a further limitation. In previous studies regarding risk factors for low Apgar scores, preterm neonates as well as multiple gestations have often been excluded ${ }^{174,175,177}$; however, we aimed to conduct a more comprehensive investigation into the risk factors for $\mathrm{AS}^{5 \min }<7$.

We identified short stature, overweight, and obesity as risk factors for $\mathrm{AS}^{5 \mathrm{~min}}<7$. It is notable, that data about height and weight was missing in $10 \%$ of the study population, and that among these women $\mathrm{AS}^{5 \mathrm{~min}}<7$ was slightly overrepresented $\left(3.2 \% \mathrm{AS}^{5 \mathrm{~min}}<7\right)$. Therefore, the results regarding maternal height and overweight/obesity as risk factors 
for low Apgar scores should be interpreted cautiously. However, these findings are confirmed by others ${ }^{175,176,187,188}$. Interestingly, Berglund et al also found an association between short stature and the risk for asphyxia associated with sub-standard care during labour ${ }^{177}$.

An advantage of our study is that data on admission-CTG was available and therefore possible to evaluate as a risk factor for $\mathrm{AS}^{5 \mathrm{~min}}<7$. This is not possible if the Swedish Medical Birth register is used as a data source, although data on a much larger population of women would be available compared with our study. The focus of this study was maternal risk factors recognised prior to delivery. It would be interesting to investigate foetal risk factors, reflected by other variables than CTG only. However, factors such as IUGR or oligohydramnios are not always identified prior to delivery. Moreover, we judged the material to be too small for this purpose.

It would also have been interesting to investigate a possible association between oxytocin augmentation and low Apgar scores, since oxytocin augmentation has previously been associated with birth asphyxia ${ }^{174}$. Furthermore, in cases assessed as subject to sub-standard obstetrical care, labour dystocia, which is often treated with oxytocin, was associated with a significant increase in asphyxia ${ }^{177}$. However, in our database information on oxytocin administration was not available, which is a limitation of this study.

Furthermore, although the electronic medical records contain detailed data on the women, information about ethnicity was lacking, which would have been of interest to study as a risk factor both for $\mathrm{AS}^{5 \mathrm{~min}}<7$ and for PTB $<32$ weeks of gestation.

Regarding Studies II and III, in which immune patterns in PTL and PPROM were compared to normal pregnancies (Study II), and prediction models for PTB $<34$ weeks and delivery within 48 hours of hospital admission due to PTL (Study II and III) were investigated, there are also some important methodological considerations.

First of all, the study cohort was rather small, but on the other hand, it was prospective, clinically well-defined, and enough number of women were included in order to find significant differences. To further evaluate the accuracy of the prediction models, a validation cohort would have been of great value.

The women with PTL who were included in the study were all assessed as being in need of hospitalisation due to an imminent risk of PTB. Except for regular contractions, the major determinant for the decision of hospitalisation was the cervical status of the women. $\mathrm{CL}<25 \mathrm{~mm}$ was the most common basis of the decision, but not a strict criterion for entry to the study. In three cases the clinician on duty made an overall assessment of the woman being at high risk of PTB, based on other factors than CL length exclusively, such as the beginning of cervical dilation despite $\mathrm{CL}>25 \mathrm{~mm}$. This approach may differ 
from other studies and may complicate comparisons. However, when the women with CL > $25 \mathrm{~mm}$ were excluded from the statistical analyses, the results did not change.

Another important aspect of studies regarding prediction models for PTB is which outcome is studied, i.e. which gestational age or time interval from hospital admission to delivery is used as a cut-off. As described in a previous section, this differs between previous studies, which is another factor that makes comparisons between studies difficult. In our study we focused on two outcomes: PTB <34 weeks of gestation and delivery within 48 hours of hospital admission. Other potential outcomes might have been PTB $<32$ weeks of gestation or delivery within seven days. Given that PTB $<32$ weeks is the definition of very PTB (and $<28$ weeks extremely PTB) that might have been an appealing cut-off point; however, as the rate of this outcome is considerably lower than PTB $<34$ weeks, substantially more women with PTL would have to be included in order to establish significant differences between groups. We decided to use PTB $<34$ weeks of gestation as the outcome, due to its known associations with neonatal complications, mainly respiratory distress ${ }^{10,15,16}$, and because, according to guidelines, antenatal administration of corticosteroids should be offered to women at risk for PTB $<34$ weeks of gestation ${ }^{59}$. The outcome of delivery within 48 hours of hospital admission was decided because it is generally considered that it takes 48 hours for corticosteroids to exert their full effect. It is notable, that of the 21 women with PTL who delivered at $<34$ weeks of gestation in this study, 14 delivered within 48 hours of admission. Of the remaining seven women, six delivered within seven days and one woman after nine days. Hence, in our study the outcome of PTB $<34$ weeks was virtually equivalent to delivery within seven days, with the exception of just one woman.

Concerning the investigated immunological parameters, those included a panel of chemokines and cytokines as well as a panel of oxylipins, both types of compounds generally measurable in plasma, although in many cases in the lower range of detectability. Moreover, a screening of 92 proteins with high sensitivity and specificity was performed. Altogether, this provided a wide-ranging assessment of inflammationassociated plasma compounds. Although the techniques of ELISA, multiplex bead assay, and PEA are all indirect detection methods, in contrast to HPLC-MS/MS, they are generally regarded as specific. It is notable that all of the four proteins (IL-6, IL17C, IL-10RB, and FGF-23) included in the prediction models were measured by PEA, which has been shown to have a very high sensitivity and specificity, and also provided the opportunity of measuring a large number of analytes in a small sample volume of one $\mu 1^{235}$. None of the chemokines and cytokines analysed with multiplex bead assay showed enough discriminative ability to be included in the prediction models, despite that IL-6, which showed a strong predictive value with PEA, was analysed with both assays. This points to the importance of having the most appropriate analysis method when investigating low-abundant proteins in plasma. 
Despite the fact that HPLC/MS-MS is generally regarded as an optimal method for detecting oxylipins ${ }^{183,236}$ the detection frequency of PGs was unfortunately very low, in most cases the concentrations were below the limit of detection (Figure 12), which prohibited their inclusion in the statistical analyses. It would have been interesting to evaluate plasma levels of PGs in PTL, as amniotic fluid levels of PGs are highly associated with labour initiation, intraamniotic inflammation in PTL, and delivery after PPROM $^{149-151}$. This might be explained either by PGs eluting too early from the column to be detected, or by the fact that ex vivo formation and degradation processes occur when blood samples are kept too long at room temperature prior to centrifugation. These circumstances are more likely to have affected some of the more unstable oxylipins than the proteins.

Another important aspect regarding the oxylipins is the use of pneumatic tube transport of blood samples at two of the three study hospitals. Since pneumatic tube transport has been reported to influence a subset of oxylipins ${ }^{237}$, we investigated the potential impact of these factors on our data set. In the univariate logistic regression analysis there was a tendency for a statistically significant association between not using pneumatic tube transport and the association of oxylipins with delivery before 34 weeks $(\mathrm{p}=0.053)$; however, in the multivariate analysis an association was not verified $(\mathrm{p}=0.127)$ (Table 2, Paper III). Regarding delivery within 48 hours, the use of pneumatic tube transport had no impact on the oxylipin results (Table 3, Paper III).

Regarding the prediction models built on combinations of plasma proteins, a high NPV was prioritised over a high PPV for secure prediction of who would not deliver preterm, an approach we considered to be most useful in a clinical perspective. Thereby, hospitalisation and unnecessary treatments could be avoided. With the chosen cut-off of an NPV at $100 \%$ for delivery within 48 hours of hospital admission, $60 \%$ of the women in our study cohort would have been exempt from unnecessary treatment, while all women who delivered within 48 hours would have received treatment in a correct way.

In Study IV, we were a little surprised to find that the proportion of SPTB $<34$ weeks of gestation, was lower than expected $(46 / 108 ; 43 \%)$ as compared with medically indicated PTB. Generally, about two thirds of PTBs are spontaneous ${ }^{4,6,7}$. However, the total incidence of PTB $<34$ weeks in the pregnancy biobank $(1.5 \%)$ was comparable to the incidence in the Swedish population in $2019^{238}$. The studied cohort might be considered relatively small ( $\mathrm{PPTB} ; \mathrm{n}=46$, controls; $\mathrm{n}=46$ ), but was considered sufficient according to the sample size calculation. Furthermore, data on ethnicity is not available in the medical records. However, the vast majority of the participants in the pregnancy biobank is Caucasian. It would have been appropriate, however, to adjust for this factor when constructing a prediction model. The same problem is present also in Studies II and III. 
Another possible limitation of Study IV is that PTL and PPROM were regarded as one clinical entity of PTB, although they are phenotypically different and at least in part result from different underlying mechanisms. However, the aim was to evaluate whether prediction of sPTB prior to 34 weeks of gestation was possible, regardless of the underlying pathology. Furthermore, concerns might be raised regarding the control group, in which only healthy non-smoking women with BMI $<30$ and previous and present normal pregnancies were included. The only variables that were used to match the case group were parity and time of the year at sampling. In this way, our control group might consist of women with fewer health problems than the general population. Therefore, this might result in a lower grade of pro-inflammatory markers and thus augment differences between cases and controls. However, regarding factors such as age, BMI, and frequency of smoking there were no major differences between the groups (Table 1, Paper IV), implying that they are comparable. 


\section{Conclusions}

Based on the studies in this thesis, the following conclusions are drawn:

- In the southeast region of Sweden, risk factors for Apgar score $<7$ at five minutes of age are PTB, low gestational age, maternal short stature, non-normal admission CTG, previous caesarean section, nulli-parity, multiple gestation, as well as overweight and obesity (Study I).

- There was a higher rate of PTB at the tertiary level of care hospital than at the secondary level. However, adjusted for a spectrum of other diagnoses, $\mathrm{AS}^{5 \mathrm{~min}}<7$ was not associated with the tertiary level of care (Study I).

- Risk factors for PTB <32 weeks of gestation are multiple gestation, preeclampsia, epilepsy, thyroid disease, smoking, and nulli-parity (Study I).

- A combination of PEA-measured inflammation-associated proteins and CL predicted PTB <34 weeks of gestation (IL-6, IL-17C, IL-10RB, and FGF-23) and within 48 hours of hospital admission (IL-6 and IL-17C) at high accuracy in women presenting with PTL<34 weeks (Study II).

- PTL and labour at term are associated with a more complex type of inflammation than previously thought, involving Th17- (CXCL1) and Th2- (CCL17) associated immunity. While there is no significant difference between PTL and PPROM, both these conditions show higher inflammatory activity than antenatal controls (Study II).

- In women with PTL, PTB $<34$ weeks is associated with lower concentrations of the oxylipin 9,10-DiHODE, and higher concentrations of 11,12-DiHETrE, while delivery within 48 hours of hospital admission is associated with lower concentrations of 9,10-DiHODE and higher concentrations of 8-HETE (Study III).

- A combination of PEA-measured plasma proteins from the first and second trimesters of pregnancy in a low-risk population was able to predict PTB with high accuracy. However, the predictive accuracy of combinations of first trimester plasma proteins was only moderate (Study IV).

- Although the predictors for SPTB identified in this thesis are promising, further studies are needed for confirmation before they can be used in clinical practise. 


\section{Concluding Remarks and Future Perspectives}

Study I verified some previous known risk factors for $\mathrm{AS}^{5 \mathrm{~min}}<7$ and for PTB $<32$ weeks of gestation, and also provided valuable information for the continuous work with preventive strategies in the southeast region of Sweden, such as the cessation of smoking, which might reduce the numbers of PTB. It has been shown that, compared to usual care, counselling during pregnancy increases the rate of smoking cessation, and that this results in a smaller proportion of infants born with low birthweight, although there is no clear impact on PTB rates ${ }^{239}$. As guidelines now favour the use of aspirin as a prophylactic agent against preeclampsia, this might reduce not only the incidence of preeclampsia, but also PTB rates ${ }^{240}$. Furthermore, the continuous efforts to reduce pregnancy complications, including low Apgar scores, must focus on obesity. Fortunately, an intervention study has shown positive results in weight gain restriction for obese pregnant women ${ }^{241}$. Moreover, the association between short stature and $\mathrm{AS}^{5 \mathrm{~min}}<7$ would be interesting to investigate further to find out if changes in clinical management could improve the situation.

Studies II and III revealed a more complex immune pattern represented in PTL, PPROM, and different stages of normal pregnancy than previously thought. Thus, further investigation is needed to better understand the mechanisms behind PTL and PPROM. Moreover, novel and interesting associations between certain oxylipins and PTB were found, indicating that oxylipins might have both protective and harmful effects on the risk of PTB. These findings need to be verified in larger studies, before a thorough evaluation of oxylipins as predictors of PTB can be done. In recent years, omics-based global approaches, evaluating gene expression (RNA), proteins and cellular phenotypes, have demonstrated precise and timely immune adaptations during pregnancy ${ }^{154-158}$. It would be of interest to apply some of these tools to increase our understanding of mechanisms in labour and possible deviations in PTL, PPROM and PTB.

The proposed prediction models for PTB <34 weeks of gestation and for delivery within 48 hours of hospital admission due to PTL, composed of combinations of PEA-based inflammation-associated proteins, appear very promising. However, these findings also need validation in other and larger cohorts. Furthermore, different cut-off levels of the included proteins to predict PTB would also need to be established. Moreover, a prerequisite for clinical utility in the context of PTL is the availability of a bedside test. Since the PEA technique is PCR-based this would be achievable and could involve a bedside filter paper test ${ }^{242}$. Also, to improve predictive accuracy, other biomarkers could be added to our candidate molecules, such as foetus-derived molecules ${ }^{77,78,99,243}$. 
A very important aspect of the studies of PTB subsequent to PTL is the effect of tocolytics treatment. In our study, all women with PTL were assessed as having a high risk of PTB and hence were treated with tocolytics. Therefore, there is no way of knowing what withholding of tocolytics from these women would have resulted in. In the search for prediction models for PTB after PTL the effect of tocolytics must be taken into consideration. After a positive evaluation in validation cohorts of predictive biomarkers, the next step would be to evaluate how the withholding of tocolytics would affect the outcome in women assessed to be at lower risk for PTB after being tested with biomarkers. To test this, randomised trials would be necessary. However, this raises important and difficult ethical concerns.

In Study IV we presented prediction models for PTB $<34$ weeks of pregnancy based on levels of plasma proteins in the first and second trimesters. Although the combined model including protein findings from both trimesters indicated predictive accuracy, we propose that a prediction model built on plasma proteins exclusively from the first trimester would offer better clinical value, as this would give women assessed as being at risk for PTB the opportunity to have preventive treatment. Hence, to begin with, the evaluation of further inflammation-associated first trimester plasma proteins would need evaluation and validation in another cohort. With this achieved, the utility of a test in relation to a certain preventive strategy or prophylactic treatment would need investigation. It is imaginable that different sub-groups of women, based on for example ethnicity or obesity, would benefit differently from different interventions, which also needs investigation. Therefore, in parallel with the search for biomarkers, future research must also include development of prophylactic treatments, otherwise identifying a woman at risk for PTB without having an effective risk-decreasing intervention to offer would again raise ethical concerns. However, the composition of inflammatory biomarkers might provide some clues to the underlying mechanisms of PTB, which might facilitate the development of preventive treatments.

Furthermore, for the comparison of studies regarding interventions to prevent PTB an evaluation core outcome set has been proposed ${ }^{244}$. Also for studies regarding prediction models, whether biomarkers are included or not, a similar future approach would be beneficial. 


\section{Acknowledgements}

This journey, or mountain climb, started almost eight years ago. That's a long time. Although it must be completely clear to everybody, I still point out that work like this depends on the advice, support, enthusiasm, and hard work of a lot of people. I would like to mention some of them.

First of all, I am very grateful towards all the women and men who volunteered to participate and donate their blood to make these projects possible. The "Retro-PRIMM"project didn't make into this thesis, but the samples are waiting in the freezer.

Professor Jan Ernerudh, my main supervisor, a person with a unique combination of expertise in so many fields and yet a very humble attitude. You are always available, preferably by e-mail at one o'clock in the morning, and always full of good advice and patience. I truly appreciate - admire even - your very dry and academic sense of humour, which often brightens my day. If I ever write another book, my next one will be an anthology of my favourites among your amusing e-mails.

Professor Marie Blomberg, co-supervisor and one of my most important role models in obstetrics, and now also in science. You were an inspiration to me already when I was a young medical student and you have kept inspiring me ever since.

Professor Maria Jenmalm, co-supervisor with a knowledge in immunology deeper than Lake Vättern! You are incredibly fast, very analytic, always in a good mood, and a wizard at lab techniques.

MD PhD Gunnel Lindell, former co-supervisor and former head of the Department of Obstetrics and Gynaecology in Kalmar. Your kind spirit and advice have taken me far.

My co-authors;

Professor Lars Brudin, not formally one of my supervisors, but you have been one very much anyway. What I know about statistics I owe to you, as well as all the tricks I know now in several computer programs. Your vast knowledge and special competence in both statistics and medicine is really special. You are always ready to do some work with a smile - no matter what day of the week or what time of the day (or the night) it is! ; Johanna Raffetseder, for pipetting samples to Uppsala, analysing CLL18, creating figures, having all the excel files in order, answering all my questions, extracting RNA $\rightarrow$ cDNA, for sharing your office, for being eager to help, and for your calm and so, so genuinely nice attitude; Sandra Hellberg, for helping out getting the whole "PRIM"-project started; ordering supplies, packing bags with test tubes, writing and re- 
writing instructions, sending big boxes to Jönköping (and Kalmar, and everywhere), pouring RNAlater in tubes with me, and for always being available and so organised, and always having a smile on your face. Besides this, thanks for letting me use your image as my Figure 2; Daniel Axelsson, for making everything run smoothly at the delivery ward in Jönköping. The PRIM project would never have been possible without all the women that were included in Jönköping. Thanks for always welcoming me and finding me a computer (with log-in details); Malin Linder Nording and Richard Lindberg, my new chemistry pals in Umeå. Thanks for generously sharing your expertise and good advice, always ready to answer questions. I really appreciated the Zoom-tour in the lab!; Professor Göran Berg, for your initiative with "GraBB" and for generously sharing your experience and vast knowledge.

For the inclusion of women in the PRIM study I am grateful to all the midwives and physicians at the labour wards in Kalmar, Jönköping, Linköping, Eksjö, Norrköping, and Västervik, and to the midwives at Kvinnohälsan in Norrköping. I also express my gratitude to everyone who handled blood and placental samples around the clock; Therese Svensson and her assistant nurse colleagues at the labour ward in Linköping, Carina Tenghamn and her colleagues at the Department of Laboratory Medicine in Jönköping, and Hanna Carlsson, and her colleagues at the Department of Clinical Chemistry in Kalmar.

For the inclusion of women in the biobank "GraBB" I thank the midwives at the antenatal clinics in Linköping and Motala.

\section{At former AIR in Linköping;}

Petra Cassel, for all your work with the Luminex, for getting samples to Uppsala, for ordering loads of supplies, for answering all my e-mails, and for letting me spend a very nice time with you in the lab; Karin Söderman; for your excellent work with GraBB, and for your rescue of some RNA in the lab. I also thank all the others who work with GraBB without me knowing; Robert Lindau, for handling lots of blood samples from Norrköping and for nice company in Aalborg and at AIR; Daniel Eklund, for helping me extracting RNA and showing an unusually nice attitude; Olivia Thingvall, for analysing CCL18; Judit Svensson-Arvelund for good advice, great inspiration, very nice company in Budapest, and for having created Figure 3 and for letting me use it in this thesis; Georgia Papapavlou and Valentina Bruno, for nice company and inspiring talks in Aalborg; Johanna Huoman, for generously sharing your desk as well as your advice, thoughts, and sense of humour every time I occupied your office in Linköping; Marie Rubér for a crash course in PowerPoint and for really nice conversations; Professor Christina Ekerfelt, for collaboration in science many years ago and for sharing your love of "the hood" with me (and for coming to my rescue when I left my 
keys inside the locked lab on a sunny Sunday afternoon in July!). I doubt that I would ever have started on this journey hadn't it been for your inspiration.

I also want to thank everyone else contributing to the really special friendly and welcoming atmosphere in the "fika-room".

Marie Nelson, Ingela Olsson, Meg Wigmo, and Maria Kellerman, for data extracting and for getting me access to medical records in Linköping. Ninnie Borendahl Wodlin, for the necessary paper work. Kristina Kernell, Ob\&Gyn, Linköping, and Sofia Olsson, Ob\&Gyn, Kalmar, for smoothly running collaboration with the inclusions of controls in our joint GraBB-projects.

At the Department of Ob\&Gyn in Kalmar I sincerely thank Ann-Marie Berglund, head of the department and dear colleague, for your support, interest in my research, and for giving me the time away from clinical work to finish this thesis. For the practical arrangements with the schedule I am grateful to Christine Petersson Strid and Cecilia Molnár. I am also grateful to all the rest of my colleagues, who have taken care of my patients while I was away from the clinic. Many, many thanks to Eva Hallström for reading 1,077 medical records with me, sending hundreds of letters, making countless phone calls and writing e-mails, and drawing blood samples in 65 women and men. Meanwhile, you shared your laughter and your wisdom of life with me. Some day we will finish the retro-PRIMM project!

Everyone at the Research section, Kalmar County Hospital; including Ingrid Wåhlin, Helene Nordmark, Jonas Bonnedahl, Cecilia Fagerström, Beate König, and fellow PhD-students for seminars, inspiration, and valuable feed-back - and funding!

Pihla Kuusela, for more writing-the-PhD-thesis-inspiration than you will ever know, for letting me use and modify your table (Table 1), and for excellent company at the ESPBC in Edinburgh.

Fellow "FOPPers" - it is such a joy to experience your enthusiasm in research! You have so much good advice to share, particularly regarding "death tables" :-) I am so thankful for being a part of the group.

Anna Röckert Tjernberg, Lisa Labbé Sandelin, and Pia Glatz for great company and assistance with the statistics tests (and eating the "potato cakes") during our very first course in Research Methodology. 
I am also very grateful to my family and many friends, but will mention only few of you here by name (and I will do it in Swedish);

"Hönsen"; Susanne Liffner, Lotta Masreliez, Lotta Ginstman och Anna RT (igen), för vänskap, stöd (både privat och angående jobb och forskning) och för allt kul vi har haft ända sedan vi började på läkarutbildningen.

De alldeles utmärkta bed-and-breakfast(-and-dinner)-ställena i Linköping; Stigbergsgatan (Malin, Fredrik T, Ella och Alma), Västanågatan (Lotta G (igen), Fredrik G, Gustaf och Ottilia) och Majgatan (Susanne (igen), Göran, Frans och Sigrid). Extremt gästvänligt och prisvärt (:)

Mina föräldrar, Kajsa Svenvik och Bo Svenvik, och mina svärföräldrar, Berit Schön och Bengt Schön - i just detta sammanhang är jag så himla tacksam för alla gånger ni har ställt upp och räddat vår invecklade vardag genom att hängivet ta hand om våra barn.

Freja, Algot och Tyra. Ni är solen, månen och stjärnorna - verkligen stjärnorna! - i mitt universum. Det finns inget som gör mig så stolt som att vara förälder till er. Tack för att ni har hjälpt till med att lägga hundratals brev i kuvert, sätta etiketter på tusentals pyttesmå provrör och stoppa rätt antal rör med rätt etikett i hundratals små påsar - och för att ni har lagat så många middagar och fixat med en massa annat så att jag kunde skriva klart den här boken. Ni är bäst. Alltid.

And Thomas, my sine qua non. Let's keep this short and simple: It's the greatest privilege to have you by my side in science, life, and love.

"Vadda, finns det mer än en sorts vita blodkroppar?

Det är ju jättejobbigt."

Freja, 11 ar, 2013 


\section{References}

1. WHO: recommended definitions, terminology and format for statistical tables related to the perinatal period and use of a new certificate for cause of perinatal deaths. Modifications recommended by FIGO as amended October 14, 1976. Acta obstetricia et gynecologica Scandinavica. 1977;56(3):247-253.

2. Blencowe H, Cousens S, Oestergaard MZ, Chou D, Moller AB, Narwal R, Adler A, Vera Garcia C, Rohde S, Say L, Lawn JE. National, regional, and worldwide estimates of preterm birth rates in the year 2010 with time trends since 1990 for selected countries: a systematic analysis and implications. Lancet. 2012;379(9832):2162-2172.

3. Chang HH, Larson J, Blencowe $\mathrm{H}$, Spong CY, Howson CP, Cairns-Smith S, Lackritz EM, Lee SK, Mason E, Serazin AC, Walani S, Simpson JL, Lawn JE. Preventing preterm births: analysis of trends and potential reductions with interventions in 39 countries with very high human development index. Lancet. 2013;381(9862):223-234.

4. Purisch SE, Gyamfi-Bannerman C. Epidemiology of preterm birth. Semin Perinatol. 2017.

5. Liu L, Oza S, Hogan D, Chu Y, Perin J, Zhu J, Lawn JE, Cousens S, Mathers C, Black RE. Global, regional, and national causes of under-5 mortality in 2000-15: an updated systematic analysis with implications for the Sustainable Development Goals. Lancet. 2016;388(10063):3027-3035.

6. Goldenberg RL, Culhane JF, lams JD, Romero R. Epidemiology and causes of preterm birth. Lancet. 2008;371(9606):75-84.

7. Romero R, Dey SK, Fisher SJ. Preterm labor: one syndrome, many causes. Science. 2014;345(6198):760-765.

8. Chawanpaiboon S, Vogel JP, Moller AB, Lumbiganon P, Petzold M, Hogan D, Landoulsi S, Jampathong N, Kongwattanakul K, Laopaiboon M, Lewis C, Rattanakanokchai S, Teng DN, Thinkhamrop J, Watananirun K, Zhang J, Zhou W, Gulmezoglu AM. Global, regional, and national estimates of levels of preterm birth in 2014: a systematic review and modelling analysis. Lancet Glob Health. 2019;7(1):e37-e46.

9. The National Board of Health and Welfare: Statistikdatabas för graviditeter, förlossningar och nyfödda. Available from:

https://sdb.socialstyrelsen.se/if_mfr_004/val.aspx.

10. McIntire DD, Leveno KJ. Neonatal mortality and morbidity rates in late preterm births compared with births at term. Obstetrics and gynecology. 2008;111(1):35-41.

11. Saigal S, Doyle LW. An overview of mortality and sequelae of preterm birth from infancy to adulthood. Lancet. 2008;371(9608):261-269.

12. Blencowe H, Cousens S, Chou D, Oestergaard M, Say L, Moller AB, Kinney M, Lawn J, Born Too Soon Preterm Birth Action G. Born too soon: the global epidemiology of 15 million preterm births. Reprod Health. 2013;10 Suppl 1:S2.

13. Ancel PY, Goffinet F, Group E-W, Kuhn P, Langer B, Matis J, Hernandorena X, Chabanier P, Joly-Pedespan L, Lecomte B, Vendittelli F, Dreyfus M, Guillois B, Burguet A, Sagot P, Sizun J, Beuchee A, Rouget F, Favreau A, Saliba E, Bednarek N, Morville P, Thiriez G, Marpeau L, Marret S, Kayem G, Durrmeyer X, Granier M, Baud O, Jarreau PH, Mitanchez D, Boileau P, Boulot P, Cambonie G, Daude H, Bedu A, Mons F, Fresson J, Vieux R, Alberge C, Arnaud C, Vayssiere C, Truffert P, Pierrat V, Subtil D, D'Ercole C, Gire C, Simeoni U, Bongain A, Sentilhes L, Roze JC, Gondry J, Leke A, Deiber M, Claris 
O, Picaud JC, Ego A, Debillon T, Poulichet A, Coline E, Favre A, Flechelles O, Samperiz S, Ramful D, Branger B, Benhammou V, Foix-L'Helias L, Marchand-Martin L, Kaminski M. Survival and morbidity of preterm children born at 22 through 34 weeks' gestation in France in 2011: results of the EPIPAGE-2 cohort study. JAMA Pediatr. 2015;169(3):230-238.

14. Ancel PY, Livinec F, Larroque B, Marret S, Arnaud C, Pierrat V, Dehan M, N'Guyen S, Escande B, Burguet A, Thiriez G, Picaud JC, Andre M, Breart G, Kaminski M, Group ES. Cerebral palsy among very preterm children in relation to gestational age and neonatal ultrasound abnormalities: the EPIPAGE cohort study. Pediatrics. 2006;117(3):828-835.

15. Fellman $\mathrm{V}$, Hellstrom-Westas L, Norman $M$, Westgren $M$, Kallen K, Lagercrantz $H$, Marsal K, Serenius F, Wennergren M. One-year survival of extremely preterm infants after active perinatal care in Sweden. Jama. 2009;301(21):2225-2233.

16. Serenius F, Kallen K, Blennow M, Ewald U, Fellman V, Holmstrom G, Lindberg E, Lundqvist P, Marsal K, Norman M, Olhager E, Stigson L, Stjernqvist K, Vollmer B, Stromberg B. Neurodevelopmental outcome in extremely preterm infants at 2.5 years after active perinatal care in Sweden. Jama. 2013;309(17):1810-1820.

17. Gilbert C. Retinopathy of prematurity: a global perspective of the epidemics, population of babies at risk and implications for control. Early Hum Dev. 2008;84(2):77-82.

18. Hirvonen M, Ojala R, Korhonen P, Haataja P, Eriksson K, Gissler M, Luukkaala T, Tammela O. Visual and Hearing Impairments After Preterm Birth. Pediatrics. 2018;142(2).

19. Thunqvist P, Tufvesson E, Bjermer L, Winberg A, Fellman V, Domellof M, Melen E, Norman $M$, Hallberg J. Lung function after extremely preterm birth-A populationbased cohort study (EXPRESS). Pediatr Pulmonol. 2018;53(1):64-72.

20. Arpino C, Compagnone E, Montanaro ML, Cacciatore D, De Luca A, Cerulli A, Di Girolamo S, Curatolo P. Preterm birth and neurodevelopmental outcome: a review. Childs Nerv Syst. 2010;26(9):1139-1149.

21. Hafstrom M, Kallen K, Serenius F, Marsal K, Rehn E, Drake H, Aden U, Faroogi A, Thorngren-Jerneck K, Stromberg B. Cerebral Palsy in Extremely Preterm Infants. Pediatrics. 2018;141(1).

22. Saigal S, Morrison K, Schmidt LA. "Health, wealth and achievements of former very premature infants in adult life". Seminars in fetal \& neonatal medicine. 2020;25(3):101107.

23. Moster D, Lie RT, Markestad T. Long-term medical and social consequences of preterm birth. The New England journal of medicine. 2008;359(3):262-273.

24. Johnson S, Marlow N. Early and long-term outcome of infants born extremely preterm. Arch Dis Child. 2017;102(1):97-102.

25. Menon R, Richardson LS. Preterm prelabor rupture of the membranes: A disease of the fetal membranes. Semin Perinatol. 2017;41(7):409-419.

26. Ananth CV, Vintzileos AM. Epidemiology of preterm birth and its clinical subtypes. The journal of maternal-fetal \& neonatal medicine: the official journal of the European Association of Perinatal Medicine, the Federation of Asia and Oceania Perinatal Societies, the International Society of Perinatal Obstet. 2006;19(12):773-782. 
27. Cobo T, Kacerovsky M, Jacobsson B. Risk factors for spontaneous preterm delivery. International journal of gynaecology and obstetrics: the official organ of the International Federation of Gynaecology and Obstetrics. 2020;150(1):17-23.

28. Ferrero DM, Larson J, Jacobsson B, Di Renzo GC, Norman JE, Martin JN, Jr., D'Alton M, Castelazo E, Howson CP, Sengpiel V, Bottai M, Mayo JA, Shaw GM, Verdenik I, Tul N, Velebil P, Cairns-Smith S, Rushwan H, Arulkumaran S, Howse JL, Simpson JL. CrossCountry Individual Participant Analysis of 4.1 Million Singleton Births in 5 Countries with Very High Human Development Index Confirms Known Associations but Provides No Biologic Explanation for 2/3 of All Preterm Births. PloS one. 2016;11(9):e0162506.

29. Laughon SK, Albert PS, Leishear K, Mendola P. The NICHD Consecutive Pregnancies Study: recurrent preterm delivery by subtype. American journal of obstetrics and gynecology. 2014;210(2):131 e131-138.

30. Koullali B, Oudijk MA, Nijman TA, Mol BW, Pajkrt E. Risk assessment and management to prevent preterm birth. Seminars in fetal \& neonatal medicine. 2016;21(2):80-88.

31. Malacova E, Regan A, Nassar N, Raynes-Greenow C, Leonard H, Srinivasjois R, A WS, Lavin T, Pereira G. Risk of stillbirth, preterm delivery, and fetal growth restriction following exposure in a previous birth: systematic review and meta-analysis. BJOG : an international journal of obstetrics and gynaecology. 2018;125(2):183-192.

32. Smith GC, Pell JP, Dobbie R. Interpregnancy interval and risk of preterm birth and neonatal death: retrospective cohort study. BMJ. 2003;327(7410):313.

33. Mayo JA, Shachar BZ, Stevenson DK, Shaw GM. Interpregnancy Interval and Adverse Pregnancy Outcomes: An Analysis of Successive Pregnancies and: Interpregnancy Interval and Pregnancy Outcomes: Causal or Not? Obstetrics and gynecology. 2017; 130(2):463.

34. Salihu H, Mbah AK, Alio AP, Kornosky JL, Whiteman VE, Belogolovkin V, Rubin LP. Nulliparity and preterm birth in the era of obesity epidemic. The journal of maternalfetal \& neonatal medicine : the official journal of the European Association of Perinatal Medicine, the Federation of Asia and Oceania Perinatal Societies, the International Society of Perinatal Obstet. 2010;23(12):1444-1450.

35. Fuchs F, Senat MV. Multiple gestations and preterm birth. Seminars in fetal \& neonatal medicine. 2016;21(2):113-120.

36. Chen KC, Liou JD, Hung TH, Kuo DM, Hsu JJ, Hsieh CC, Hsieh TT. Perinatal outcomes of polyhydramnios without associated congenital fetal anomalies after the gestational age of 20 weeks. Chang Gung Med J. 2005;28(4):222-228.

37. Jenkins TM, Mackey SF, Benzoni EM, Tolosa JE, Sciscione AC. Non-obstetric surgery during gestation: risk factors for lower birthweight. Aust N Z J Obstet Gynaecol. 2003;43(1):27-31.

38. Baldwin EA, Borowski KS, Brost BC, Rose $\mathrm{CH}$. Antepartum nonobstetrical surgery at $>/=23$ weeks' gestation and risk for preterm delivery. American journal of obstetrics and gynecology. 2015;212(2):232 e231-235.

39. Vujic J, Marsoner K, Lipp-Pump AH, Klaritsch P, Mischinger HJ, Kornprat P. Nonobstetric surgery during pregnancy - an eleven-year retrospective analysis. $B M C$ Pregnancy Childbirth. 2019;19(1):382.

40. Manuck TA. Racial and ethnic differences in preterm birth: A complex, multifactorial problem. Semin Perinatol. 2017;41(8):511-518.

41. Porter TF, Fraser AM, Hunter $\mathrm{CY}$, Ward RH, Varner MW. The risk of preterm birth across generations. Obstetrics and gynecology. 1997;90(1):63-67. 
42. Venetis CA, Papadopoulos SP, Campo R, Gordts S, Tarlatzis BC, Grimbizis GF. Clinical implications of congenital uterine anomalies: a meta-analysis of comparative studies. Reprod Biomed Online. 2014;29(6):665-683.

43. Kyrgiou M, Athanasiou A, Kalliala IEJ, Paraskevaidi M, Mitra A, Martin-Hirsch PP, Arbyn $\mathrm{M}$, Bennett $\mathrm{P}$, Paraskevaidis E. Obstetric outcomes after conservative treatment for cervical intraepithelial lesions and early invasive disease. Cochrane Database Syst Rev. 2017;11:CD012847.

44. Morken NH, Kallen K, Hagberg H, Jacobsson B. Preterm birth in Sweden 1973-2001: rate, subgroups, and effect of changing patterns in multiple births, maternal age, and smoking. Acta obstetricia et gynecologica Scandinavica. 2005;84(6):558-565.

45. McCall SJ, Green DR, Macfarlane GJ, Bhattacharya S. Spontaneous very preterm birth in relation to social class, and smoking: a temporal-spatial analysis of routinely collected data in Aberdeen, Scotland (1985-2010). J Public Health (Oxf). 2020;42(3):534-541.

46. da Silva AA, Simoes VM, Barbieri MA, Bettiol H, Lamy-Filho F, Coimbra LC, Alves MT. Young maternal age and preterm birth. Paediatric and perinatal epidemiology. 2003;17(4):332-339.

47. Fuchs F, Monet B, Ducruet T, Chaillet N, Audibert F. Effect of maternal age on the risk of preterm birth: A large cohort study. PloS one. 2018;13(1):e0191002.

48. Ehrenberg HM, Dierker L, Milluzzi C, Mercer BM. Low maternal weight, failure to thrive in pregnancy, and adverse pregnancy outcomes. American journal of obstetrics and gynecology. 2003;189(6):1726-1730.

49. Cnattingius S, Villamor E, Johansson S, Edstedt Bonamy AK, Persson M, Wikstrom AK, Granath F. Maternal obesity and risk of preterm delivery. Jama. 2013;309(22):23622370 .

50. Thompson JM, Irgens LM, Rasmussen S, Daltveit AK. Secular trends in socio-economic status and the implications for preterm birth. Paediatric and perinatal epidemiology. 2006;20(3):182-187.

51. Kim CJ, Romero R, Chaemsaithong P, Chaiyasit N, Yoon BH, Kim YM. Acute chorioamnionitis and funisitis: definition, pathologic features, and clinical significance. American journal of obstetrics and gynecology. 2015;213(4 Suppl):S29-52.

52. Martin JA, Hamilton BE, Osterman MJK, Driscoll AK. Births: Final Data for 2018. National vital statistics reports : from the Centers for Disease Control and Prevention, National Center for Health Statistics, National Vital Statistics System. 2019;68(13):147.

53. Menon R, Bonney EA, Condon J, Mesiano S, Taylor RN. Novel concepts on pregnancy clocks and alarms: redundancy and synergy in human parturition. Hum Reprod Update. 2016;22(5):535-560.

54. Bond DM, Middleton P, Levett KM, van der Ham DP, Crowther CA, Buchanan SL, Morris J. Planned early birth versus expectant management for women with preterm prelabour rupture of membranes prior to 37 weeks' gestation for improving pregnancy outcome. Cochrane Database Syst Rev. 2017;3:CD004735.

55. Kenyon SL, Taylor DJ, Tarnow-Mordi W, Group OC. Broad-spectrum antibiotics for preterm, prelabour rupture of fetal membranes: the ORACLE I randomised trial. ORACLE Collaborative Group. Lancet. 2001;357(9261):979-988.

56. Kenyon S, Boulvain M, Neilson JP. Antibiotics for preterm rupture of membranes. Cochrane Database Syst Rev. 2013(12):CD001058. 
57. Bendix J, Hegaard HK, Langhoff-Roos J, Bergholt T. Changing prevalence and the risk factors for antenatal obstetric hospitalizations in Denmark 2003-2012. Clin Epidemiol. 2016;8:165-175.

58. Martin AS, Zhang Y, Crawford S, Boulet SL, McKane P, Kissin DM, Jamieson DJ, States Monitoring Assisted Reproductive Technology C. Antenatal Hospitalizations Among Pregnancies Conceived With and Without Assisted Reproductive Technology. Obstetrics and gynecology. 2016;127(5):941-950.

59. Roberts D, Brown J, Medley N, Dalziel SR. Antenatal corticosteroids for accelerating fetal lung maturation for women at risk of preterm birth. Cochrane Database Syst Rev. 2017;3:CD004454.

60. Shanks AL, Grasch JL, Quinney SK, Haas DM. Controversies in antenatal corticosteroids. Seminars in fetal \& neonatal medicine. 2019;24(3):182-188.

61. Khulan B, Drake AJ. Glucocorticoids as mediators of developmental programming effects. Best Pract Res Clin Endocrinol Metab. 2012;26(5):689-700.

62. Perna-Barrull D, Gieras A, Rodriguez-Fernandez S, Tolosa E, Vives-Pi M. Immune System Remodelling by Prenatal Betamethasone: Effects on beta-Cells and Type 1 Diabetes. Front Endocrinol (Lausanne). 2020;11:540.

63. Dalziel SR, Walker NK, Parag V, Mantell C, Rea HH, Rodgers A, Harding JE. Cardiovascular risk factors after antenatal exposure to betamethasone: 30-year follow-up of a randomised controlled trial. Lancet. 2005;365(9474):1856-1862.

64. Lamont RF, Jorgensen JS. Safety and Efficacy of Tocolytics for the Treatment of Spontaneous Preterm Labour. Curr Pharm Des. 2019;25(5):577-592.

65. Flenady V, Hawley G, Stock OM, Kenyon S, Badawi N. Prophylactic antibiotics for inhibiting preterm labour with intact membranes. Cochrane Database Syst Rev. 2013(12):CD000246.

66. Berghella V, Palacio M, Ness A, Alfirevic Z, Nicolaides KH, Saccone G. Cervical length screening for prevention of preterm birth in singleton pregnancy with threatened preterm labor: systematic review and meta-analysis of randomized controlled trials using individual patient-level data. Ultrasound in obstetrics \& gynecology : the official journal of the International Society of Ultrasound in Obstetrics and Gynecology. 2017;49(3):322-329.

67. van Baaren GJ, Mol BW. Re: Cervical length screening for prevention of preterm birth in singleton pregnancy with threatened preterm labor: systematic review and metaanalysis of randomized controlled trials using individual patient-level data. $V$.

Berghella, M. Palacio, A. Ness, Z. Alfirevic, K. H. Nicolaides and G. Saccone. Ultrasound Obstet Gynecol 2017; 49: 322-329. Ultrasound in obstetrics \& gynecology : the official journal of the International Society of Ultrasound in Obstetrics and Gynecology. 2017;49(3):301-302.

68. Tsoi E, Fuchs IB, Rane S, Geerts L, Nicolaides KH. Sonographic measurement of cervical length in threatened preterm labor in singleton pregnancies with intact membranes. Ultrasound in obstetrics \& gynecology : the official journal of the International Society of Ultrasound in Obstetrics and Gynecology. 2005;25(4):353-356.

69. Fuchs IB, Henrich W, Osthues K, Dudenhausen JW. Sonographic cervical length in singleton pregnancies with intact membranes presenting with threatened preterm labor. Ultrasound in obstetrics \& gynecology : the official journal of the International Society of Ultrasound in Obstetrics and Gynecology. 2004;24(5):554-557. 
70. Vafaei H, Rahimirad N, Hosseini SM, Kasraeian M, Asadi N, Raeisi Shahraki H, Bazrafshan K. Triage by cervical length sonographic measurements for targeted therapy in threatened preterm labor: A double blind randomized clinical trial. Int J Reprod Biomed. 2017;15(11):697-702.

71. Sotiriadis A, Papatheodorou S, Kavvadias A, Makrydimas G. Transvaginal cervical length measurement for prediction of preterm birth in women with threatened preterm labor: a meta-analysis. Ultrasound in obstetrics \& gynecology : the official journal of the International Society of Ultrasound in Obstetrics and Gynecology. 2010;35(1):54-64.

72. Alfirevic Z, Allen-Coward H, Molina F, Vinuesa CP, Nicolaides K. Targeted therapy for threatened preterm labor based on sonographic measurement of the cervical length: a randomized controlled trial. Ultrasound in obstetrics \& gynecology : the official journal of the International Society of Ultrasound in Obstetrics and Gynecology. 2007;29(1):47-50.

73. Melamed N, Hiersch L, Domniz N, Maresky A, Bardin R, Yogev Y. Predictive value of cervical length in women with threatened preterm labor. Obstetrics and gynecology. 2013;122(6):1279-1287.

74. Hiersch L, Yogev Y, Domniz N, Meizner I, Bardin R, Melamed N. The role of cervical length in women with threatened preterm labor: is it a valid predictor at any gestational age? American journal of obstetrics and gynecology. 2014;211(5):532 e531-539.

75. Palacio M, Sanin-Blair J, Sanchez M, Crispi F, Gomez O, Carreras E, Coll O, Cararach V, Gratacos $\mathrm{E}$. The use of a variable cut-off value of cervical length in women admitted for preterm labor before and after 32 weeks. Ultrasound in obstetrics \& gynecology: the official journal of the International Society of Ultrasound in Obstetrics and Gynecology. 2007;29(4):421-426.

76. Palacio M, Caradeux J, Sanchez M, Cobo T, Figueras F, Coll O, Gratacos E, Cararach V. Uterine Cervical Length Measurement to Reduce Length of Stay in Patients Admitted for Threatened Preterm Labor: A Randomized Trial. Fetal Diagn Ther. 2018;43(3):184190.

77. Berghella $\mathrm{V}$, Saccone $\mathrm{G}$. Fetal fibronectin testing for prevention of preterm birth in singleton pregnancies with threatened preterm labor: a systematic review and metaanalysis of randomized controlled trials. American journal of obstetrics and gynecology. 2016;215(4):431-438.

78. Conde-Agudelo A, Romero R. Cervical phosphorylated insulin-like growth factor binding protein-1 test for the prediction of preterm birth: a systematic review and metaanalysis. American journal of obstetrics and gynecology. 2016;214(1):57-73.

79. Pirjani R, Moini A, Almasi-Hashiani A, Farid Mojtahedi M, Vesali S, Hosseini L, Sepidarkish M. Placental alpha microglobulin-1 (PartoSure) test for the prediction of preterm birth: a systematic review and meta-analysis. The journal of maternal-fetal \& neonatal medicine : the official journal of the European Association of Perinatal Medicine, the Federation of Asia and Oceania Perinatal Societies, the International Society of Perinatal Obstet. 2019:1-13.

80. Dehaene I, Lorthe E, Gurney L, Turtiainen P, Schwickert A, Svenvik M, Care A, Bergman $L$, from the International Spontaneous Preterm birth Young investigators g. Accuracy of the combination of commercially available biomarkers and cervical length measurement to predict preterm birth in symptomatic women: A systematic review. 
European journal of obstetrics, gynecology, and reproductive biology. 2021;258:198207.

81. Botsis D, Makrakis E, Papagianni V, Kouskouni E, Grigoriou O, Dendrinos S, Creatsas G. The value of cervical length and plasma proMMP-9 levels for the prediction of preterm delivery in pregnant women presenting with threatened preterm labor. European journal of obstetrics, gynecology, and reproductive biology. 2006;128(1-2):108-112.

82. Cobo T, Palacio M, Navarro-Sastre A, Ribes A, Bosch J, Filella X, Gratacos E. Predictive value of combined amniotic fluid proteomic biomarkers and interleukin- 6 in preterm labor with intact membranes. American journal of obstetrics and gynecology. 2009;200(5):499 e491-496.

83. Holst RM, Hagberg H, Wennerholm UB, Skogstrand K, Thorsen P, Jacobsson B. Prediction of spontaneous preterm delivery in women with preterm labor: analysis of multiple proteins in amniotic and cervical fluids. Obstetrics and gynecology. 2009;114(2 Pt 1):268-277.

84. Tsiartas P, Holst RM, Wennerholm UB, Hagberg H, Hougaard DM, Skogstrand K, Pearce $B D$, Thorsen $\mathrm{P}$, Kacerovsky M, Jacobsson B. Prediction of spontaneous preterm delivery in women with threatened preterm labour: a prospective cohort study of multiple proteins in maternal serum. BJOG : an international journal of obstetrics and gynaecology. 2012;119(7):866-873.

85. Laudanski P, Lemancewicz A, Kuc P, Charkiewicz K, Ramotowska B, Kretowska M, Jasinska E, Raba G, Karwasik-Kajszczarek K, Kraczkowski J, Laudanski T. Chemokines profiling of patients with preterm birth. Mediators of inflammation. 2014;2014:185758.

86. Jung EY, Park JW, Ryu A, Lee SY, Cho SH, Park KH. Prediction of impending preterm delivery based on sonographic cervical length and different cytokine levels in cervicovaginal fluid in preterm labor. J Obstet Gynaecol Res. 2016;42(2):158-165.

87. Park H, Park KH, Kim YM, Kook SY, Jeon SJ, Yoo HN. Plasma inflammatory and immune proteins as predictors of intra-amniotic infection and spontaneous preterm delivery in women with preterm labor: a retrospective study. BMC Pregnancy Childbirth. 2018;18(1):146.

88. Hong S, Park KH, Kim YM, Lee YE, Park Y, Lee JE. A Protein Microarray Analysis of Plasma Proteins for the Prediction of Spontaneous Preterm Delivery in Women with Preterm Labor. Reprod Sci. 2020;27(5):1187-1196.

89. Cobo T, Aldecoa V, Figueras F, Herranz A, Ferrero S, Izquierdo M, Murillo C, Amoedo R, Rueda C, Bosch J, Martinez-Portilla RJ, Gratacos E, Palacio M. Development and validation of a multivariable prediction model of spontaneous preterm delivery and microbial invasion of the amniotic cavity in women with preterm labor. American journal of obstetrics and gynecology. 2020;223(3):421 e421-421 e414.

90. Goldenberg RL, Goepfert AR, Ramsey PS. Biochemical markers for the prediction of preterm birth. American journal of obstetrics and gynecology. 2005;192(5 Suppl):S3646.

91. Society for Maternal-Fetal Medicine. Electronic address pso, McIntosh J, Feltovich $\mathrm{H}$, Berghella $\mathrm{V}$, Manuck T. The role of routine cervical length screening in selected highand low-risk women for preterm birth prevention. American journal of obstetrics and gynecology. 2016;215(3):B2-7.

92. Kuusela P, Wennerholm UB, Fadl H, Wesstrom J, Lindgren P, Hagberg H, Jacobsson B, Valentin L. Second trimester cervical length measurements with transvaginal 
ultrasound: A prospective observational agreement and reliability study. Acta obstetricia et gynecologica Scandinavica. 2020;99(11):1476-1485.

93. Menon R, Torloni MR, Voltolini C, Torricelli M, Merialdi M, Betran AP, Widmer M, Allen T, Davydova I, Khodjaeva Z, Thorsen P, Kacerovsky M, Tambor V, Massinen T, Nace J, Arora C. Biomarkers of spontaneous preterm birth: an overview of the literature in the last four decades. Reprod Sci. 2011;18(11):1046-1070.

94. Conde-Agudelo A, Papageorghiou AT, Kennedy SH, Villar J. Novel biomarkers for the prediction of the spontaneous preterm birth phenotype: a systematic review and meta-analysis. BJOG : an international journal of obstetrics and gynaecology. 2011;118(9):1042-1054.

95. Shah SJ, Yu KH, Sangar V, Parry SI, Blair IA. Identification and quantification of preterm birth biomarkers in human cervicovaginal fluid by liquid chromatography/tandem mass spectrometry. J Proteome Res. 2009;8(5):2407-2417.

96. O'Brien JM, Peeler GH, Pitts DW, Salama MM, Sibai BM, Mercer BM. Cervicovaginal prolactin: a marker for spontaneous preterm delivery. American journal of obstetrics and gynecology. 1994;171(4):1107-1111.

97. Yoon BH, Oh SY, Romero R, Shim SS, Han SY, Park JS, Jun JK. An elevated amniotic fluid matrix metalloproteinase-8 level at the time of mid-trimester genetic amniocentesis is a risk factor for spontaneous preterm delivery. American journal of obstetrics and gynecology. 2001;185(5):1162-1167.

98. lams JD, Goldenberg RL, Mercer BM, Moawad AH, Meis PJ, Das AF, Caritis SN, Miodovnik M, Menard MK, Thurnau GR, Dombrowski MP, Roberts JH, National Institute of Child H, Human Development Maternal-Fetal Medicine Units N. The preterm prediction study: can low-risk women destined for spontaneous preterm birth be identified? American journal of obstetrics and gynecology. 2001;184(4):652655.

99. Ngo TTM, Moufarrej MN, Rasmussen MH, Camunas-Soler J, Pan W, Okamoto J, Neff NF, Liu K, Wong RJ, Downes K, Tibshirani R, Shaw GM, Skotte L, Stevenson DK, Biggio $J R$, Elovitz MA, Melbye M, Quake SR. Noninvasive blood tests for fetal development predict gestational age and preterm delivery. Science. 2018;360(6393):1133-1136.

100. lams JD, Romero R, Culhane JF, Goldenberg RL. Primary, secondary, and tertiary interventions to reduce the morbidity and mortality of preterm birth. Lancet. 2008;371(9607):164-175.

101. Matei A, Saccone G, Vogel JP, Armson AB. Primary and secondary prevention of preterm birth: a review of systematic reviews and ongoing randomized controlled trials. European journal of obstetrics, gynecology, and reproductive biology. 2019;236:224-239.

102. Hoffman MK, Goudar SS, Kodkany BS, Metgud M, Somannavar M, Okitawutshu J, Lokangaka A, Tshefu A, Bose CL, Mwapule A, Mwenechanya M, Chomba E, Carlo WA, Chicuy J, Figueroa L, Garces A, Krebs NF, Jessani S, Zehra F, Saleem S, Goldenberg RL, Kurhe K, Das P, Patel A, Hibberd PL, Achieng E, Nyongesa P, Esamai F, Liechty EA, Goco $\mathrm{N}$, Hemingway-Foday J, Moore J, Nolen TL, McClure EM, Koso-Thomas M, Miodovnik M, Silver R, Derman RJ, Group AS. Low-dose aspirin for the prevention of preterm delivery in nulliparous women with a singleton pregnancy (ASPIRIN): a randomised, double-blind, placebo-controlled trial. Lancet. 2020;395(10220):285-293.

103. Middleton P, Gomersall JC, Gould JF, Shepherd E, Olsen SF, Makrides M. Omega-3 fatty acid addition during pregnancy. Cochrane Database Syst Rev. 2018;11:CD003402. 
104. Sosa CG, Althabe F, Belizan JM, Bergel E. Bed rest in singleton pregnancies for preventing preterm birth. Cochrane Database Syst Rev. 2015(3):CD003581.

105. Kovacevich GJ, Gaich SA, Lavin JP, Hopkins MP, Crane SS, Stewart J, Nelson D, Lavin LM. The prevalence of thromboembolic events among women with extended bed rest prescribed as part of the treatment for premature labor or preterm premature rupture of membranes. American journal of obstetrics and gynecology. 2000;182(5):1089-1092.

106. Zakar T, Hertelendy F. Progesterone withdrawal: key to parturition. American journal of obstetrics and gynecology. 2007;196(4):289-296.

107. Ruddock NK, Shi SQ, Jain S, Moore G, Hankins GD, Romero R, Garfield RE. Progesterone, but not 17-alpha-hydroxyprogesterone caproate, inhibits human myometrial contractions. American journal of obstetrics and gynecology. 2008;199(4):391 e391-397.

108. Sykes L, Bennett PR. Efficacy of progesterone for prevention of preterm birth. Best Pract Res Clin Obstet Gynaecol. 2018;52:126-136.

109. da Fonseca EB, Bittar RE, Carvalho MH, Zugaib M. Prophylactic administration of progesterone by vaginal suppository to reduce the incidence of spontaneous preterm birth in women at increased risk: a randomized placebo-controlled double-blind study. American journal of obstetrics and gynecology. 2003;188(2):419-424.

110. Fonseca EB, Celik E, Parra M, Singh M, Nicolaides KH, Fetal Medicine Foundation Second Trimester Screening G. Progesterone and the risk of preterm birth among women with a short cervix. The New England journal of medicine. 2007;357(5):462469.

111. Hassan SS, Romero R, Vidyadhari D, Fusey S, Baxter JK, Khandelwal M, Vijayaraghavan J, Trivedi Y, Soma-Pillay P, Sambarey P, Dayal A, Potapov V, O'Brien J, Astakhov V, Yuzko O, Kinzler W, Dattel B, Sehdev H, Mazheika L, Manchulenko D, Gervasi MT, Sullivan L, Conde-Agudelo A, Phillips JA, Creasy GW, Trial P. Vaginal progesterone reduces the rate of preterm birth in women with a sonographic short cervix: a multicenter, randomized, double-blind, placebo-controlled trial. Ultrasound in obstetrics \& gynecology : the official journal of the International Society of Ultrasound in Obstetrics and Gynecology. 2011;38(1):18-31.

112. Romero R, Nicolaides K, Conde-Agudelo A, Tabor A, O'Brien JM, Cetingoz E, Da Fonseca E, Creasy GW, Klein K, Rode L, Soma-Pillay P, Fusey S, Cam C, Alfirevic Z, Hassan SS. Vaginal progesterone in women with an asymptomatic sonographic short cervix in the midtrimester decreases preterm delivery and neonatal morbidity: a systematic review and metaanalysis of individual patient data. American journal of obstetrics and gynecology. 2012;206(2):124 e121-119.

113. Norman JE, Marlow N, Messow CM, Shennan A, Bennett PR, Thornton S, Robson SC, McConnachie A, Petrou S, Sebire NJ, Lavender T, Whyte S, Norrie J, group Os. Vaginal progesterone prophylaxis for preterm birth (the OPPTIMUM study): a multicentre, randomised, double-blind trial. Lancet. 2016;387(10033):2106-2116.

114. Romero R, Nicolaides KH, Conde-Agudelo A, O'Brien JM, Cetingoz E, Da Fonseca E, Creasy GW, Hassan SS. Vaginal progesterone decreases preterm birth $</=34$ weeks of gestation in women with a singleton pregnancy and a short cervix: an updated metaanalysis including data from the OPPTIMUM study. Ultrasound in obstetrics \& gynecology : the official journal of the International Society of Ultrasound in Obstetrics and Gynecology. 2016;48(3):308-317. 
115. Romero R, Conde-Agudelo A, Da Fonseca E, O'Brien JM, Cetingoz E, Creasy GW, Hassan SS, Nicolaides $\mathrm{KH}$. Vaginal progesterone for preventing preterm birth and adverse perinatal outcomes in singleton gestations with a short cervix: a meta-analysis of individual patient data. American journal of obstetrics and gynecology. 2018;218(2):161-180.

116. Alfirevic Z, Stampalija T, Medley N. Cervical stitch (cerclage) for preventing preterm birth in singleton pregnancy. Cochrane Database Syst Rev. 2017;6:CD008991.

117. Goya M, Pratcorona L, Merced C, Rodo C, Valle L, Romero A, Juan M, Rodriguez A, Munoz B, Santacruz B, Bello-Munoz JC, Llurba E, Higueras T, Cabero L, Carreras E, Pesario Cervical para Evitar Prematuridad Trial G. Cervical pessary in pregnant women with a short cervix (PECEP): an open-label randomised controlled trial. Lancet. 2012;379(9828):1800-1806.

118. Berghella V, Ciardulli A, Rust OA, To M, Otsuki K, Althuisius S, Nicolaides KH, Roman A, Saccone $\mathrm{G}$. Cerclage for sonographic short cervix in singleton gestations without prior spontaneous preterm birth: systematic review and meta-analysis of randomized controlled trials using individual patient-level data. Ultrasound in obstetrics \& gynecology : the official journal of the International Society of Ultrasound in Obstetrics and Gynecology. 2017;50(5):569-577.

119. Conde-Agudelo A, Romero R, Nicolaides KH. Cervical pessary to prevent preterm birth in asymptomatic high-risk women: a systematic review and meta-analysis. American journal of obstetrics and gynecology. 2020;223(1):42-65 e42.

120. Green ES, Arck PC. Pathogenesis of preterm birth: bidirectional inflammation in mother and fetus. Semin Immunopathol. 2020;42(4):413-429.

121. Confavreux C, Hutchinson M, Hours MM, Cortinovis-Tourniaire P, Moreau T. Rate of pregnancy-related relapse in multiple sclerosis. Pregnancy in Multiple Sclerosis Group. The New England journal of medicine. 1998;339(5):285-291.

122. Littlejohn EA. Pregnancy and rheumatoid arthritis. Best Pract Res Clin Obstet Gynaecol. 2020;64:52-58.

123. Forger F, Villiger PM. Immunological adaptations in pregnancy that modulate rheumatoid arthritis disease activity. Nat Rev Rheumatol. 2020;16(2):113-122.

124. Polman $\mathrm{CH}, \mathrm{O}$ 'Connor PW, Havrdova E, Hutchinson M, Kappos L, Miller DH, Phillips JT, Lublin FD, Giovannoni G, Wajgt A, Toal M, Lynn F, Panzara MA, Sandrock AW, Investigators A. A randomized, placebo-controlled trial of natalizumab for relapsing multiple sclerosis. The New England journal of medicine. 2006;354(9):899-910.

125. Svensson-Arvelund J, Ernerudh J, Buse E, Cline JM, Haeger JD, Dixon D, Markert UR, Pfarrer C, Vos PD, Faas MM. The Placenta in Toxicology. Part II: Systemic and Local Immune Adaptations in Pregnancy. Toxicologic pathology. 2014;42(2):327-338.

126. Mor $G$, Aldo $P$, Alvero AB. The unique immunological and microbial aspects of pregnancy. Nature reviews Immunology. 2017;17(8):469-482.

127. Gomez-Lopez N, Vega-Sanchez R, Castillo-Castrejon M, Romero R, Cubeiro-Arreola K, Vadillo-Ortega F. Evidence for a role for the adaptive immune response in human term parturition. Am J Reprod Immunol. 2013;69(3):212-230.

128. Kourtis AP, Read JS, Jamieson DJ. Pregnancy and infection. The New England journal of medicine. 2014;370(23):2211-2218.

129. Wastnedge EAN, Reynolds RM, van Boeckel SR, Stock SJ, Denison FC, Maybin JA, Critchley HOD. Pregnancy and COVID-19. Physiol Rev. 2021;101(1):303-318. 
130. Abbas AK, Lichtman AH, Pillai S. In: Cellular and Molecular Immunology. Seventh edition ed.: Elsevier; 2012:1-14, 203-224.

131. Erlebacher A. Immunology of the maternal-fetal interface. Annual review of immunology. 2013;31:387-411.

132. Svensson J, Jenmalm MC, Matussek A, Geffers R, Berg G, Ernerudh J. Macrophages at the fetal-maternal interface express markers of alternative activation and are induced by M-CSF and IL-10. J Immunol. 2011;187(7):3671-3682.

133. Svensson-Arvelund J, Mehta RB, Lindau R, Mirrasekhian E, Rodriguez-Martinez H, Berg G, Lash GE, Jenmalm MC, Ernerudh J. The human fetal placenta promotes tolerance against the semiallogeneic fetus by inducing regulatory $T$ cells and homeostatic $\mathrm{M} 2$ macrophages. J Immunol. 2015;194(4):1534-1544.

134. Mjosberg J, Berg G, Jenmalm MC, Ernerudh J. FOXP3+ regulatory T cells and T helper 1, T helper 2, and T helper 17 cells in human early pregnancy decidua. Biology of reproduction. 2010;82(4):698-705.

135. Sykes L, MacIntyre DA, Yap XJ, Teoh TG, Bennett PR. The Th1:th2 dichotomy of pregnancy and preterm labour. Mediators of inflammation. 2012;2012:967629.

136. Wegmann TG, Lin H, Guilbert L, Mosmann TR. Bidirectional cytokine interactions in the maternal-fetal relationship: is successful pregnancy a TH2 phenomenon? Immunology today. 1993;14(7):353-356.

137. Karjalainen MK, Ojaniemi M, Haapalainen AM, Mahlman M, Salminen A, Huusko JM, Maatta TA, Kaukola T, Anttonen J, Ulvila J, Haataja R, Teramo K, Kingsmore SF, Palotie A, Muglia LJ, Ramet M, Hallman M. CXCR3 Polymorphism and Expression Associate with Spontaneous Preterm Birth. J Immunol. 2015;195(5):2187-2198.

138. Ernerudh J, Berg G, Mjosberg J. Regulatory T helper cells in pregnancy and their roles in systemic versus local immune tolerance. Am J Reprod Immunol. 2011;66 Suppl 1:3143.

139. Mjosberg J, Svensson J, Johansson E, Hellstrom L, Casas R, Jenmalm MC, Boij R, Matthiesen L, Jonsson JI, Berg G, Ernerudh J. Systemic reduction of functionally suppressive CD4dimCD25highFoxp3+ Tregs in human second trimester pregnancy is induced by progesterone and 17beta-estradiol. J Immunol. 2009;183(1):759-769.

140. Schober L, Radnai D, Schmitt E, Mahnke K, Sohn C, Steinborn A. Term and preterm labor: decreased suppressive activity and changes in composition of the regulatory $T$ cell pool. Immunol Cell Biol. 2012;90(10):935-944.

141. Koucky M, Malickova K, Cindrova-Davies T, Germanova A, Parizek A, Kalousova M, Hajek Z, Zima T. Low levels of circulating T-regulatory lymphocytes and short cervical length are associated with preterm labor. Journal of reproductive immunology. 2014;106:110-117.

142. Ferguson KK, McEIrath TF, Chen YH, Mukherjee B, Meeker JD. Longitudinal profiling of inflammatory cytokines and C-reactive protein during uncomplicated and preterm pregnancy. Am J Reprod Immunol. 2014;72(3):326-336.

143. Gomez-Lopez N, StLouis D, Lehr MA, Sanchez-Rodriguez EN, Arenas-Hernandez M. Immune cells in term and preterm labor. Cell Mol Immunol. 2014;11(6):571-581.

144. Dennis EA, Norris PC. Eicosanoid storm in infection and inflammation. Nature reviews Immunology. 2015;15(8):511-523.

145. Gabbs M, Leng S, Devassy JG, Monirujjaman M, Aukema HM. Advances in Our Understanding of Oxylipins Derived from Dietary PUFAs. Adv Nutr. 2015;6(5):513-540. 
146. Shearer GC, Newman JW. Impact of circulating esterified eicosanoids and other oxylipins on endothelial function. Current atherosclerosis reports. 2009;11(6):403-410.

147. Serhan CN. Pro-resolving lipid mediators are leads for resolution physiology. Nature. 2014;510(7503):92-101.

148. Nordgren TM, Anderson Berry A, Van Ormer M, Zoucha S, Elliott E, Johnson R, McGinn E, Cave C, Rilett K, Weishaar K, Maddipati SS, Appeah H, Hanson C. Omega-3 Fatty Acid Supplementation, Pro-Resolving Mediators, and Clinical Outcomes in Maternal-Infant Pairs. Nutrients. 2019;11(1).

149. Park JY, Romero R, Lee J, Chaemsaithong P, Chaiyasit N, Yoon BH. An elevated amniotic fluid prostaglandin F2alpha concentration is associated with intra-amniotic inflammation/infection, and clinical and histologic chorioamnionitis, as well as impending preterm delivery in patients with preterm labor and intact membranes. The journal of maternal-fetal \& neonatal medicine : the official journal of the European Association of Perinatal Medicine, the Federation of Asia and Oceania Perinatal Societies, the International Society of Perinatal Obstet. 2016;29(16):2563-2572.

150. Lee SE, Park IS, Romero R, Yoon BH. Amniotic fluid prostaglandin F2 increases even in sterile amniotic fluid and is an independent predictor of impending delivery in preterm premature rupture of membranes. The journal of maternal-fetal \& neonatal medicine: the official journal of the European Association of Perinatal Medicine, the Federation of Asia and Oceania Perinatal Societies, the International Society of Perinatal Obstet. 2009;22(10):880-886.

151. Lee SE, Romero R, Park IS, Seong HS, Park CW, Yoon BH. Amniotic fluid prostaglandin concentrations increase before the onset of spontaneous labor at term. The journal of maternal-fetal \& neonatal medicine: the official journal of the European Association of Perinatal Medicine, the Federation of Asia and Oceania Perinatal Societies, the International Society of Perinatal Obstet. 2008;21(2):89-94.

152. Ramsden CE, Makrides M, Yuan ZX, Horowitz MS, Zamora D, Yelland LN, Best K, Jensen J, Taha AY, Gibson RA. Plasma oxylipins and unesterified precursor fatty acids are altered by DHA supplementation in pregnancy: Can they help predict risk of preterm birth? Prostaglandins, leukotrienes, and essential fatty acids. 2020;153:102041.

153. Olsen SF, Halldorsson TI, Thorne-Lyman AL, Strom M, Gortz S, Granstrom C, Nielsen PH, Wohlfahrt J, Lykke JA, Langhoff-Roos J, Cohen AS, Furtado JD, Giovannucci EL, Zhou W. Plasma Concentrations of Long Chain N-3 Fatty Acids in Early and MidPregnancy and Risk of Early Preterm Birth. EBioMedicine. 2018;35:325-333.

154. Romero R, Erez O, Maymon E, Chaemsaithong P, Xu Z, Pacora P, Chaiworapongsa T, Done B, Hassan SS, Tarca AL. The maternal plasma proteome changes as a function of gestational age in normal pregnancy: a longitudinal study. American journal of obstetrics and gynecology. 2017;217(1):67 e61-67 e21.

155. Aghaeepour N, Lehallier B, Baca Q, Ganio EA, Wong RJ, Ghaemi MS, Culos A, El-Sayed YY, Blumenfeld YJ, Druzin ML, Winn VD, Gibbs RS, Tibshirani R, Shaw GM, Stevenson DK, Gaudilliere B, Angst MS. A proteomic clock of human pregnancy. American journal of obstetrics and gynecology. 2018;218(3):347 e341-347 e314.

156. Aghaeepour N, Ganio EA, Mcllwain D, Tsai AS, Tingle M, Van Gassen S, Gaudilliere DK, Baca Q, McNeil L, Okada R, Ghaemi MS, Furman D, Wong RJ, Winn VD, Druzin ML, ElSayed YY, Quaintance C, Gibbs R, Darmstadt GL, Shaw GM, Stevenson DK, Tibshirani R, Nolan GP, Lewis DB, Angst MS, Gaudilliere B. An immune clock of human pregnancy. Sci Immunol. 2017;2(15). 
157. Gomez-Lopez N, Romero R, Hassan SS, Bhatti G, Berry SM, Kusanovic JP, Pacora P, Tarca AL. The Cellular Transcriptome in the Maternal Circulation During Normal Pregnancy: A Longitudinal Study. Front Immunol. 2019;10:2863.

158. Ghaemi MS, DiGiulio DB, Contrepois K, Callahan B, Ngo TTM, Lee-McMullen B, Lehallier B, Robaczewska A, Mcllwain D, Rosenberg-Hasson Y, Wong RJ, Quaintance C, Culos A, Stanley N, Tanada A, Tsai A, Gaudilliere D, Ganio E, Han X, Ando K, McNeil L, Tingle $M$, Wise $P$, Maric I, Sirota M, Wyss-Coray T, Winn VD, Druzin ML, Gibbs R, Darmstadt GL, Lewis DB, Partovi Nia V, Agard B, Tibshirani R, Nolan G, Snyder MP, Relman DA, Quake SR, Shaw GM, Stevenson DK, Angst MS, Gaudilliere B, Aghaeepour $\mathrm{N}$. Multiomics modeling of the immunome, transcriptome, microbiome, proteome and metabolome adaptations during human pregnancy. Bioinformatics. 2019;35(1):95103.

159. Norwitz ER, Bonney EA, Snegovskikh VV, Williams MA, Phillippe M, Park JS, Abrahams VM. Molecular Regulation of Parturition: The Role of the Decidual Clock. Cold Spring Harb Perspect Med. 2015;5(11).

160. Frascoli M, Coniglio L, Witt R, Jeanty C, Fleck-Derderian S, Myers DE, Lee TH, Keating S, Busch MP, Norris PJ, Tang Q, Cruz G, Barcellos LF, Gomez-Lopez N, Romero R, MacKenzie TC. Alloreactive fetal T cells promote uterine contractility in preterm labor via IFN-gamma and TNF-alpha. Sci Trans/ Med. 2018;10(438).

161. Dubicke A, Fransson E, Centini G, Andersson E, Bystrom B, Malmstrom A, Petraglia F, Sverremark-Ekstrom E, Ekman-Ordeberg G. Pro-inflammatory and anti-inflammatory cytokines in human preterm and term cervical ripening. Journal of reproductive immunology. 2010;84(2):176-185.

162. Apgar V. A proposal for a new method of evaluation of the newborn infant. Current researches in anesthesia \& analgesia. 1953;32(4):260-267.

163. Bharti B, Bharti S. A review of the Apgar score indicated that contextualization was required within the contemporary perinatal and neonatal care framework in different settings. Journal of clinical epidemiology. 2005;58(2):121-129.

164. WHO International Statistical Classification of Diseases and Related Health Problems 11th Revision. https://icd.who.int/en.

165. Iliodromiti S, Mackay DF, Smith GC, Pell JP, Nelson SM. Apgar score and the risk of cause-specific infant mortality: a population-based cohort study. Lancet. 2014.

166. Moster D, Lie RT, Irgens LM, Bjerkedal T, Markestad T. The association of Apgar score with subsequent death and cerebral palsy: A population-based study in term infants. The Journal of pediatrics. 2001;138(6):798-803.

167. Wennergen M, Krantz M, Hjalmarson O, Karlsson K. Low Apgar score as a risk factor for respiratory disturbances in the newborn infant. Journal of perinatal medicine. 1987;15(2):153-160.

168. Persson M, Razaz N, Tedroff K, Joseph KS, Cnattingius S. Five and 10 minute Apgar scores and risks of cerebral palsy and epilepsy: population based cohort study in Sweden. BMJ. 2018;360:k207.

169. Moster D, Lie RT, Markestad T. Joint association of Apgar scores and early neonatal symptoms with minor disabilities at school age. Archives of disease in childhood Fetal and neonatal edition. 2002;86(1):F16-21.

170. Larsson HJ, Eaton WW, Madsen KM, Vestergaard M, Olesen AV, Agerbo E, Schendel D, Thorsen P, Mortensen PB. Risk factors for autism: perinatal factors, parental 
psychiatric history, and socioeconomic status. American journal of epidemiology. 2005;161(10):916-925; discussion 926-918.

171. Odd DE, Rasmussen F, Gunnell D, Lewis G, Whitelaw A. A cohort study of low Apgar scores and cognitive outcomes. Archives of disease in childhood Fetal and neonatal edition. 2008;93(2):F115-120.

172. Li J, Cnattingus S, Gissler M, Vestergaard M, Obel C, Ahrensberg J, Olsen J. The 5minute Apgar score as a predictor of childhood cancer: a population-based cohort study in five million children. BMJ open. 2012;2(4).

173. Odd DE, Doyle P, Gunnell D, Lewis G, Whitelaw A, Rasmussen F. Risk of low Apgar score and socioeconomic position: a study of Swedish male births. Acta Paediatr. 2008;97(9):1275-1280.

174. Milsom I, Ladfors L, Thiringer K, Niklasson A, Odeback A, Thornberg E. Influence of maternal, obstetric and fetal risk factors on the prevalence of birth asphyxia at term in a Swedish urban population. Acta obstetricia et gynecologica Scandinavica. 2002;81(10):909-917.

175. Straube S, Voigt M, Jorch G, Hallier E, Briese V, Borchardt U. Investigation of the association of Apgar score with maternal socio-economic and biological factors: an analysis of German perinatal statistics. Archives of gynecology and obstetrics. 2010;282(2):135-141.

176. Chen M, McNiff C, Madan J, Goodman E, Davis JM, Dammann O. Maternal obesity and neonatal Apgar scores. The journal of maternal-fetal \& neonatal medicine : the official journal of the European Association of Perinatal Medicine, the Federation of Asia and Oceania Perinatal Societies, the International Society of Perinatal Obstet. 2010;23(1):89-95.

177. Berglund S, Grunewald C, Pettersson H, Cnattingius S. Risk factors for asphyxia associated with substandard care during labor. Acta obstetricia et gynecologica Scandinavica. 2010;89(1):39-48.

178. Kallen K. The impact of maternal smoking during pregnancy on delivery outcome. European journal of public health. 2001;11(3):329-333.

179. Sandberg M, Frykman A, Ernerudh J, Berg G, Matthiesen L, Ekerfelt C, Nilsson LJ, Jenmalm MC. Cord blood cytokines and chemokines and development of allergic disease. Pediatr Allergy Immunol. 2009;20(6):519-527.

180. Hakansson I, Tisell A, Cassel P, Blennow K, Zetterberg H, Lundberg P, Dahle C, Vrethem $M$, Ernerudh J. Neurofilament levels, disease activity and brain volume during followup in multiple sclerosis. J Neuroinflammation. 2018;15(1):209.

181. Spath J, Brodin T, Cerveny D, Lindberg R, Fick J, Nording ML. Oxylipins at intermediate larval stages of damselfly Coenagrion hastulatum as biochemical biomarkers for anthropogenic pollution. Environ Sci Pollut Res Int. 2021.

182. Gouveia-Figueira S, Nording ML. Validation of a tandem mass spectrometry method using combined extraction of 37 oxylipins and 14 endocannabinoid-related compounds including prostamides from biological matrices. Prostaglandins Other Lipid Mediat. 2015;121(Pt A):110-121.

183. Guo B, Chen B, Liu A, Zhu W, Yao S. Liquid chromatography-mass spectrometric multiple reaction monitoring-based strategies for expanding targeted profiling towards quantitative metabolomics. Curr Drug Metab. 2012;13(9):1226-1243.

184. Rasmark Roepke E, Bruno V, Nedstrand E, Boij R, Strid CP, Piccione E, Berg G, Svensson-Arvelund J, Jenmalm MC, Ruber M, Ernerudh J. Low-molecular-weight- 
heparin increases Th1- and Th17-associated chemokine levels during pregnancy in women with unexplained recurrent pregnancy loss: a randomised controlled trial. Sci Rep. 2019;9(1):12314.

185. Gardner MO, Goldenberg RL, Gaudier FL, Dubard MB, Nelson KG, Hauth JC. Predicting low Apgar scores of infants weighing less than 1000 grams: the effect of corticosteroids. Obstetrics and gynecology. 1995;85(2):170-174.

186. Cnattingius S, Johansson S, Razaz N. Apgar Score and Risk of Neonatal Death among Preterm Infants. The New England journal of medicine. 2020;383(1):49-57.

187. Camilleri AP. The obstetric significance of short stature. European journal of obstetrics, gynecology, and reproductive biology. 1981;12(6):347-356.

188. Kappel B, Eriksen G, Hansen KB, Hvidman L, Krag-OIsen B, Nielsen J, Videbech P, Wohlert M. Short stature in Scandinavian women. An obstetrical risk factor. Acta obstetricia et gynecologica Scandinavica. 1987;66(2):153-158.

189. Schummers L, Hutcheon JA, Bodnar LM, Lieberman E, Himes KP. Risk of adverse pregnancy outcomes by prepregnancy body mass index: a population-based study to inform prepregnancy weight loss counseling. Obstetrics and gynecology. 2015;125(1):133-143.

190. Cedergren MI. Maternal morbid obesity and the risk of adverse pregnancy outcome. Obstetrics and gynecology. 2004;103(2):219-224.

191. McCowan LM, Figueras F, Anderson NH. Evidence-based national guidelines for the management of suspected fetal growth restriction: comparison, consensus, and controversy. American journal of obstetrics and gynecology. 2018;218(2S):S855-S868.

192. Shaw GM, Wise PH, Mayo J, Carmichael SL, Ley C, Lyell DJ, Shachar BZ, Melsop K, Phibbs CS, Stevenson DK, Parsonnet J, Gould JB, March of Dimes Prematurity Research Center at Stanford University School of M. Maternal prepregnancy body mass index and risk of spontaneous preterm birth. Paediatric and perinatal epidemiology. 2014;28(4):302-311.

193. Aye IL, Lager S, Ramirez VI, Gaccioli F, Dudley DJ, Jansson T, Powell TL. Increasing maternal body mass index is associated with systemic inflammation in the mother and the activation of distinct placental inflammatory pathways. Biology of reproduction. 2014;90(6):129.

194. Madan JC, Davis JM, Craig WY, Collins M, Allan W, Quinn R, Dammann O. Maternal obesity and markers of inflammation in pregnancy. Cytokine. 2009;47(1):61-64.

195. Chaemsaithong P, Romero R, Docheva N, Chaiyasit N, Bhatti G, Pacora P, Hassan SS, Yeo L, Erez O. Comparison of rapid MMP-8 and interleukin-6 point-of-care tests to identify intra-amniotic inflammation/infection and impending preterm delivery in patients with preterm labor and intact membranes(). The journal of maternal-fetal \& neonatal medicine : the official journal of the European Association of Perinatal Medicine, the Federation of Asia and Oceania Perinatal Societies, the International Society of Perinatal Obstet. 2018;31(2):228-244.

196. Herrera-Munoz A, Fernandez-Alonso AM, Fischer-Suarez N, Chedraui P, Perez-Lopez FR. Maternal serum cytokine levels in pregnancies complicated with threatened preterm labour. Gynecol Endocrinol. 2017;33(5):408-412.

197. Li H, Chen J, Huang A, Stinson J, Heldens S, Foster J, Dowd P, Gurney AL, Wood WI. Cloning and characterization of IL-17B and IL-17C, two new members of the IL-17 cytokine family. Proceedings of the National Academy of Sciences of the United States of America. 2000;97(2):773-778. 
198. Ramirez-Carrozzi V, Sambandam A, Luis E, Lin Z, Jeet S, Lesch J, Hackney J, Kim J, Zhou M, Lai J, Modrusan Z, Sai T, Lee W, Xu M, Caplazi P, Diehl L, de Voss J, Balazs M, Gonzalez L, Jr., Singh H, Ouyang W, Pappu R. IL-17C regulates the innate immune function of epithelial cells in an autocrine manner. Nat Immunol. 2011;12(12):11591166.

199. Hee L, Kirkegaard I, Vogel I, Thorsen P, Skogstrand K, Hougaard DM, Uldbjerg N, Sandager $P$. Low serum interleukin-17 is associated with preterm delivery. Acta obstetricia et gynecologica Scandinavica. 2011;90(1):92-96.

200. Ito M, Nakashima A, Hidaka T, Okabe M, Bac ND, Ina S, Yoneda S, Shiozaki A, Sumi S, Tsuneyama K, Nikaido T, Saito S. A role for IL-17 in induction of an inflammation at the fetomaternal interface in preterm labour. Journal of reproductive immunology. 2010;84(1):75-85.

201. Donnelly RP, Sheikh F, Kotenko SV, Dickensheets $H$. The expanded family of class II cytokines that share the IL-10 receptor-2 (IL-10R2) chain. J Leukoc Biol. 2004;76(2):314-321.

202. Sheppard P, Kindsvogel W, Xu W, Henderson K, Schlutsmeyer S, Whitmore TE, Kuestner R, Garrigues U, Birks C, Roraback J, Ostrander C, Dong D, Shin J, Presnell S, Fox B, Haldeman B, Cooper E, Taft D, Gilbert T, Grant FJ, Tackett M, Krivan W, McKnight G, Clegg C, Foster D, Klucher KM. IL-28, IL-29 and their class II cytokine receptor IL-28R. Nat Immunol. 2003;4(1):63-68.

203. Itoh N, Ohta H, Konishi M. Endocrine FGFs: Evolution, Physiology, Pathophysiology, and Pharmacotherapy. Front Endocrinol (Lausanne). 2015;6:154.

204. Imel EA, Econs MJ. Fibroblast growth factor 23: roles in health and disease. Journal of the American Society of Nephrology : JASN. 2005;16(9):2565-2575.

205. Mosavat M, Omar SZ, Sthanshewar P. Serum FGF-21 and FGF-23 in association with gestational diabetes: a longitudinal case-control study. Horm Mol Biol Clin Investig. 2020;41(2).

206. Owen MPT, Northrop EJ, Rich JJJ, Perry GA, Messman RD, Dinh TTN, McCarty KJ, Yang J, Wan D, Lemley CO. Oxylipin concentrations in bovine corpora lutea during maternal recognition of pregnancy. Theriogenology. 2020;142:384-389.

207. Aung MT, Yu Y, Ferguson KK, Cantonwine DE, Zeng L, McElrath TF, Pennathur S, Mukherjee $B$, Meeker JD. Prediction and associations of preterm birth and its subtypes with eicosanoid enzymatic pathways and inflammatory markers. Sci Rep. 2019;9(1):17049.

208. Simmonds LA, Sullivan TR, Skubisz M, Middleton PF, Best KP, Yelland LN, Quinlivan J, Zhou SJ, Liu G, McPhee AJ, Gibson RA, Makrides M. Omega-3 fatty acid supplementation in pregnancy-baseline omega-3 status and early preterm birth: exploratory analysis of a randomised controlled trial. BJOG : an international journal of obstetrics and gynaecology. 2020;127(8):975-981.

209. Brann E, Edvinsson A, Rostedt Punga A, Sundstrom-Poromaa I, Skalkidou A. Inflammatory and anti-inflammatory markers in plasma: from late pregnancy to early postpartum. Sci Rep. 2019;9(1):1863.

210. Piccinni MP, Scaletti C, Vultaggio A, Maggi E, Romagnani S. Defective production of LIF, M-CSF and Th2-type cytokines by T cells at fetomaternal interface is associated with pregnancy loss. Journal of reproductive immunology. 2001;52(1-2):35-43.

211. Eckmann-Scholz C, Wilke C, Acil Y, Alkatout I, Salmassi A. Macrophage colonystimulating factor (M-CSF) in first trimester maternal serum: correlation with 
pathologic pregnancy outcome. Archives of gynecology and obstetrics. 2016;293(6):1213-1217.

212. Yellon SM. Immunobiology of Cervix Ripening. Front Immunol. 2019;10:3156.

213. Chen J, Khalil RA. Matrix Metalloproteinases in Normal Pregnancy and Preeclampsia. Prog Mol Biol Trans/ Sci. 2017;148:87-165.

214. Oh KJ, Hong JS, Romero R, Yoon BH. The frequency and clinical significance of intraamniotic inflammation in twin pregnancies with preterm labor and intact membranes. The journal of maternal-fetal \& neonatal medicine : the official journal of the European Association of Perinatal Medicine, the Federation of Asia and Oceania Perinatal Societies, the International Society of Perinatal Obstet. 2019;32(4):527-541.

215. Karnell JL, Rieder SA, Ettinger R, Kolbeck R. Targeting the CD40-CD40L pathway in autoimmune diseases: Humoral immunity and beyond. Adv Drug Deliv Rev. 2019;141:92-103.

216. Sitaru AG, Speer CP, Holzhauer S, Obergfell A, Walter U, Grossmann R. Chorioamnionitis is associated with increased CD40L expression on cord blood platelets. Thromb Haemost. 2005;94(6):1219-1223.

217. Lukanov TH, Bojinova SI, Popova VS, Emin AL, Veleva GL, Gecheva SP, Konova El. Flow cytometric investigation of CD40-CD40 ligand system in preeclampsia and normal pregnancy. Clin App/ Thromb Hemost. 2010;16(3):306-312.

218. Boij R, Svensson J, Nilsson-Ekdahl K, Sandholm K, Lindahl TL, Palonek E, Garle M, Berg $\mathrm{G}$, Ernerudh J, Jenmalm M, Matthiesen L. Biomarkers of coagulation, inflammation, and angiogenesis are independently associated with preeclampsia. Am J Reprod Immunol. 2012;68(3):258-270.

219. Gotsch F, Romero R, Friel L, Kusanovic JP, Espinoza J, Erez O, Than NG, Mittal P, Edwin S, Yoon BH, Kim CJ, Mazaki-Tovi S, Chaiworapongsa T, Hassan SS. CXCL10/IP-10: a missing link between inflammation and anti-angiogenesis in preeclampsia? The journal of maternal-fetal \& neonatal medicine : the official journal of the European Association of Perinatal Medicine, the Federation of Asia and Oceania Perinatal Societies, the International Society of Perinatal Obstet. 2007;20(11):777-792.

220. Brien ME, Boufaied I, Bernard N, Forest JC, Giguere Y, Girard S. Specific inflammatory profile in each pregnancy complication: A comparative study. Am J Reprod Immunol. 2020:e13316.

221. Laudanski P, Lemancewicz A, Pierzynski P, Akerlund M, Laudanski T. Decreased serum level of macrophage inflammatory chemokine-3beta/CCL19 in preterm labor and delivery. European journal of obstetrics, gynecology, and reproductive biology. 2006;124(1):23-26.

222. Kim CJ, Romero R, Chaemsaithong P, Kim JS. Chronic inflammation of the placenta: definition, classification, pathogenesis, and clinical significance. American journal of obstetrics and gynecology. 2015;213(4 Suppl):S53-69.

223. Petkau G, Turner M. Signalling circuits that direct early B-cell development. Biochem J. 2019;476(5):769-778.

224. Karsunky H, Merad M, Cozzio A, Weissman IL, Manz MG. Flt3 ligand regulates dendritic cell development from Flt3+ lymphoid and myeloid-committed progenitors to Flt3+ dendritic cells in vivo. J Exp Med. 2003;198(2):305-313.

225. Robert J. Growth Factors and Tyrosine Kinase Receptors. In: Robert J, ed. Textbook of Cell Signalling in Cancer: An Educational Approach. Cham: Springer International Publishing; 2015:1-26. 
226. Lecarpentier E, Vieillefosse S, Haddad B, Fournier T, Leguy MC, Guibourdenche J, Tsatsaris V. Placental growth factor (PIGF) and sFlt-1 during pregnancy: physiology, assay and interest in preeclampsia. Ann Biol Clin (Paris). 2016;74(3):259-267.

227. Herraiz I, Simon E, Gomez-Arriaga PI, Quezada MS, Garcia-Burguillo A, Lopez-Jimenez EA, Galindo A. Clinical implementation of the sFlt-1/PIGF ratio to identify preeclampsia and fetal growth restriction: A prospective cohort study. Pregnancy Hypertens. 2018;13:279-285.

228. Herraiz I, Llurba E, Verlohren S, Galindo A, Spanish Group for the Study of Angiogenic Markers in P. Update on the Diagnosis and Prognosis of Preeclampsia with the Aid of the sFlt-1/ PIGF Ratio in Singleton Pregnancies. Fetal Diagn Ther. 2018;43(2):81-89.

229. Lynch AM, Wagner BD, Deterding RR, Giclas PC, Gibbs RS, Janoff EN, Holers VM, Santoro NF. The relationship of circulating proteins in early pregnancy with preterm birth. American journal of obstetrics and gynecology. 2016;214(4):517 e511-517 e518.

230. Saade GR, Boggess KA, Sullivan SA, Markenson GR, lams JD, Coonrod DV, Pereira LM, Esplin MS, Cousins LM, Lam GK, Hoffman MK, Severinsen RD, Pugmire T, Flick JS, Fox AC, Lueth AJ, Rust SR, Mazzola E, Hsu C, Dufford MT, Bradford CL, Ichetovkin IE, Fleischer TC, Polpitiya AD, Critchfield GC, Kearney PE, Boniface JJ, Hickok DE. Development and validation of a spontaneous preterm delivery predictor in asymptomatic women. American journal of obstetrics and gynecology. 2016;214(5):633 e631-633 e624.

231. Cantonwine DE, Zhang Z, Rosenblatt K, Goudy KS, Doss RC, Ezrin AM, Page G, Brohman $B$, McElrath TF. Evaluation of proteomic biomarkers associated with circulating microparticles as an effective means to stratify the risk of spontaneous preterm birth. American journal of obstetrics and gynecology. 2016;214(5):631 e631-631 e611.

232. Locatelli A, Incerti M, Ghidini A, Greco M, Villa E, Paterlini G. Factors associated with umbilical artery acidemia in term infants with low Apgar scores at 5 min. European journal of obstetrics, gynecology, and reproductive biology. 2008;139(2):146-150.

233. Hogan L, Ingemarsson I, Thorngren-Jerneck K, Herbst A. How often is a low 5-min Apgar score in term newborns due to asphyxia? European journal of obstetrics, gynecology, and reproductive biology. 2007;130(2):169-175.

234. Victory R, Penava D, Da Silva O, Natale R, Richardson B. Umbilical cord pH and base excess values in relation to adverse outcome events for infants delivering at term. American journal of obstetrics and gynecology. 2004;191(6):2021-2028.

235. Assarsson E, Lundberg M, Holmquist G, Bjorkesten J, Thorsen SB, Ekman D, Eriksson A, Rennel Dickens E, Ohlsson S, Edfeldt G, Andersson AC, Lindstedt P, Stenvang J, Gullberg M, Fredriksson S. Homogenous 96-plex PEA immunoassay exhibiting high sensitivity, specificity, and excellent scalability. PloS one. 2014;9(4):e95192.

236. Mainka M, Dalle C, Petera M, Dalloux-Chioccioli J, Kampschulte N, Ostermann AI, Rothe M, Bertrand-Michel J, Newman JW, Gladine C, Schebb NH. Harmonized procedures lead to comparable quantification of total oxylipins across laboratories. $J$ Lipid Res. 2020;61(11):1424-1436.

237. Rund KM, Nolte F, Doricic J, Greite R, Schott S, Lichtinghagen R, Gueler F, Schebb NH. Clinical blood sampling for oxylipin analysis - effect of storage and pneumatic tube transport of blood on free and total oxylipin profile in human plasma and serum. Analyst. 2020;145(6):2378-2388. 
238. Swedish Pregnancy Registry Yearly Report 2019.

https://www.medscinet.com/GR/uploads/hemsida/dokumentarkiv/Graviditetsregistre ts\%20\%C3\%85rsrapport\%202019_2.0.pdf.

239. Chamberlain C, O'Mara-Eves A, Porter J, Coleman T, Perlen SM, Thomas J, McKenzie JE. Psychosocial interventions for supporting women to stop smoking in pregnancy. Cochrane Database Syst Rev. 2017;2:CD001055.

240. Askie LM, Duley L, Henderson-Smart DJ, Stewart LA, Group PC. Antiplatelet agents for prevention of pre-eclampsia: a meta-analysis of individual patient data. Lancet. 2007;369(9575):1791-1798.

241. Claesson IM, Sydsjo G, Brynhildsen J, Cedergren M, Jeppsson A, Nystrom F, Sydsjo A, Josefsson $A$. Weight gain restriction for obese pregnant women: a case-control intervention study. BJOG : an international journal of obstetrics and gynaecology. 2008;115(1):44-50.

242. Siart B, de Oliveira FMS, Shen Q, Bjorkesten J, Pekar T, Steinborn R, Nimmerichter A, Kamali-Moghaddam M, Wallner B. Protein measurements in venous plasma, earlobe capillary plasma and in plasma stored on filter paper. Anal Biochem. 2019;566:146150.

243. Nikolova T, Bayev O, Nikolova N, Di Renzo GC. Evaluation of a novel placental alpha microglobulin-1 (PAMG-1) test to predict spontaneous preterm delivery. Journal of perinatal medicine. 2014;42(4):473-477.

244. van 't Hooft J, Duffy JMN, Daly M, Williamson PR, Meher S, Thom E, Saade GR, Alfirevic Z, Mol BWJ, Khan KS, Global Obstetrics N. A Core Outcome Set for Evaluation of Interventions to Prevent Preterm Birth. Obstetrics and gynecology. 2016;127(1):49-58. 


\section{Appendices}

Appendix 1.

Inflammation-associated proteins analysed by proximity extension assay (Studies II and IV) and their corresponding UniprotIDs in the Olink-panel.

\begin{tabular}{|c|c|c|c|c|c|}
\hline Protein & Uniprot ID & Protein & Uniprot ID & Protein & Uniprot ID \\
\hline 4E-BP1 & Q13541 & CXCL10 & P02778 & IL-20RA & Q9UHF4 \\
\hline ADA & P00813 & CXCL11 & 014625 & IL-22RA1 & Q8N6P7 \\
\hline ARTN & Q5T4W7 & DNER & Q8NFT8 & KITLG & P21583 \\
\hline AXIN-1 & 015169 & FGF-5 & P12034 & LAP TGF- $\beta-1$ & P01137 \\
\hline Beta-NGF & P01138 & FGF-19 & 095750 & LIF & P15018 \\
\hline CASP-8 & Q14790 & FGF-21 & Q9NSA1 & LIF-R & P42702 \\
\hline CCL2 & P13500 & FGF-23 & Q9GZV9 & LT- $\alpha$ & P01374 \\
\hline CCL3 & P10147 & Flt3L & P49771 & M-CSF & P09603 \\
\hline CCL4 & P13236 & GDNF & P39905 & MMP-1 & P03956 \\
\hline CCL7 & P80098 & HGF & P14210 & MMP-10 & P09238 \\
\hline CCL8 & P80075 & IFN- $\gamma$ & P01579 & NRTN & Q99748 \\
\hline CCL11 & P51671 & IL-1 $\alpha$ & P01583 & NT-3 & P20783 \\
\hline CCL13 & Q99616 & IL-2 & P60568 & OPG & 000300 \\
\hline CCL19 & Q99731 & IL-4 & P05112 & OSM & P13725 \\
\hline CCL20 & P78556 & IL-5 & P05113 & PD-L1 & Q9NZQ7 \\
\hline CCL23 & P55773 & IL-6 & P05231 & S100A12 & P80511 \\
\hline CCL25 & 015444 & IL-7 & P13232 & SIRT2 & Q8IXJ6 \\
\hline CCL28 & Q9NRJ3 & IL-10 & P22301 & SLAMF1 & Q13291 \\
\hline CD5 & P06127 & IL-12B & P29460 & ST1A1 & P50225 \\
\hline CD6 & P30203 & IL-13 & P35225 & STAMBP & 095630 \\
\hline CD8A & P01732 & IL-17A & Q16552 & TGF- $\alpha$ & P01135 \\
\hline CD40 & P25942 & IL-17C & Q9P0M4 & TNF & P01375 \\
\hline CD244 & Q9BZW8 & IL-18 & Q14116 & TNFRSF9 & Q07011 \\
\hline CDCP1 & Q9H5V8 & IL-20 & Q9NYY1 & TNFSF14 & 043557 \\
\hline CST5 & P28325 & IL-24 & Q13007 & TRAIL & P50591 \\
\hline CX3CL1 & P78423 & IL-33 & 095760 & TRANCE & 014788 \\
\hline CXCL1 & P09341 & IL-2RB & P14784 & TSLP & Q969D9 \\
\hline CXCL5 & P42830 & IL-10RA & Q13651 & TWEAK & 043508 \\
\hline CXCL6 & P80162 & IL-10RB & Q08334 & UPA & P00749 \\
\hline CXCL8 & P10145 & IL-15RA & Q13261 & VEGF-A & P15692 \\
\hline CXCL9 & Q07325 & IL-18R1 & Q13478 & & \\
\hline
\end{tabular}




\section{Appendix 2.}

Abbreviation list of the oxylipin compounds analysed in Study III.

\begin{tabular}{|c|c|c|c|}
\hline 9,10,13-TriHOME & 9,10,13-trihydroxy-octadecenoic acid & 9-HETE & 9-hydroxy-eicosatetraenoic acid \\
\hline 9,12,13-TriHOME & 9,12,13-trihydroxy-octadecenoic acid & 11-HETE & 11-hydroxy-eicosatetraenoic acid \\
\hline PGF2a & Prostaglandin $\mathrm{F} 2 \mathrm{a}$ & 12-HETE & 12-hydroxy-eicosatetraenoic acid \\
\hline Resolvin D1 & 7,8,17-trihydroxy-docosahexaenoic acid & 15-HETE & 15-hydroxy-eicosatetraenoic acid \\
\hline Resolvin D2 & 7,16,17-trihydroxy-docosahexaenoic acid & 20-HETE & 20-hydroxy-eicosatetraenoic acid \\
\hline TXB2 & Thromboxane B2 & 5-HEPE & 5-hydroxy-eicosapentaenoic acid \\
\hline LTB4 & Leukotriene B4 & 12-HEPE & 12,13-dihydroxy-octadecenoic acid \\
\hline PGD2 & Prostaglandin D2 & 15-HEPE & 15-hydroxy-eicosapentaenoic acid \\
\hline PGE2 & Prostaglandin E2 & 17-HDoHE & 17-hydroxy-docosahexaenoic acid \\
\hline 9,10-DiHOME & 9,10-dihydroxy-octadecenoic acid & 15-HETrE & 15-hydroxy-eicosatrienoic acid \\
\hline 12,13-DiHOME & 12-hydroxy-eicosapentaenoic acid & 5-0x0-ETE & 5-oxo-eicosatetraenoic acid \\
\hline 9,10-DiHODE & 9,10-dihydroxy-octadecadienoic acid & 12-OXo-ETE & 12-oxo-eicosatetraenoic acid \\
\hline 12,13-DiHODE & 12,13-dihydroxy-octadecadienoic acid & 15-0X0-ETE & 15-oxo-eicosatetraenoic acid \\
\hline 15,16-DiHODE & 15,16-dihydroxy-octadecadienoic acid & 9-0X0-ODE & 9-oxo-10,12-octadecadienoic acid \\
\hline 5,6-DiHETrE & 5,6-dihydroxy-eicosatrienoic acid & 13-OX0-ODE & 13-oxo-octadecadienoic acid \\
\hline 8,9-DiHETrE & 8,9-dihydroxy-eicosatrienoic acid & 9(10)-ЕpOME & 9(10)-epoxy-octadecenoic acid \\
\hline 11,12-DiHETrE & 11,12-dihydroxy-eicosatrienoic acid & 12(13)-EpOME & 12(13)-epoxy-octadecenoic acid \\
\hline 14,15-DiHETrE & 14,15-dihydroxy-eicosatrienoic acid & EKODE & 12(13)-epoxy-9-keto-octadecenoic acid \\
\hline 8,9-DiHETE & 8,9-dihydroxy-eicosatetraenoic acid & 9(10)-EpODE & 9(10)-epoxy-octadecadienoic acid \\
\hline 11,12-DiHETE & 11,12-dihydroxy-eicosatetraenoic acid & 12(13)-ЕрОDE & 12(13)-epoxy-octadecadienoic acid \\
\hline 14,15-DiHETE & 14,15-dihydroxy-eicosatetraenoic acid & 15(16)-EpODE & 15(16)-epoxy-octadecadienoic acid \\
\hline 17,18-DiHETE & 17,18-dihydroxy-eicosatetraenoic acid & 8(9)-EpETrE & 8(9)-epoxy-eicosatrienoic acid \\
\hline 7,8-DiHDPE & 7,8-dihydroxy-docosapentaenoic acid & 11(12)-EpETrE & 11(12)-epoxy-eicosatrienoic acid \\
\hline 10,11-DiHDPE & 10,11-dihydroxy-docosapentaenoic acid & 14(15)-EpETrE & 14(15)-epoxy-eicosatrienoic acid \\
\hline 13,14-DiHDPE & 13,14-dihydroxy-docosapentaenoic acid & 8(9)-EpETE & 8(9)-epoxy-eicosatetraenoic acid \\
\hline 16,17-DiHDPE & 16,17-dihydroxy-docosapentaenoic acid & 11(12)-EpETE & 11(12)-epoxy-eicosatetraenoic acid \\
\hline 19,20-DiHDPE & 19,20-dihydroxy-docosapentaenoic acid & 14(15)-EpETE & 14(15)-epoxy-eicosatetraenoic acid \\
\hline 9-HODE & 9-hydroxy-octadecadienoic acid & 17(18)-EpETE & 17(18)-epoxy-eicosatetraenoic acid \\
\hline 13-HODE & 13-hydroxy-octadecadienoic acid & 7(8)-EpDPE & 7(8)-epoxy docosapentaenoic acid \\
\hline 9-HOTrE & 9S-hydroxy-octadecatrienoic acid & 10(11)-EpDPE & 10(11)-epoxy docosapentaenoic acid \\
\hline 13-HOTrE & 13-hydroxy-octadecatrienoic acid & 13(14)-EpDPE & 13(14)-epoxy docosapentaenoic acid \\
\hline 5-HETE & 5-hydroxy-eicosatetraenoic acid & 16(17)-EpDPE & 16(17)-epoxy docosapentaenoic acid \\
\hline 8-HETE & 8-hydroxy-eicosatetraenoic acid & 19(20)-EpDPE & 19(20)-epoxy docosapentaenoic acid \\
\hline
\end{tabular}


Papers I-IV 


\section{Papers}

The papers associated with this thesis have been removed for copyright reasons. For more details about these see:

http://urn.kb.se/resolve?urn=urn:nbn:se:liu:diva-174828 



\section{FACULTY OF MEDICINE AND HEALTH SCIENCES}

Linköping University Medical Dissertation No. 1779, 2021

Department of Biomedical and Clinical Sciences

Linköping University

SE-581 83 Linköping, Sweden

www.liu.se

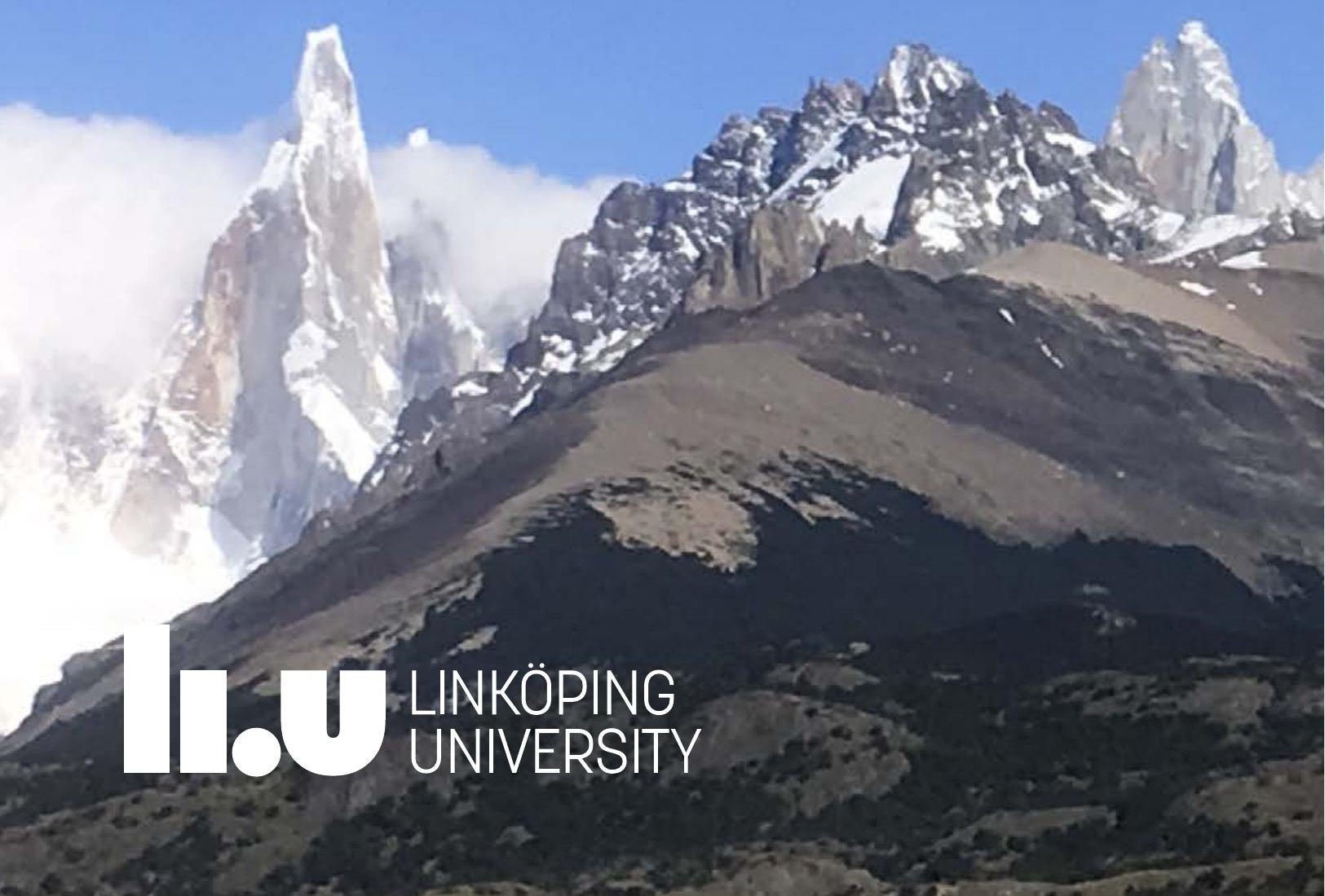

